\title{
DELIRIUM IN CARDIAC SURGERY
}

A study on risk-assessment and long-term consequences

Sandra Koster 
Thesis, University of Twente, 2011

ISBN 978-90-365-3230-3

(C) Sandra Koster

Printed by: Gildeprint Enschede

The studies presented in this thesis were performed at the Department of Cardiothoracic Surgery, Thoraxcenter Twente, Medisch Spectrum Twente Enschede.

All rights are reserved. No part of this publication may be reproduced, stored in a retrieval system, or transmitted in any form or by any means, mechanically, by photocopying, recording or otherwise, without the written permission of the author and the publisher of the articles concerned.

Financial support by the Dutch Heart Foundation and Medisch Spectrum Twente for the publication of this thesis is gratefully acknowledged. The printing of this thesis was also kindly supported by Dr. G.J. van Hoytemastichting, Stichting Thoraxcentrum Twente, St. OCCT, St. Jude Medical, and Maquet. 


\title{
DELIRIUM IN CARDIAC SURGERY
}

A STUDY ON RISK-ASSESSMENT AND LONG-TERM CONSEQUENCES

\section{PROEFSCHRIFT}

\author{
ter verkrijging van \\ de graad van doctor aan de Universiteit Twente, \\ op gezag van de rector magnificus, \\ prof. dr. H. Brinksma, \\ volgens besluit van het College voor Promoties \\ in het openbaar te verdedigen \\ op vrijdag 14 oktober 2011 om 14.45 uur
}

door

Sandra Koster

geboren op 12 november 1977

te Rotterdam 
Dit proefschrift is goedgekeurd door de promotoren, Prof. dr. J.A.M. van der Palen en Prof. dr. M.J. Schuurmans 


\section{PROMOTIECOMMISSIE}

Promotoren:

Prof. dr. J.A.M. van der Palen

Prof. dr. M.J. Schuurmans

Overige leden:

Prof. dr. E.T. Bohlmeijer

Prof. dr. G.C.M. Kusters

Prof. dr. R.C. van der Mast

Prof. dr. B. van Rompaey

Dr. J.G. Grandjean 



\section{Contents}

$\begin{array}{lll}\text { Chapter } 1 & \text { Introduction } & 9\end{array}$

Chapter 2 The Delirium Observation Screening scale recognizes

delirium early after cardiac surgery

Chapter 3 Risk factors of delirium after cardiac surgery

A systematic review

Chapter $4 \quad$ Delirium after cardiac surgery and predictive validity of a risk checklist

Chapter 5 Prediction of delirium after cardiac surgery with a risk checklist

Chapter 6 The long-term cognitive and functional outcomes of postoperative delirium after cardiac surgery

Chapter 8 Discussion

Summary

Samenvatting

Dankwoord

Curriculum Vitae 



\title{
Chapter 1
}

\author{
Introduction
}


"Help! They want to hurt me......

If I go to sleep they will poison me....

I see lots of people in my room....

Nurse, can you remove these bugs here??"

The above statements are frequently heard in various departments of hospitals or nursing homes, but also at home a delirium may develop. The patients are restless and disoriented in time, place, and person. Often this is accompanied with motor restlessness, anxiety, hallucinations, delusions, and paranoia. But it is also possible a patient develops a hypoactive or quiet delirium, whereas the patient is just very apathetic and withdrawn.

As a nurse and later as a nurse practitioner in cardiac surgery I frequently saw patients with a delirium. From one moment to the other patients were confused, especially during the night shift. I noted the impact of delirium on the patients and their caregivers, but also on the nurses and doctors. At that time, in the Department of Cardiothoracic Surgery and in the hospital as well, there was no instrument to recognize delirium and I had the idea delirium was frequently overlooked or misdiagnosed. Delirium and the corresponding consequences intrigued me and I started to read books and articles about delirium and went to conferences about this subject. During my training as a nurse practitioner I explored delirium more, and started with initiating and doing research about delirium. My interest was especially focused on the risk factors and consequences of delirium with the intention to improve the care and cure of patients with a postoperative delirium.

Delirium is a common temporary mental disorder among hospitalized elderly patients (1). According to the American Psychiatric Association's Diagnostic and Statistical Manual of Mental Disorders (DSM-IV), delirium is defined as "a disturbance of consciousness with reduced ability to focus, sustain, or shift attention; a change in cognition; or the development of a perceptual disturbance that occurs over a short period of time and tends to fluctuate over the course of the day" (2). According to the DSM-IV criteria, the history, 
physical examination and laboratory tests support delirium as a direct physiologic consequence of a general medical condition, substance intoxication or withdrawal, use of a medication, toxin exposure, or combination of these factors.

In the literature, the incidence and prevalence of delirium vary widely between different study populations. The reported incidence of postoperative delirium in 26 relevant and valid studies reviewed by Dyer et al. ranged from $0 \%$ to $73.5 \%$ (3). The sample of patients, the method of the study, and the diagnostic criteria used, influence the incidence reported (4). Generally, an incidence of $25 \%$ is assumed among hospitalized elderly patients (1). As a result of demographic aging, the incidence of delirium is likely to increase in the foreseeable future.

Delirium has been related to high morbidity and mortality, a prolonged hospital stay, higher costs, nursing home placement, and reduced cognitive and functional recovery.

The Inspection of Healthcare in the Netherlands reported that a delirium is often overlooked in hospitalized patients (1). A delirium is also often misdiagnosed as depression or dementia, or considered as normal behavior in elderly patients due to the lack of knowledge and awareness of nurses and doctors (4-8). Because of the fluctuating presentation of delirium during the day, nurses are in a strategic position to observe changes in patients' behavior because of their frequent patient contact (4).

The likelihood of developing delirium increases proportionally with the number of existing risk factors. Some of the most important predisposing risk factors for developing delirium are the presence of cognitive impairment, sleep deprivation, immobility, visual and hearing impairment, and dehydration (9). If the patient has an increased risk of developing delirium, preventative interventions can be considered (10).

The fundamental pathofysiological mechanism of delirium remain unclear. At the moment the focus is on the possible role of a low level of oxygen in relation with delirium. Despite several studies in different populations the exact pathophysiology and etiology of delirium are unknown. What is known is that the onset of delirium in each individual patient is caused by an interaction of predisposing and precipitating 
factors and a delirium is often seen in older patients; it is a multifactorial problem. Older patients who undergo cardiac surgery have an increased risk of developing delirium. Developments in operative and anesthetic techniques have enabled older patients to undergo cardiac surgery (1), so it is important to pay special attention to cardiac surgery patients and delirium.

In the Netherlands annually about 18000 patients undergo cardiac surgery, including about 6000 patients aged over 65 , mainly men. These patients have an increased risk to develop delirium. Incidences reported in this group of patients range from $3.1 \%$ (11) to $52 \%$ (12). In patients who undergo cardiac surgery, a delirium is associated with more postoperative complications $(4-6 ; 9 ; 13)$. Still, however, much is unknown about delirium in this specific population.

The studies described in this thesis were undertaken to study risk assessment and the long-term consequences of delirium to improve early identification of patients at an increased risk to develop a delirium following elective cardiac surgery. To conduct these studies we first have validated the Delirium Observation Screening (DOS) scale in accordance with the diagnosis of the psychiatrist, using the DSM-IV criteria as the gold standard.

The first research question was:

"Is the Delirium Observation Screening scale a valid instrument to detect delirium in cardiac surgery patients?"

The next step was to study risk assessment of delirium. First, we studied the literature on risk factors. Based on this review we measured the incidence of delirium after cardiac surgery and assessed which of the risk factors contributed to a postoperative delirium after cardiac surgery. The delirium risk checklist was completed during the Preoperative Outpatient Screening two to six weeks prior to the cardiac surgery, and measured the delirium risk factors. The DOS scale was used pre- and post operatively to assess whether patients had developed a delirium. The psychiatrist was consulted to confirm or refute the diagnosis of delirium. 
An additional research question was formulated:

"Is it possible to develop a risk checklist to identify patients with an increased risk of postoperative delirium following elective cardiac surgery?"

After this study the next step was to validate the delirium risk checklist again in elective cardiac surgery patients. After the first study we decided to test the delirium model on a complete independent data set. It is important to do true validation studies in prognostic research. Most of the time researchers do not repeat a study or validate their model only statistically, for example with bootstrapping; but we repeated our study and included some additional risk factors. So we generated an enhanced version of the risk checklist.

Finally, the long-term consequences of a postoperative delirium after cardiac surgery were studied, including mortality, re-admission rate, and cognitive and functional outcomes. Since the first study about the consequences was done 12-18 months after cardiac surgery in a relative small sample, it was deemed useful to study the consequences of delirium again in a larger sample to draw for example more firm conclusions about mortality and re-admission. In this second study we added other important outcomes such as quality of life and the cognitive function, measured with two validated instruments (SF-36 and CFQ). The SF-36 is a multipurpose, short-form health survey with 36 questions. It yields an 8-scale profile of functional health and well-being scores as well as psychometrically-based physical and mental health summary measures and a preference-based health utility index (14). The Cognitive Failures Questionnaire (CFQ) is a measure of selfreported deficits in the completion of simple everyday tasks that a person should normally be capable of completing without error and includes failures in attention, memory, perception, and motor function (15).

Two additional research questions were formulated:

"What are the long-term cognitive and functional consequences of delirium after cardiac surgery?" 
"What are the consequences of delirium, including mortality, re-admission, quality of life and cognitive and functional function, six months after cardiac surgery?"

This thesis is organized into eight chapters.

In chapter 2 the first research question "Is the Delirium Observation Screening scale a valid instrument to detect delirium in cardiac surgery patients?" will be answered. In chapters 4 and 5 the second question "Is it possible to develop a risk checklist to identify patients with an increased risk of postoperative delirium following elective cardiac surgery?" will be answered. In chapter 6 and 7 the last question "What are the long-term and six months cognitive and functional consequences of delirium after cardiac surgery?" will be answered.

Chapter 1 describes the background of this study on delirium.

Chapter 2 shows the results of the DOS scale, tested in a population of elective cardiac surgery patients.

Chapter $\mathbf{3}$ gives an overview of the literature on risk factors of delirium in cardiac surgery patients. An overview is given of all candidate predictors of delirium after cardiac surgery and the multivariate risk factors.

Chapter $\mathbf{4}$ shows the first results of the delirium risk checklist, tested in a population of elective cardiac surgery patients.

Chapter $\mathbf{5}$ shows the results of the second study of the delirium risk checklist; again tested in cardiac surgery patients. The number of patients studied was much larger and also a new delirium risk checklist with added risk factors was completed. Chapter $\mathbf{6}$ gives reports of the long-term consequences of a postoperative delirium after cardiac surgery.

Chapter 7 reports the consequences, including mortality, re-admission, and cognitive and functional function of a postoperative delirium six months after elective cardiac surgery. We also reported the quality of life six months after cardiac surgery in patients with and without a postoperative delirium with the SF36. The cognitive function was measured with the validated instrument CFQ. 
Chapter 8 describes the studies in a broader perspective. The methodological issues are discussed, the main conclusions are further outlined and implications for clinical practice and future research are made.

\section{References}

(1) van Blanken G, Robben PBM. Delirium vaak niet herkend. Medisch Contact 2005;60:1724-7.

(2) American Psychiatric Association. Diagnostic and Statistical Manual of Mental Disorders. 4th ed. 1994. Washington.

(3) Dyer CB, Ashton CM, Teasdale TA. Postoperative delirium. A review of 80 primary data-collection studies. Arch Intern Med 1995 Mar 13;155(5):461-5.

(4) Schuurmans MJ, Duursma SA, Shortridge-Baggett LM. Early recognition of delirium: review of the literature. J Clin Nurs 2001 Nov;10(6):721-9.

(5) Amador LF, Goodwin JS. Postoperative delirium in the older patient. J Am Coll Surg 2005 May;200(5):767-73.

(6) Cole MG, McCusker J, Bellavance F, Primeau FJ, Bailey RF, Bonnycastle $\mathrm{MJ}$, et al. Systematic detection and multidisciplinary care of delirium in older medical inpatients: a randomized trial. CMAJ 2002 Oct 1;167(7):753-9.

(7) Lipowski ZJ. Delirium: Acute Confusional States. Oxford: Oxford University Press; 1990.

(8) Timmers J, Kalisvaart K, Schuurmans M, de Jonge J. A review of delirium rating scales. Tijdschr Gerontol Geriatr 2004 Feb;35(1):5-14.

(9) Inouye SK, Bogardus ST, Jr., Charpentier PA, Leo-Summers L, Acampora $D$, Holford TR, et al. A multicomponent intervention to prevent delirium in hospitalized older patients. N Engl J Med 1999 Mar 4;340(9):669-76.

(10) Yildizeli B, Ozyurtkan MO, Batirel HF, Kuscu K, Bekiroglu N, Yuksel M. Factors associated with postoperative delirium after thoracic surgery. Ann Thorac Surg 2005 Mar;79(3):1004-9.

(11) Norkiene I, Ringaitiene D, Misiuriene I, Samalavicius R, Bubulis R, Baublys A, et al. Incidence and precipitating factors of delirium after coronary artery bypass grafting. Scand Cardiovasc J 2007 Jun;41(3):180-5. 
(12) Rudolph JL, Jones RN, Levkoff SE, Rockett C, Inouye SK, Sellke FW, et al. Derivation and validation of a preoperative prediction rule for delirium after cardiac surgery. Circulation 2009 Jan 20;119(2):229-36.

(13) Bucerius J, Gummert JF, Borger MA, Walther T, Doll N, Falk V, et al. Predictors of delirium after cardiac surgery delirium: effect of beating-heart (off-pump) surgery. J Thorac Cardiovasc Surg 2004 Jan;127(1):57-64.

(14) Aaronson NK, Muller M, Cohen PD, Essink-Bot ML, Fekkes M, Sanderman $R$, Sprangers MA, te Velde A, Verrips E: Translation, validation, and norming of the Dutch language version of the SF-36 Health Survey in community and chronic disease populations. J Clin Epidemiol. 1998; 51:1055-68.

(15) Broadbent DE, Cooper PF, FitzGerald P, Parkes KR: The Cognitive Failures Questionnaire (CFQ) and its correlates. Br J Clin Psychol. 1982; 21:1-16. 


\section{Chapter 2}

\section{The Delirium Observation Screening scale recognizes delirium early after cardiac surgery}

Sandra Koster Ab G. Hensens Frits G.J. Oosterveld Arie Wijma Job van der Palen 


\begin{abstract}
Background. Delirium or acute confusion is a temporary mental disorder which occurs frequently among hospitalized elderly patients. Patients who undergo cardiac surgery have an increased risk of developing delirium. Prevention or early recognition of delirium is essential. The Delirium Observation Screening (DOS) scale was developed to facilitate early recognition of delirium by nurses' observations during routine clinical care.
\end{abstract}

Aim. The aim of this study was to validate the DOS scale in accordance with the diagnosis of the psychiatrist, using the DSM-IV criteria as the gold standard. Methods. In this observational study, the DOS scale was used to assess whether 112 patients who underwent elective cardiac surgery had developed a postoperative delirium. The psychiatrist was consulted to confirm or refute the diagnosis delirium. Wilcoxon's Rank Sum Test was utilized to compare patients with and without delirium on duration of hospital stay. A Receiver Operating Characteristic Curve of the DOS scale was constructed with accompanying Area Under the Curve (AUC).

Results. Based on the diagnosis of the psychiatrist, the incidence of delirium following cardiac surgery was $21.4 \%$ and the mean duration of delirium was two and a half days. The time to discharge was 11 days longer in patients with delirium. In 27 of the 112 patients a DOS score of $\geq 3$ was found, that indicates delirium. The sensitivity and specificity of the DOS scale was $100 \%$ and $96.6 \%$ respectively. The AUC was 0.98 .

Conclusion. The DOS scale is a very good instrument to facilitate early recognition of delirium by nurses' observation of patients who undergo cardiac surgery. Early recognition will expedite good postoperative management such as implementation of appropriate interventions, and may decrease negative consequences caused by postoperative delirium. 


\section{Introduction}

\section{Definition of delirium}

Delirium is a common temporary mental disorder among hospitalized elderly patients (1). According to the American Psychiatric Association's Diagnostic and Statistical Manual of Mental Disorders (DSM-IV), delirium is defined as "a disturbance of consciousness with reduced ability to focus, sustain, or shift attention; a change in cognition; or the development of a perceptual disturbance that occurs over a short period of time and tends to fluctuate over the course of the day" (2). Delirium is characterized by a disturbance in consciousness and cognitive function or perception that develops in hours to days and fluctuates during the course of the day $(3,4)$. Van Gemert and Schuurmans defined delirium as a frequent form of psychopathology in elderly hospitalized patients; it is a symptom of acute somatic illness (5). According to the DSM-IV, the history, physical examination and laboratory tests support delirium as a direct physiologic consequence of a general medical condition, substance intoxication or withdrawal, use of a medication, toxin exposure, or combination of these factors (2). Inouye et al. described delirium as a common, serious, and potentially preventable source of morbidity and mortality among hospitalized elderly patients (6).

\section{Incidence and prevalence of delirium}

In the literature, the incidence and prevalence of delirium vary widely between different study populations. The reported incidence of postoperative delirium in 26 relevant and valid studies reviewed by Dyer et al. ranged from $0 \%$ to $73.5 \%(7)$. Ten to $30 \%$ of patients admitted to a general hospital develop delirium and a prevalence of up to $60 \%$ is recognized in frail elderly patients. Patients in intensive care units (ICU) are at high risk of developing delirium (8). In a recent study in postoperative elderly patients an incidence of $43 \%$ was found (9). The sample of patients, the method of the study and the diagnostic criteria used, influence the incidence reported (10). Generally, an incidence of $25 \%$ is assumed among hospitalized elderly patients (1). As a result of demographic aging, the incidence of delirium is likely to increase in the foreseeable future. 
Incidence and prevalence of delirium in patients undergoing cardiac surgery Patients who undergo cardiac surgery have an increased risk of developing delirium. In a recent study the incidence of delirium following cardiac surgery was found to be $21 \%$ and the Euroscore (European System for Cardiac Operative Risk Evaluation) and a disturbance in electrolytes could predict a postoperative delirium in patients who underwent elective cardiac surgery (11). In another study the incidence of delirium was $13.5 \%$ following elective cardiac surgery and increased to $20.0 \%$ in patients 60 years and older (4). In a recent study in a Cardiovascular Intensive Care Unit, the prevalence of postoperative delirium was $41.7 \%$ as diagnosed by the psychiatrist based on DSM-IV criteria (12). Finally, in two recent studies in a cardiac surgery ward the delirium incidence varied widely, namely $6 \%$ and $23 \%(13,14)$.

Developments in operative and anesthetic techniques have enabled older patients to undergo (cardiac) surgery (15). This may be an important cause of the increase in the frequency of delirium in the foreseeable future.

\section{Consequences of delirium}

Delirium has been related to high morbidity and mortality, a prolonged hospital stay, higher costs, nursing home placement, and reduced cognitive and functional recovery. In patients who undergo cardiac surgery, a delirium is associated with more postoperative complications. Patients with postoperative delirium were more prone to have postoperative respiratory insufficiency (32.9\% versus $7.0 \%)$. In addition, patients with delirium had a significantly higher prevalence of sternum instability ( $7.5 \%$ versus $1.9 \%)$ and were more likely to require surgical revision of the sternal wound $(6.4 \%$ versus $1.4 \%)(16)$. Therefore early recognition or prevention of delirium is important $(10,16-19)$.

Furthermore, the presence of a delirium is a safety risk for patients, as they are unlikely to understand instructions, cannot use patient controlled analgesia in a correct way, and have a greater risk of injury such as a fall out of bed. This is due to impaired cognitive function, which can persist for at least one year (20). 


\section{Recognition of delirium}

The Inspection of Healthcare in the Netherlands reported that a delirium is often overlooked in hospitalized patients (1). A delirium is also often misdiagnosed as depression or dementia, or considered normal behavior in elderly patients due to the lack of knowledge and awareness of nurses and doctors $(3,10,17,18,21)$. Because of the fluctuating presentation of delirium during the day, nurses are in a strategic position to observe changes in patients' behavior because of their frequent patient contact (10).

\section{DOS scale}

There are various delirium screening instruments to assess delirium. The Delirium Observation Screening (DOS) scale has been designed to measure early symptoms of delirium that nurses can assess during regular nursing care. It is based on the DSM-IV criteria for delirium (22). In several studies the DOS scale was tested in hip fracture patients and patients admitted to the Department of geriatric medicine. In these studies the DOS scale showed high internal consistency (0.93-0.96) (21-24). The predictive validity against the diagnosis of delirium made by a geriatrician was also good in the above mentioned studies. The sensitivity of the DOS scale was $89-100 \%$ with a specificity of $68-88 \%(21-23)$. The DOS scale is a reliable and valid instrument to recognize delirium based on nurses' observations during regular care (21). The DOS scale was reviewed by nurses as easy to use and relevant in practice $(5,21)$ and it allows a delirium to be recognized at an early stage (22). We validated the DOS scale in cardiac surgery patients because this has not been done previously. During the development stage, the DOS scale was designed with 25 behavioral items. In recent studies with geriatric and hip fracture patients, the scale was reduced to 13 items that were able to be rated as present or absent in less than 5 minutes (5). Three items of the DOS scale $(3,8,9)$ were reverse scored, that means "normal behavior" was rated as "always" (5). 


\section{Objective of the study}

Because of the increase of delirium in the foreseeable future as a result of demographic aging and development in operative and anesthetic techniques, it is important to investigate the causes, risk factors, and screening instruments of delirium in order to develop effective prevention and treatment management. The aim of this study was to validate the DOS scale in accordance with the diagnosis of the psychiatrist, using the DSM-IV criteria as the gold standard.

\section{Methods}

\section{Design and sample}

Between November 2006 and June 2007 a prospective cohort study included 112 consecutive patients, 45 years and older, who underwent elective cardiac surgery at the Department of Cardiothoracic Surgery. Excluded were patients who did not undergo preoperative screening, patients with existing dementia and patients with a preoperative delirium. Informed consent was obtained in accordance with the hospital's policy.

\section{Ethics Committee approval}

The Ethics Committee of Medisch Spectrum Twente was asked whether approval was needed. Because this is an observational study, without invasive procedures, approval was not deemed necessary.

\section{Procedure}

Patients were followed from admission until the time of discharge from the hospital. The DOS scale with 13 items was used pre- and post operatively to assess whether patients had delirium. The DOS scale describes typical behavioral patterns related to delirium in 13 statements or questions, which the observer has to answer with "never" (score $=0$ ) or "sometimes or always" (score=1) if applicable (see Table 1). When the patient was admitted to the hospital for cardiac surgery, the DOS scale was applied once to assess if the patient had a delirium or not. Patients with a preoperative delirium were excluded. A DOS score of $\geq 3$ indicates delirium (22) (see Table 1 for the working method of the DOS scale). When the DOS score was 
$\geq 2$, the psychiatrist was consulted to confirm or refute the diagnosis delirium. The psychiatrist was not consulted when the DOS score was $<2$, since the probability of delirium is extremely unlikely $(5,10,23)$.

Table 1. The working method of the DOS scale

The patient:

1. Dozes off during conversation or activities

2. Is easily distracted by stimuli from the environment

3. Does not lose attention to conversation or action

4. Does not finish question or answer

5. Gives answers that do not fit the question

6. Reacts slowly to instructions

7. Thinks to be somewhere else

8. Knows which part of the day it is

9. Remembers recent event

10. Is picking, disorderly, restless

11. Pulls IV tubes, feeding tubes, catheters etc.

12. Is easy or sudden emotional (frightened, angry, irritated)

13. Sees/hears things which are not there

Never $=0$ points; Sometimes or always $=1$ point.

A total score of three or more points indicate a delirium.

The diagnostic criteria used by the psychiatrist to confirm or refute the diagnosis delirium were based on the nursing documentation and the DSM-IV (2) (Table 2).

Table 2. Diagnostic criteria of DSM-IV for the diagnosis of delirium

A Disturbance of consciousness with reduced ability to focus, sustain or shift attention

B Changed cognition or the development of a perceptual disturbance

C Disturbance develops in a short period of time and fluctuates over the course of the day

D There is evidence from history, physical examination or laboratory findings that the disturbance is:

1. Physiological consequence of general condition

2. Caused by intoxication

3. Caused by medication

4. Caused by more than one etiology 
Post operatively the nurses applied the DOS scale at the end of every shift, based on their observations during that shift. Data were collected during the day of admission until the fifth postoperative day. If the patient had not developed a delirium by then, the DOS scale was not applied anymore. If the patient had developed a delirium during the first five postoperative days, the DOS scale was used until the patient was delirium free for two consecutive days.

\section{Statistical analysis}

With regards to the test characteristics of the DOS scale the sensitivity, specificity and the predictive value of a positive and negative result were estimated. The diagnosis of the psychiatrist was considered the gold standard. A Receiver Operating Characteristic curve (ROC curve) was constructed and the Area Under the Curve (AUC) with 95\% confidence intervals was calculated. To compare patients with and without delirium on duration of hospital stay, Wilcoxon's Rank Sum Test was utilized.

\section{Results}

\section{Characteristics of the patients}

One hundred and fourteen patients were invited to participate in the study of whom two refused for personal reasons. The majority were males $(63.4 \%)$ and the mean age was 70 years $(S D=7.3)$. The most commonly performed cardiac surgery included Coronary Artery Bypass Grafting (CABG) (37.5\%) and heart valve surgery (36.6\%). The combination of these two operations was performed in $13.4 \%$ of the patients, while other cardiac surgery was performed in $12.5 \%$.

Incidence, prevalence, duration delirium and duration hospital stay In 24 patients (21.4\%) the psychiatrist diagnosed postoperative delirium. Four patients $(3.6 \%)$, of whom two had developed a postoperative delirium, died during the postoperative stage. Eight patients (33.3\%) developed a delirium on the first postoperative day $(S D=1.59)$. These patients had the highest $D O S$ scores (maximum of 9 points) (see also Figure 1). The prevalence of delirium according to the DOS scale from the operation day (day 0 ) until the fifth postoperative day 
successively was $7.1 \%$ (day 0 ), $8.9 \%$ (day 1 ), $6.3 \%$ (day 2), $4.5 \%$ (day 3 ), $2.7 \%$ (day 4 ) and $3.6 \%$ (day 5). The mean duration of delirium was 2.5 days ( $\mathrm{SD}=2.1$ ) (see also Figure 2). In the event of delirium, the duration of hospital stay was significantly higher $(p<0.01)$. In patients with a postoperative delirium, the mean hospital stay was 22 days $(S D=21.0)$ versus 11 days $(S D=5.9)$ in patients without a postoperative delirium.

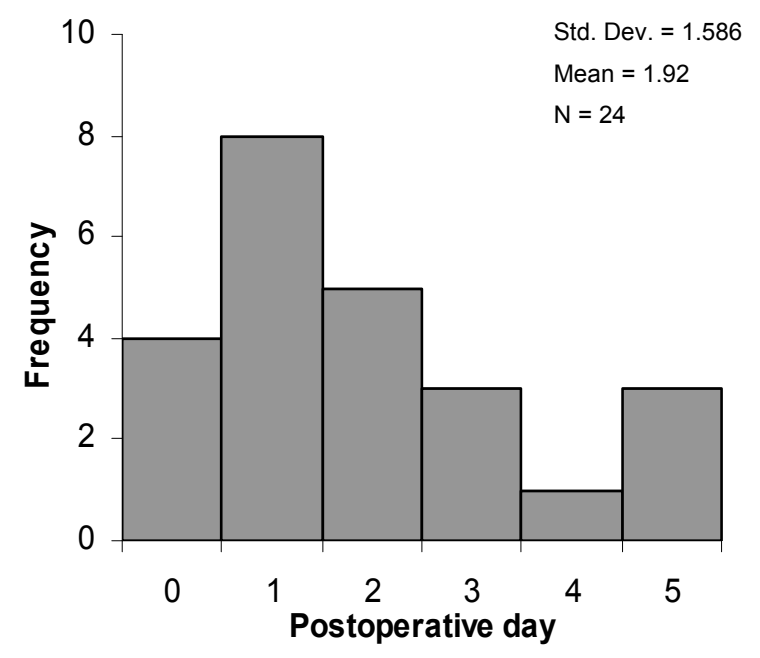

Figure 1. Postoperative day on which delirium was diagnosed for the first time

\section{Validity DOS scale}

In this study none of the patients had a preoperative delirium. The maximum DOS score at admission was two points $(1.8 \%)$ and the psychiatrist found no delirium in these patients. Most of the patients $(91.1 \%)$ had a score of zero points on the DOS scale at the time of admission. In 27 patients a DOS score of $\geq 3$ was observed, which indicates delirium (Table 3). In 24 of these patients the psychiatrist also declared the diagnosis delirium. This results in a positive predictive value of the DOS scale of $88.9 \%$ (24/27 patients). The sensitivity of the DOS scale with the diagnosis by the psychiatrist as the gold standard was $100 \%$ (24/24 patients). The psychiatrist was consulted for six patients $(5.4 \%)$ when a DOS score of 2 was found. None of these six patients were found to be delirious. The specificity of the 
DOS score could only be estimated if it was assumed that there was no delirium in patients with a DOS score of $<2$ points. When the DOS score was $<2$ and the nurses did not observe a delirium, the diagnosis "no delirium" was assumed. With this assumption the specificity was $96.6 \%$ (85/88). Finally, the predictive value of a negative test was $100 \%$ (85/85). The DOS scale yielded an Area Under the ROC Curve of $0.98(95 \% \mathrm{Cl}=0.96-1.00 ; p<0.001)$ (see also Figure 3 ).

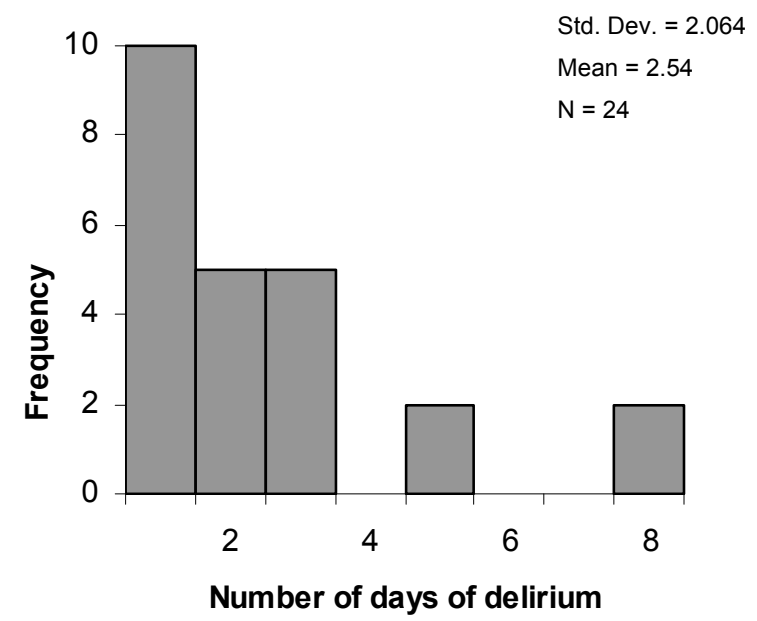

Figure 2. Duration of delirium in days

\section{Discussion}

The sensitivity and specificity of the DOS scale amounted to $100 \%$ and $96.6 \%$, respectively.

Table 3. Outcome DOS scale in comparison with diagnosis psychiatrist $(N=112)$

\begin{tabular}{lccc} 
& Diagnosis psychiatrist & & Total \\
& Delirium & No delirium & \\
& & & \\
\hline DOS scale & 24 & 3 & 85 \\
Delirium & 0 & 85 & 112 \\
No delirium & 24 & 88 & \\
Total & & & \\
& & & \\
\hline
\end{tabular}


This makes the DOS scale an extremely useful instrument for determining delirium in patients undergoing cardiac surgery. In comparison with earlier studies the sensitivity and specificity values are substantially higher (21-23).

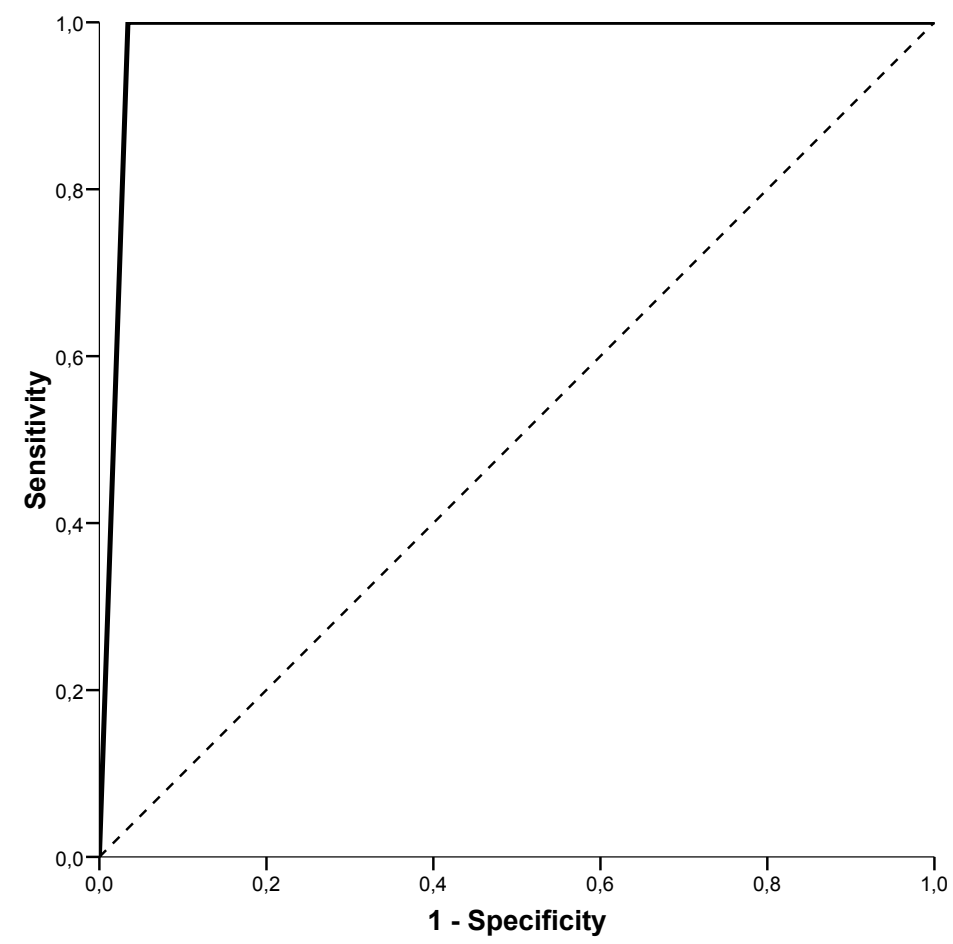

Figure 3. ROC curve of the DOS scale

Only six patients had a postoperative DOS score of 2 . The specificity of the DOS scale could only be estimated if it was assumed that there was no delirium in patients with a DOS score of $<2$ points. In 79 patients with a DOS score $<2$ the psychiatrist was not consulted and it was assumed that there was no delirium. It is very unlikely that a delirium was present in these patients because of the similarity between the DOS scale items and the diagnostic criteria for delirium. In a study with 92 patients (mean age 82 years) with a hip fracture, eighteen patients developed a delirium diagnosed by the psychiatrist. One patient had a DOS score $<3$ but was diagnosed as delirious by the psychiatrist (24). In another study, 87 patients (from one general medical and three surgical wards) were included of whom nine patients developed delirium. In this study one patient with delirium had 
a DOS score $<3$ (5). As observed in our study, the probability of having delirium with a DOS score $<2$ seems to be very low as confirmed by the psychiatrist.

A limitation is the fact that the psychiatrist was only contacted when there was potential for delirium, which may bias the psychiatrist to expect delirium. However, this bias is probably small since the psychiatrist was also consulted when the DOS score was 2 .

In three patients a postoperative delirium was measured with the DOS scale and this was not confirmed by the psychiatrist. These three patients had a DOS score of three on the operation day (day 0 ). On the first postoperative day these patients received zero points on the DOS scale while they were still receiving an opioid. It is plausible that the observed delirium according to the DOS scale was related to the recent narcosis. It may be better to apply the DOS scale from the first postoperative day, so that the outcome of the DOS scale is less influenced by the side effects of the narcosis. In intensive care patients the DOS scale is probably not the best instrument, because patients are intubated most of the time. Another screening instrument, like the NEECHAM Confusion Scale ICU or the CAM-ICU, is more recommended $(25,26)$.

There are several rating scales that can be helpful in detecting delirium. The most common screening instruments are the Confusional Assessment Method (CAM), the NEECHAM Confusion Scale (NEECHAM) and the Delirium Observation Screening (DOS) scale (21). Because of the fluctuating nature of delirium and the frequent contact of nurses with patients, nurses are in a strategic position to observe changes in patients' behavior at an early stage. Therefore, the choice was made for a screening instrument based on nurses' observations. The CAM must be rated by trained doctors or nurses (27) and was therefore not used. The NEECHAM and DOS scale are both very acceptable in terms of sensitivity and specificity (5). In a recent study the DOS scale was found to be significantly easier to use and highly relevant to nurses' practice (5). The DOS scale can be used without the need for training.

The DOS scale is a useful, valid, and user friendly screening instrument to use in patients who undergo cardiac surgery. Early recognition of postoperative delirium can be realized with the DOS scale and this will expedite good postoperative 
management such as the implementation of appropriate interventions. In addition, the DOS scale will probably decrease negative consequences caused by delirium after cardiac surgery.

Research evidence on effectiveness of interventions to prevent delirium is sparse. Further studies of delirium prevention are needed in cardiac surgery patients (8).

\section{References}

(1) van Blanken G, Robben PBM. Delirium vaak niet herkend. Medisch Contact 2005;60:1724-7.

(2) American Psychiatric Association. Diagnostic and Statistical Manual of Mental Disorders. 4th ed. 1994. Washington.

(3) Lipowski ZJ. Delirium: Acute Confusional States. Oxford: Oxford University Press; 1990.

(4) van der Mast RC, Huyse FJ, Rosier PF. Guideline 'Delirium'. Ned Tijdschr Geneeskd 2005 May 7;149(19):1027-32.

(5) Gemert van LA, Schuurmans MJ. The Neecham Confusion Scale and the Delirium Observation Screening Scale: capacity to discriminate and ease of use in clinical practice. BMC Nurs 2007;6:3.

(6) Inouye SK. The dilemma of delirium: clinical and research controversies regarding diagnosis and evaluation of delirium in hospitalized elderly medical patients. Am J Med 1994 Sep;97(3):278-88.

(7) Dyer CB, Ashton CM, Teasdale TA. Postoperative delirium. A review of 80 primary data-collection studies. Arch Intern Med 1995 Mar 13;155 (5):461-5.

(8) Siddiqi N, Stockdale R, Britton AM, Holmes J. Interventions for preventing delirium in hospitalised patients. Cochrane Database Syst Rev 2007;2(CD005563).

(9) Robinson TN, Eiseman B. Postoperative delirium in the elderly: diagnosis and management. Clin Interv Aging 2008;3(2):351-5.

(10) Schuurmans MJ,Duursma SA, Shortridge-Baggett LM. Early recognition of delirium: review of the literature. J Clin Nurs 2001 Nov;10(6):721-9. 
(11) Koster S, Oosterveld FG, Hensens AG,Wijma A, van der Palen J. Delirium after cardiac surgery and predictive validity of a risk checklist. Ann Thorac Surg 2008 Dec;86(6):1883-7.

(12) Chang YL, Tsai YF, Lin PJ, Chen MC, Liu CY. Prevalence and risk factors for postoperative delirium in a cardiovascular intensive care unit. Am J Crit Care 2008 Nov; 17(6):567-75.

(13) Loponen P, Luther M, Wistbacka JO, Nissinen J, Sintonen H, Huhtala H, et al. Postoperative delirium and health related quality of life after coronary artery bypass grafting. Scand Cardiovasc J 2008 Mar 4:1-8.

(14) Tan MC, Felde A, Kuskowski M,Ward H, Kelly RF, Adabag AS, et al. Incidence and predictors of post-cardiotomy delirium. Am J Geriatr Psychiatry 2008 Jul;16(7):575-83.

(15) Yildizeli B, Ozyurtkan MO, Batirel HF, Kuscu K, Bekiroglu N, Yuksel M. Factors associated with postoperative delirium after thoracic surgery. Ann Thorac Surg 2005 Mar;79(3):1004-9.

(16) Bucerius J, Gummert JF, Borger MA, Walther T, Doll N, Falk V, et al. Predictors of delirium after cardiac surgery delirium: effect of beatingheart (off-pump) surgery. J Thorac Cardiovasc Surg 2004 Jan;127 (1):57-64.

(17) Amador LF, Goodwin JS. Postoperative delirium in the older patient. J Am Coll Surg 2005 May;200(5):767-73.

(18) Cole MG, McCusker J, Bellavance F, Primeau FJ, Bailey RF, Bonnycastle $\mathrm{MJ}$, et al. Systematic detection and multidisciplinary care of delirium in older medical inpatients: a randomized trial. CMAJ 2002 Oct 1;167(7):753-9.

(19) Inouye SK, Bogardus Jr ST, Charpentier PA, Leo-Summers L,Acampora D, Holford TR, et al. A multicomponent intervention to prevent delirium in hospitalized older patients. N Engl J Med 1999 Mar 4;340(9):669-76.

(20) McCusker J, Cole M, Dendukuri N, Belzile E, Primeau F. Delirium in older medical inpatients and subsequent cognitive and functional status: a prospective study. CMAJ 2001 Sep 4;165(5):575-83.

(21) Timmers J, Kalisvaart K, Schuurmans M, de Jonge J. A review of delirium rating scales. Tijdschr Gerontol Geriatr 2004 Feb;35(1):5-14. 
(22) Schuurmans MJ, Shortridge-Baggett LM, Duursma SA. The Delirium Observation Screening Scale: a screening instrument for delirium. Res Theory Nurs Pract 2003;17(1):31-50.

(23) Schuurmans MJ, Rogier ADTSBLM, Duursma SA. Early symptoms of delirium observed by nurses in hip fracture patients. Early recognition of delirium; 2001. p. 91-108.

(24) Schuurmans MJ, Donders ART, Shortridge-Baggett LM, Duursma SA. Delirium case finding: pilot testing of a new screening scale for nurses. J Am Geriatr Soc 2002;50(4):S3.

(25) Immers HE, Schuurmans MJ, van de Bijl JJ. Recognition of delirium in ICU patients: a diagnostic study of the NEECHAM confusion scale in ICU patients. BMC Nurs 2005;4:7.

(26) Ely EW, Margolin R, Francis J, May L, Truman B, Dittus R, et al. Evaluation of deliriumin critically ill patients: validation of the Confusion Assessment Method for the Intensive Care Unit (CAM-ICU). Crit Care Med 2001 Jul;29(7):1370-9.

(27) Inouye SK, van Dyck CH, Alessi CA, Balkin S, Siegal AP, Horwitz RI. Clarifying confusion: the confusion assessment method. A new method for detection of delirium. Ann Intern Med 1990 Dec 15;113(12):941-8. 


\title{
Chapter 3
}

\section{Risk factors of delirium after cardiac surgery}

\author{
A systematic review
}

\author{
Sandra Koster \\ Ab G. Hensens \\ Marieke J. Schuurmans \\ Job van der Palen
}

Eur J Cardiovasc Nurs. 2010 Sep 24. (Epub ahead of print) 


\section{Abstract}

Background. Delirium or acute confusion is a temporary mental disorder that occurs frequently among hospitalized elderly patients, but also in younger patients a delirium can develop. Patients who undergo cardiac surgery have an increased risk of developing delirium that is associated with many negative consequences. Therefore, prevention of delirium is essential. Despite the high incidence of delirium, a paucity of data on risk factors for delirium exists.

Aim. The aim of this study was to summarize the available information concerning these risk factors.

Methods. A literature research was performed using the PubMed, Cinahl, and Cochrane Library databases and was limited to the last 10 years.

Results. Our review revealed 27 risk factors; 12 predisposing and 15 precipitating factors for delirium after cardiac surgery. The most established predisposing risk factors were atrial fibrillation, cognitive impairment, depression, history of stroke, older age, and peripheral vascular disease. The most established precipitating risk factor was a red blood cell transfusion. An abnormal albumin level was reported as the most established precipitating risk factor among blood values tested. A low cardiac output and the use of an Intra Aortic Balloon Pump or inotropic medication seem to be the most relevant risk factors associated with a postoperative delirium. Conclusion. A multifactorial risk model should be applied to identify patients at an increased risk of developing delirium following elective cardiac surgery. In these patients, if possible, preventative interventions can be taken and early recognition of delirium can be realized. This could potentially decrease the incidence of delirium and negative consequences caused by a postoperative delirium. 


\section{Introduction}

Developments in operative and anesthetic techniques have enabled older patients to undergo cardiac surgery (1). Older patients who undergo cardiac surgery have an increased risk of developing delirium. Delirium is a common temporary mental disorder among hospitalized elderly patients (2) (see Table 1 for the diagnostic criteria of delirium). In recent studies, the reported incidence of delirium following cardiac surgery ranged from $13.5 \%$ to $41.7 \%$ (3). The wide range in reported incidences could be explained by the different study designs, a difference in the method of assessing delirium and the differences in the study population. Given the demographic changes the incidence of delirium however will increase in the foreseeable future.

Prevention or early recognition of delirium is important since delirium correlates with a prolonged hospital stay, nursing home placement, reduced cognitive and functional recovery, and increased morbidity and mortality (4-8). In patients who undergo cardiac surgery, a delirium is associated with more postoperative complications. In addition, patients with postoperative delirium were more prone to have postoperative respiratory insufficiency, had a significantly higher prevalence of sternum instability and were more likely to require surgical revision of the sternal wound (5).

Table 1. Diagnostic criteria of DSM-IV for the diagnosis of delirium
A Disturbance of consciousness with reduced ability to focus, sustain or shift attention
B Changed cognition or the development of a perceptual disturbance
C Disturbance develops in a short period of time and fluctuates over the course of the day
D There is evidence from history, physical examination or laboratory findings that the disturbance is:

1. Physiological consequence of general condition

2. Caused by intoxication

3. Caused by medication

4. Caused by more than one etiology

The exact pathophysiology and etiology of delirium are unknown, and the onset of delirium in each individual patient is caused by an interaction of predisposing and 
precipitating factors. The likelihood of developing delirium increases proportionally with the number of existing risk factors (7). If the patient has an increased risk of developing delirium, preventative interventions can be considered (1). The first step is to check the risk factors pre-, peri- and postoperative.

The aim of this study was to systematically review predisposing and precipitating risk factors for the development of delirium in patients who undergo cardiac surgery.

\section{Materials and methods}

A comprehensive review in Pub Med, Cinahl, and the Cochrane Library was performed, limited to English language studies because of convenience reasons. Since only in the last decade most delirium studies have been based on validated delirium assessment tools (9) the review included the period January 1999 through December 2009. Diagnostic tools to diagnose delirium were developed in the last decade. In 1990 the Confusion Assessment Method (10) was developed, in 1996 the Neecham confusion scale (11), and in 2003 the Delirium Observation Screening scale (12). Search terms were "delirium", "cardiac surgery", and "risk factor(s)".

Papers were included if they reported on original research in cardiac surgery patients, were prospective or retrospective studies and contained at least one risk factor for delirium if the risk factor reached the significance level of $5 \%$ in a univariate or multivariate analysis. After the systematic search, a check for duplicates, and removal of reviews, 51 publications remained (Figure 1). Of these, the abstracts were screened for the outcome delirium, cardiac surgery, and risk factors. Twenty-three were removed because these studies did not report on delirium, cardiac surgery, and risk factors, so 28 publications seemed to meet all of the inclusion criteria based on the abstract. These 28 were all appraised by reading the full text. 


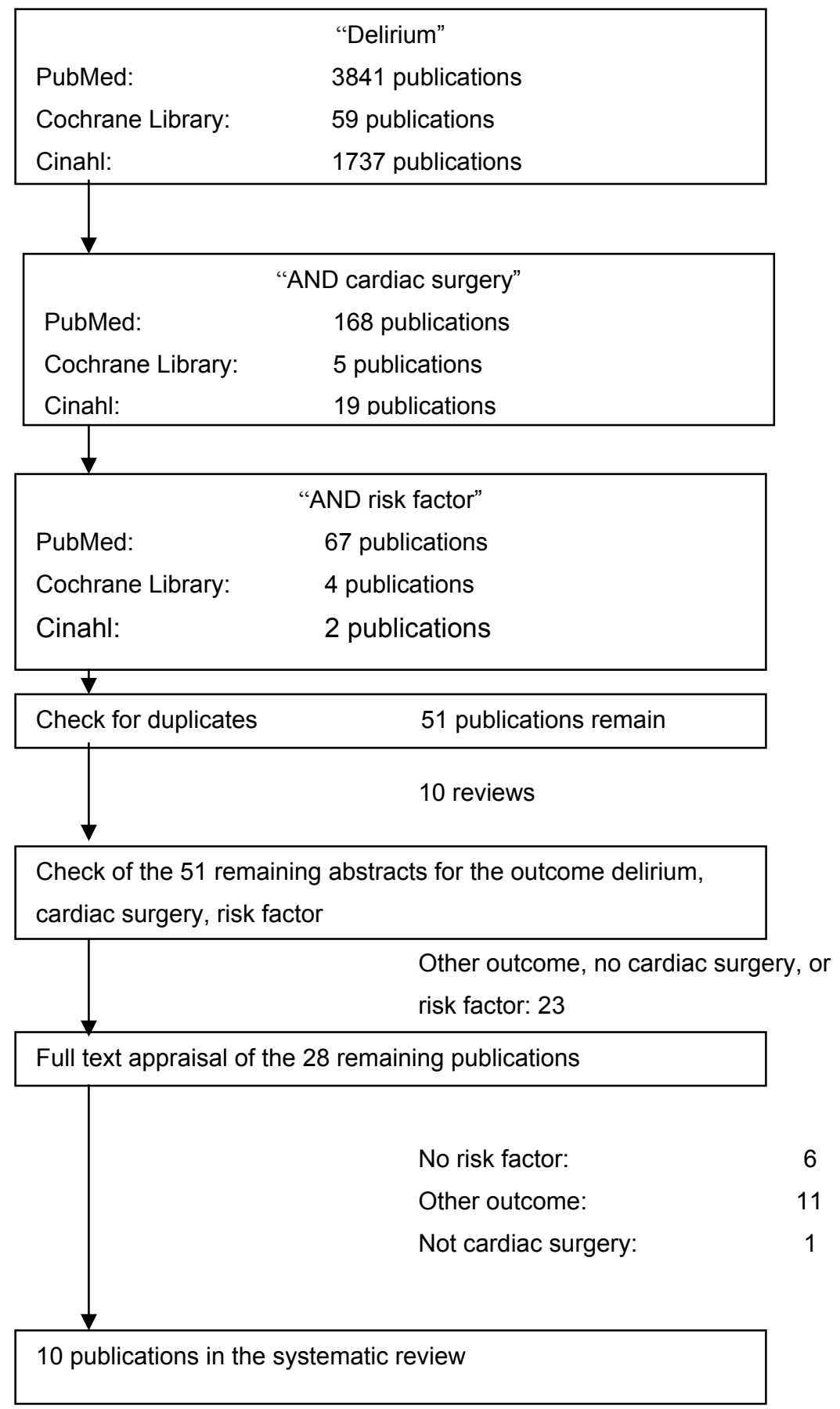

Figure 1. Presentation of the bibliographic research 
After further analysis of the full text only 10 papers were included in the systematic review, of which two papers were from the same study, but with different viewpoints. Eleven papers were excluded because there was another outcome, six papers did not contain a risk factor for delirium, and one paper did not report on research in cardiac surgery patients. To evaluate the quality of the papers, the studies were evaluated by one researcher (SK) on six criteria according to van Rompaey et al., scoring one point for each criterion (9). This resulted in a maximum score of six points for the best papers (Table 2).

\section{Results}

Description of the included papers

Table 3 presents a description of the included studies and Table 4 presents an overview of the multivariate risk factors of the included studies. The included papers were published from 1999 until 2009. Most studies (seven papers) reported on a prospective cohort study and three studies had a retrospective design. The critical appraisal resulted in the maximum score for six publications, whereas four publications scored intermediate (Table 2). In two of the intermediate papers, the selection criteria for the patients were not clearly formulated $(5,13)$. In three papers, the delirium assessment method was not definite, since there was no use of a psychiatric interview or a validated assessment tool to diagnose delirium $(5,14,15)$.

\section{Incidence of delirium after cardiac surgery}

The reported incidence of delirium for patients after cardiac surgery ranged from $3 \%$ to $52 \%$. (Table 3 ). The lowest number of included patients was 53 , whereas the largest sample contained 16,184 cardiac surgery patients. In eight studies the data were collected in cardiac surgery wards and in two studies in a cardiovascular intensive care unit.

The delirium diagnosis was primarily based on the DSM-IV criteria and once on the DSM-III-R criteria. The Confusion Assessment Method (CAM) was principally used as a delirium assessment tool (10). 
Table 2. Quality scoring of the included studies

\begin{tabular}{|c|c|c|c|c|c|c|c|}
\hline Author & $\begin{array}{l}\text { Study } \\
\text { design }\end{array}$ & $\begin{array}{l}\text { Selection } \\
\text { of } \\
\text { patients }\end{array}$ & $\begin{array}{l}\text { Delirium } \\
\text { assessment }\end{array}$ & $\begin{array}{l}\text { Multivariate } \\
\text { analysis }\end{array}$ & Plausible & $\begin{array}{l}\text { Clinically } \\
\text { relevant }\end{array}$ & Total \\
\hline $\begin{array}{l}\text { Banach et al. } \\
(19)^{\mathrm{a}}\end{array}$ & 1 & 1 & 1 & 1 & 1 & 1 & 6 \\
\hline $\begin{array}{l}\text { Bucerius et } \\
\text { al. (5) }\end{array}$ & 1 & 0 & 0 & 1 & 1 & 1 & 4 \\
\hline $\begin{array}{l}\text { Chang et al. } \\
\text { (13) }\end{array}$ & 1 & 0 & 1 & 1 & 1 & 1 & 5 \\
\hline $\begin{array}{l}\text { Kazmierski et } \\
\text { al. }(20)^{a}\end{array}$ & 1 & 1 & 1 & 1 & 1 & 1 & 6 \\
\hline $\begin{array}{l}\text { Koster et al. } \\
\text { (3) }\end{array}$ & 1 & 1 & 1 & 1 & 1 & 1 & 6 \\
\hline $\begin{array}{l}\text { Norkiene et } \\
\text { al. (14) }\end{array}$ & 1 & 1 & 0 & 1 & 1 & 1 & 5 \\
\hline $\begin{array}{l}\text { Rolfson et al. } \\
\text { (15) }\end{array}$ & 1 & 1 & 0 & 1 & 1 & 1 & 5 \\
\hline $\begin{array}{l}\text { Rudolph et } \\
\text { al. (33) }\end{array}$ & 1 & 1 & 1 & 1 & 1 & 1 & 6 \\
\hline $\begin{array}{l}\text { Tan et al. } \\
\text { (37) }\end{array}$ & 1 & 1 & 1 & 1 & 1 & 1 & 6 \\
\hline $\begin{array}{l}\text { Veliz- } \\
\text { Reissmüller } \\
\text { et al. (38) }\end{array}$ & 1 & 1 & 1 & 1 & 1 & 1 & 6 \\
\hline
\end{tabular}

Criteria for appraisal: (1) the study design. The description of the aim, the design and the methods were evaluated. The size of the sample was large enough to answer the formulated research questions; (2) the selection of patients was clearly formulated and sustained. A severe selection bias could not be detected; (3) the delirium assessment was able to retrieve all delirious patients. A psychiatric interview or validated assessment tool was used to diagnose the delirious state; (4) multivariate analysis was used to minimize possible confounding factors; (5) the statistical analysis made the results plausible; (6) the results were clinically relevant to cardiac surgery patients.

a The data of Banach et al. and Kazmierski et al. are from the same study. 


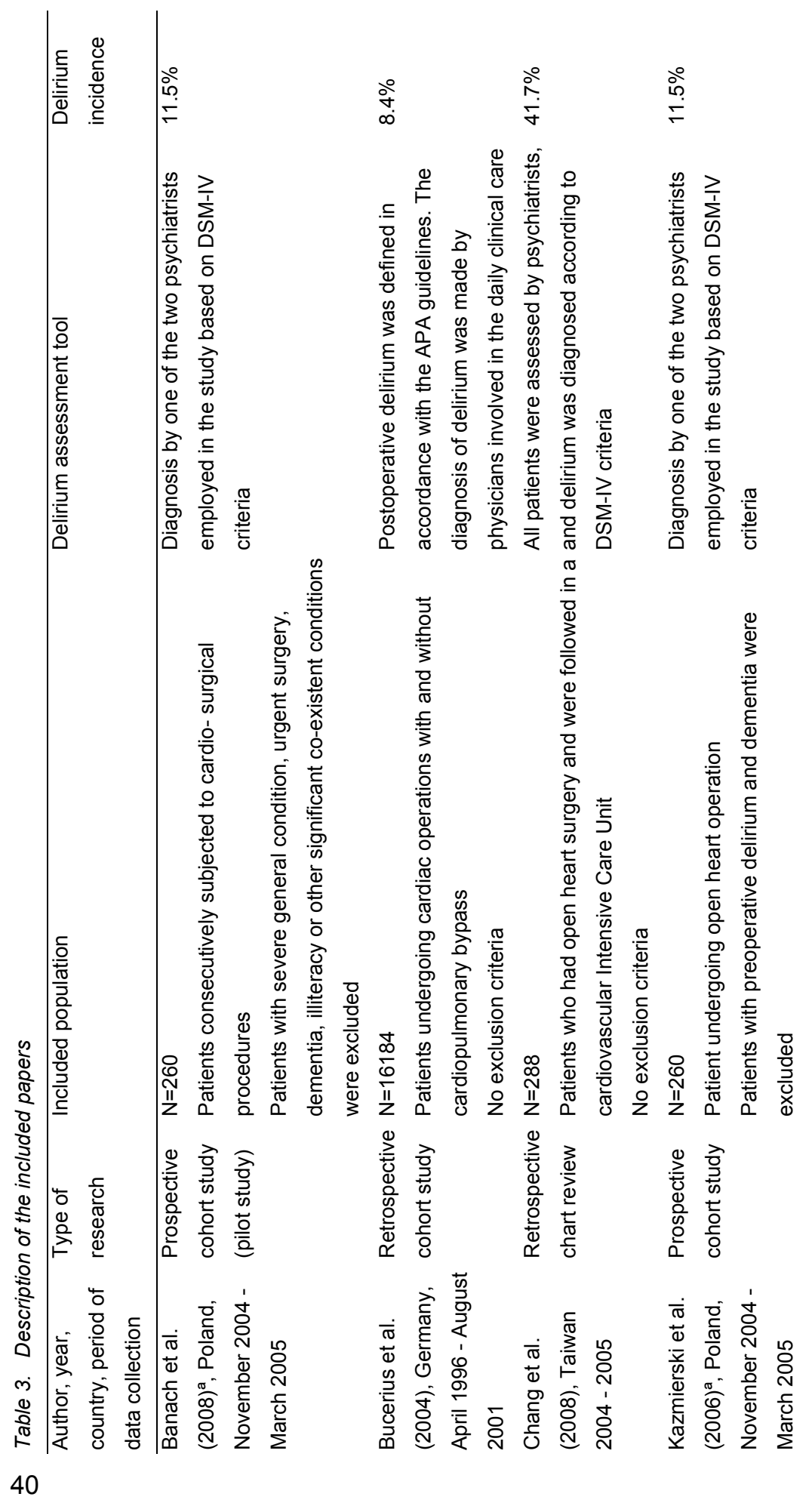




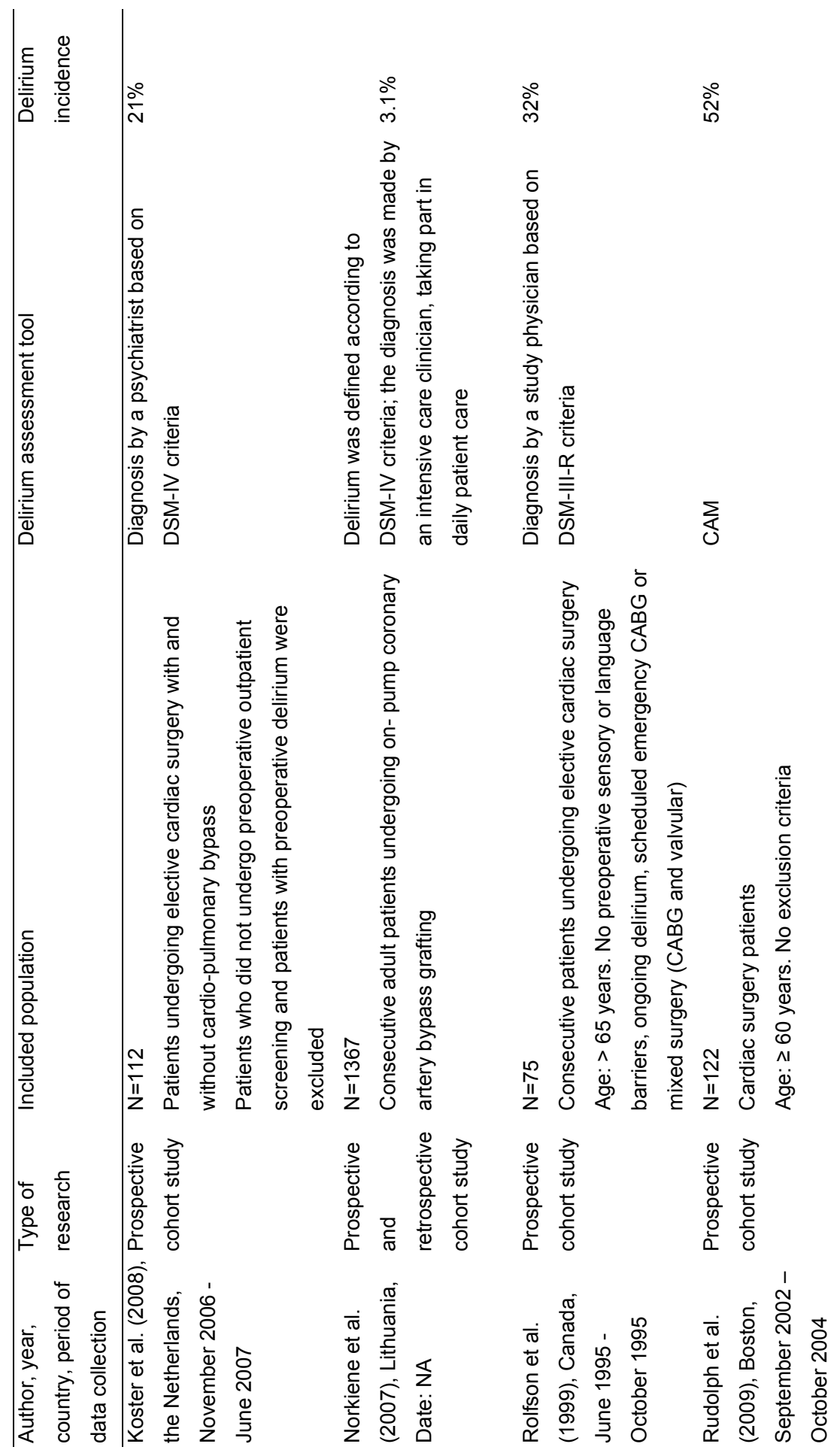




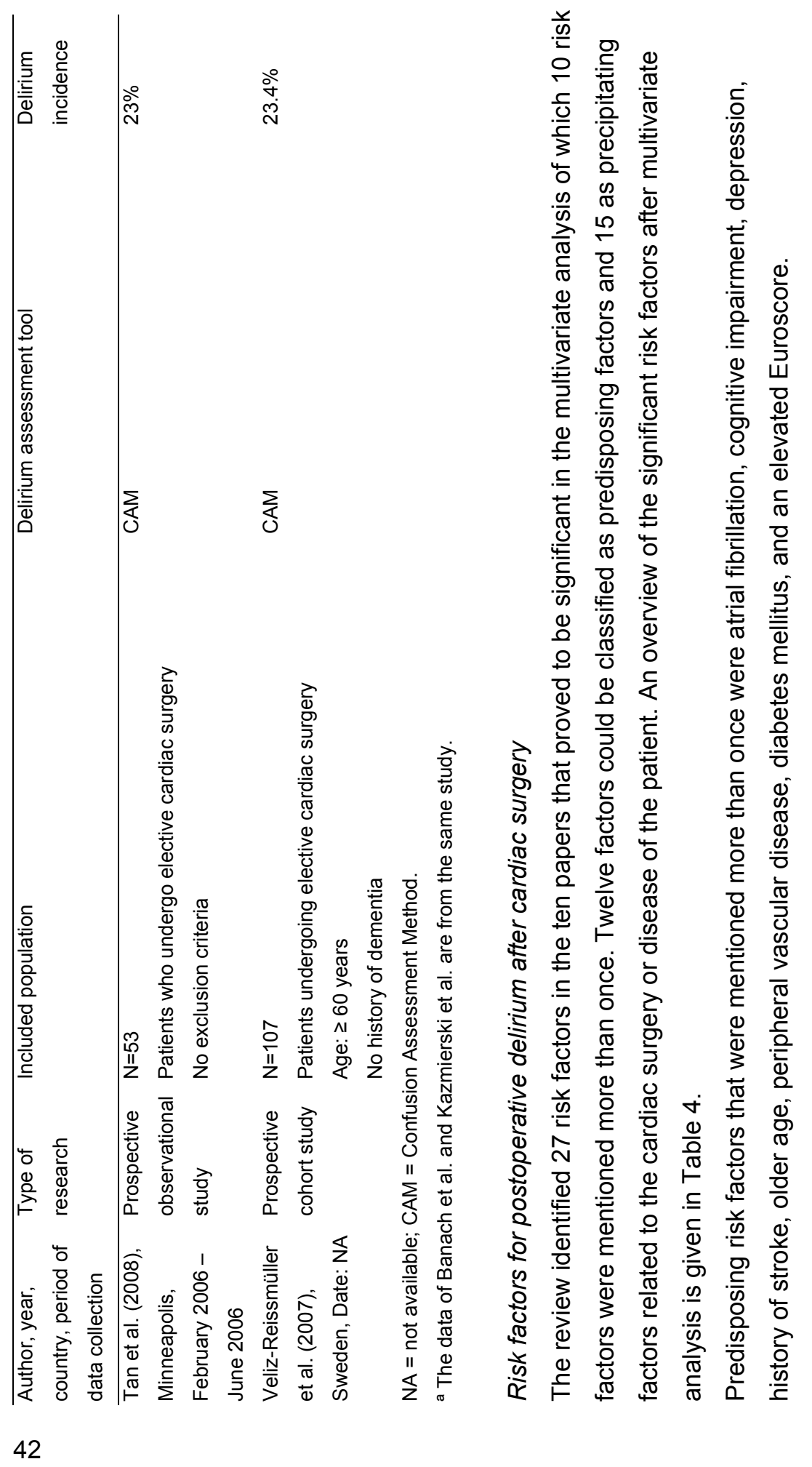




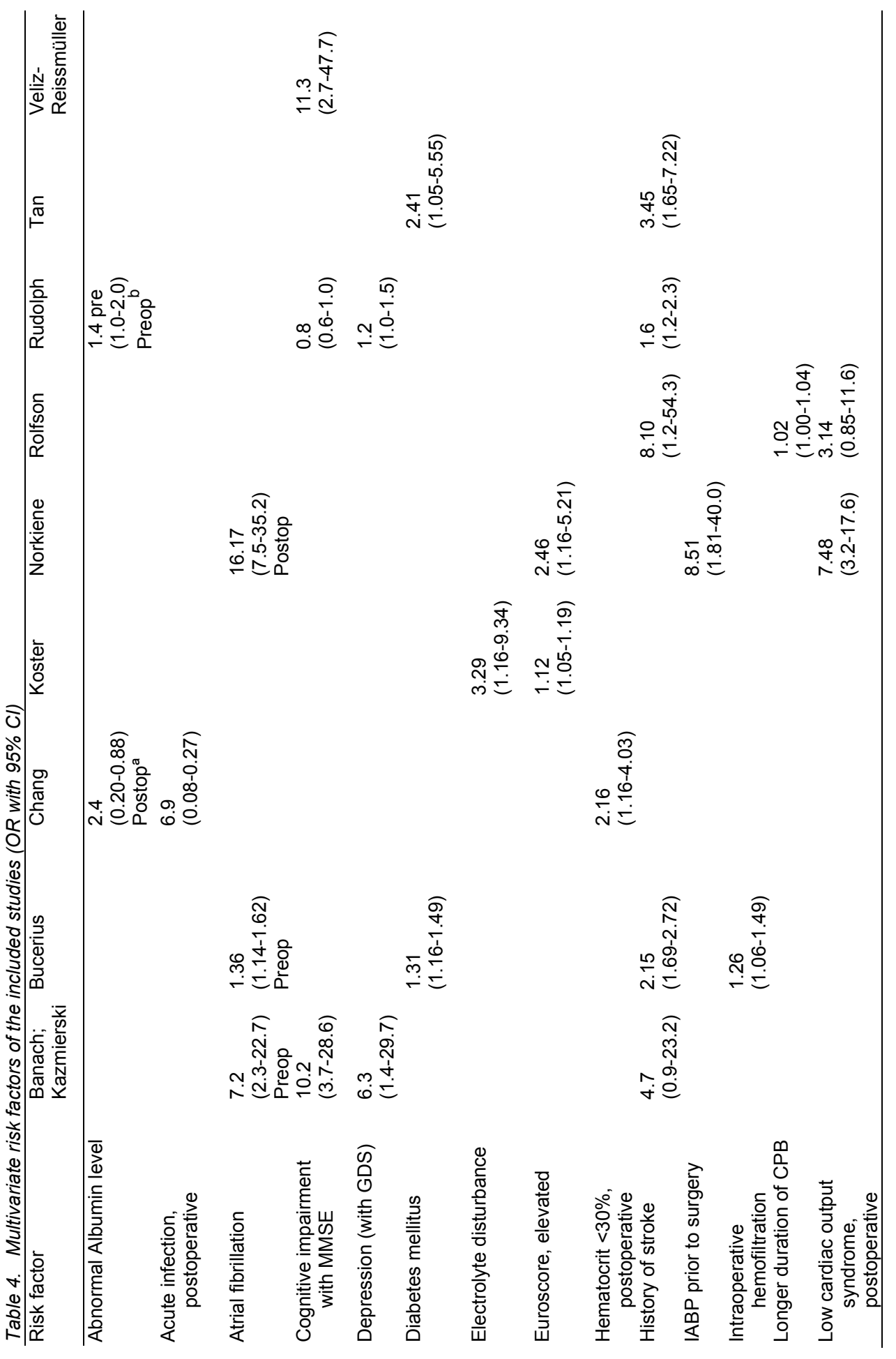




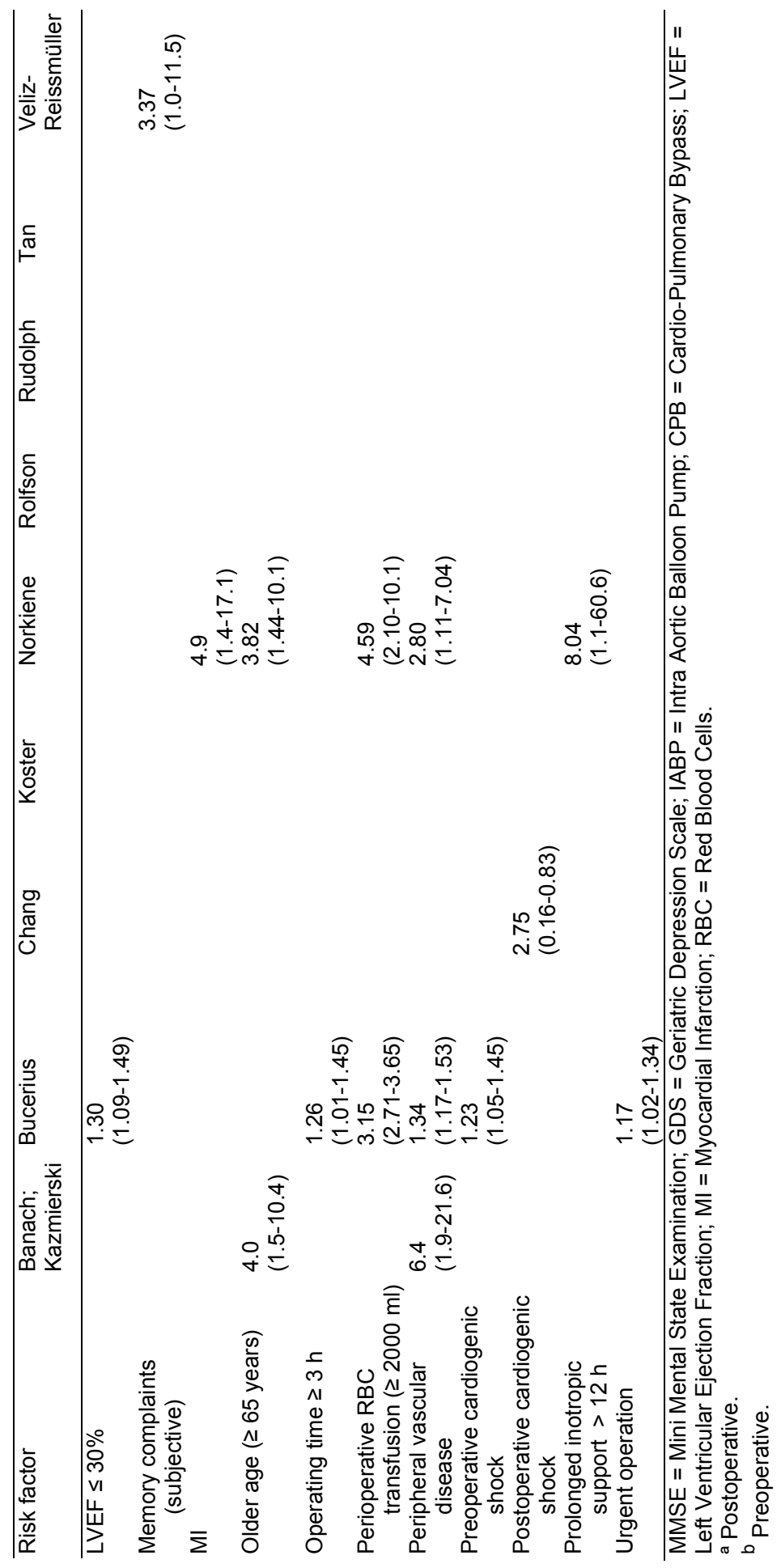


The precipitating risk factor that was mentioned more than once was a red blood cell transfusion. An abnormal albumin level, pre- and postoperative, was reported as a relevant precipitating risk factor among blood values. Of the hemodynamic parameters a low cardiac output and the use of an Intra Aortic Balloon Pump (IABP) or inotropic medication are relevant risk factors associated with postoperative delirium after cardiac surgery. However, these factors are not independent of one another; a low cardiac output leads to the need for inotropic stimulation and IABP and is therefore in all likelihood the true risk factor for delirium.

Table 4 shows a wide range in reported odds ratios in several risk factors. For atrial fibrillation for example, the odds ratio varies from 1.36 to 36.17 .

\section{Discussion}

The incidence of delirium in the selected papers shows a broad range from $3 \%$ to $52 \%$. Generally, an incidence of $25 \%$ is assumed among hospitalized elderly patients (2). The number of patients, the methods of the studies and the diagnostic criteria used influence the results reported; therefore, it is difficult to compare the results of the 10 studies. The number of patients in the papers shows a broad range from 53 to 16,184 patients. Small studies are often underpowered for finding significant risk factors, whereas in large studies always risk factors will be found. Three papers had a retrospective design and in this design the assessment of delirium can be difficult and underestimation of delirium can be expected. Finally the diagnostic criteria to diagnose delirium were different in the studies. Delirium was assessed using the validated diagnostic algorithm of the CAM and also the Mini Mental State Examination (MMSE) was used. The CAM has been validated for assessing delirium and is capable of distinguishing between delirium and dementia (16). The CAM for the intensive care unit (CAM-ICU) is a tool for screening for delirium in ventilated patients that with proper training can be administered quickly by staff nurses in the ICU (17). The MMSE is the most commonly used test for complaints of memory problems or when a diagnosis of dementia is being considered. This combined assessment for delirium has been shown to be highly 
reliable when administered by trained, non clinician interviewers. The diagnostic criteria of a psychiatrist to confirm or refute the diagnosis delirium are mostly based on the DSM-IV criteria for delirium (18) next to the nursing documentation. The DSM-IV criteria are based on specific diagnostic criteria to differentiate delirium from other syndromes like anxiety, depression, and dementia. The diagnosis of delirium can be questioned in three papers since no diagnostic tool was used or was not described clearly. In the study by Rolfson et al. the diagnosis of delirium was based on a version of the DSM that is no longer current and the diagnosing physician who was not blinded to the study (15).

The predisposing risk factors that were found more than once were atrial fibrillation, cognitive impairment, depression, history of stroke, older age, and peripheral vascular disease. Cognitive impairment, a history of stroke, older age and peripheral disease are risk factors that are not modifiable. Atrial fibrillation and depression are factors that can be modify in some way. In patients with preoperative atrial fibrillation, preventative measures could be taken with regard to anti arrhythmic and anticoagulant therapy (19). However, at present there is no data to support the premise that preoperative restoration to normal sinus rhythm has any affect on postoperative delirium. Furthermore, alleviation or elimination of depression has been described by Kazmierski et al. (20). In case of depressive symptoms or a major depression, consultation with a psychiatrist might be indicated to initiate appropriate therapy prior to cardiac surgery. Research on this topic is needed because at this moment there is no data to support the hypothesis that alleviation or elimination of depression has an effect on postoperative delirium. The precipitating risk factor that was mentioned more than once was a red blood cell transfusion. Avoiding perioperative blood transfusions and accepting lower levels of hemoglobin is controversial. An abnormal albumin level, pre- and postoperative, was reported as a relevant precipitating risk factor. According to the results of van der Mast et al., the albumin level and the postoperative physical condition must be improved after cardiac surgery for the probable prevention of delirium $(21,22)$. In elective cardiac surgery patients, with the preoperative help of a dietician and the preoperative implementation of physiotherapy, the postoperative nutritional and physical condition can be improved. 
Of the hemodynamic parameters, a low cardiac output and the use of an Intra Aortic Balloon Pump (IABP) or inotropic medication are relevant risk factors associated with postoperative delirium. There seems to be a correlation between delirium and the severity of cardiac failure in the postoperative period.

Delirium after cardiac surgery was a frequent problem in most of the studied populations, so it deserves attention. In the two largest studies (Bucerius and Norkiene) the delirium assessment method was not well-defined, since there was no use of a psychiatric interview or a validated assessment tool to diagnose delirium. Also, the retrospective design in these two studies is possibly not the best design in studies that measure the incidence of delirium. Therefore, it is very plausible that patients with a delirium were misclassified, so the incidence delirium in these two studies is underestimated. Although we studied cardiac surgery patients, delirium is also a very common phenomenon in hip fracture patients or patients in internal or geriatric medicine (23-25). If a delirium is more a result of general anesthesia than of the cardiac surgery itself, we might find less delirium in the future as more procedures are done percutaneously. Off-pump surgery does not seem to be a strong protecting variable of delirium at the moment. In practice it is difficult to alleviate or eliminate the risk factors or markers of delirium. Firstly, it is not always possible because the surgery cannot be delayed, and secondly, at present there is a paucity of data to support that elimination of these risk factors or markers has any effect on the incidence of postoperative delirium. On the other hand, in patients with a high risk of developing delirium it may not be possible to prevent delirium, but early recognition of postoperative delirium can be realized. Therefore the risk factors can be used to identify patients at an increased risk of developing postoperative delirium following cardiac surgery. This can be done by means of systematic observations of their behavior. This ensures that patients can be treated efficiently and the postoperative morbidity and mortality can thereby be reduced (26). To prevent delirium, it is difficult to influence the risk factors, but it is possible to change the environment and to anticipate on that. In a recent study it seems reasonable to implement patient-focused care, and to broaden this perspective to include reorientation, communication, and minimization of pharmacologic exposure $(7,27)$. Also trials emphasizing early 
mobilization suggest that this non pharmacologic approach is associated with an improvement in delirium incidence (28). Next, a pharmacologic sleep-wake cycle adjustment seems to reduce the incidence delirium (27).

The following predisposing risk factors are important from a practical viewpoint for identification and early recognition of delirium: cognitive impairment, depression, history of stroke, and older age. In patients with one or more of these risk factors prophylactic medication could be an option, however, this should be studied further. In a trial in hip surgery patients prophylactic Haloperidol was not effective in preventing delirium but did reduce its severity and duration (29).

\section{Weakness of the evidence base}

A number of critical considerations pertaining to our study can be made. Some risk factors such as "depression" or "cognitive impairment" were not well-defined. Another limitation is the fact that environmental risk factors were not retrieved but might be relevant. According to Inouye et al. supportive care concerning environmental risk factors include for example: creating a calm, comfortable environment with the use of orienting influences, such as calendars, clocks, and familiar objects from home. Next, nurses should encourage normal sleep-wake cycles by opening blinds and encouraging wakefulness and mobility during the daytime and allow the patient an uninterrupted period of sleep at night with low levels of noise and light (30). Also pain and pain management strategies are important factors related to the development of postoperative delirium. According to Vaurio et al. pain was independently associated with a greater risk for the development of postoperative delirium (31). According to Walzer et al., intubation duration and/or ICU stay should be minimized and sleep/sensory deprivation or hyper stimulation should be avoided (32). Next, there is a wide range in reported odds ratios for the observed risk factors. The most plausible reasons for the wide range in reported odds ratios are the differences in population characteristics and, for example, operation and medical care related factors. Also it can partly be based on chance, given the large confidence intervals around the point estimates for relatively small studies. Random misclassification will also lead to a dilution of the odds ratio in the direction of 1 . In papers where delirium has not been assessed 
with validated instruments, this might be a larger problem such as in the study by Bucerius that indeed has the lowest odds ratios (5).

Euroscore is mentioned more than once as a predisposing risk factor for delirium. Considering that the Euroscore itself contains relevant risk factors for mortality (older age, emergency surgery, etc.), a positive correlation between the Euroscore and postoperative delirium is not too farfetched. It might be more interesting, concerning prevention, to know the separate risk factors contributing to delirium and not the Euroscore containing several risk factors itself. On the other hand, the Euroscore is easy to measure and relevant in cardiac surgery patients.

From the studies it was not possible to determine whether any of the risk factors were true independent causal variables or only markers that reflected the general medical condition of the patient. The clinical pathway to delirium is at present unknown.

\section{Conclusions}

Despite having been analyzed for over 10 years, the knowledge base regarding the risk factors of delirium after cardiac surgery is still sparse. We have identified 27 risk factors; 12 predisposing and 15 precipitating factors of delirium after cardiac surgery. These can be used to develop a checklist of risk factors for delirium. Use of such a checklist may facilitate the ability to identify patients with a high risk of developing delirium and detect delirium at an early stage and thereby provide a suitable treatment when indicated; postoperative management might decrease the negative consequences caused by delirium following cardiac surgery $(33,34)$. Research evidence on effectiveness of interventions to prevent delirium is sparse. Further studies concerning delirium prevention are needed (35). Further studies should investigate whether improving modifiable risk factors actually leads to a decreased incidence of postoperative delirium. It also might be interesting to test some hypotheses, for example the link between cardiac output and cerebral perfusion in relation with delirium. This theory could be tested relatively straightforwardly in critical care areas with the technology available there. A recent study showed that a music intervention reduced anxiety and increased well-being in patients during coronary angiographic procedures (36). A music intervention 
might also have a positive effect on a postoperative delirium. This theory should be investigated in further studies.

\section{References}

(1) Yildizeli B,OzyurtkanMO, Batirel HF,Kuscu K, BekirogluN, YukselM. Factors associated with postoperative delirium after thoracic surgery. Ann Thorac SurG 2005;79:1004-9.

(2) van Blanken G, Robben PBM. Delirium vaak niet herkend. Med Contact 2005;60:1724-7.

(3) Koster S, Oosterveld FG, Hensens AG, Wijma A, van der Palen J. Delirium after cardiac surgery and predictive validity of a risk checklist. Ann Thorac Surg 2008;86:1883-7.

(4) Amador LF, Goodwin JS. Postoperative delirium in the older patient. J Am Coll Surg 2005;200:767-73.

(5) Bucerius J, Gummert JF, Borger MA, Walther T, Doll N, Falk V, et al. Predictors of delirium after cardiac surgery delirium: effect of beating-heart (off-pump) surgery. J Thorac Cardiovasc Surg 2004;127:57-64.

(6) Cole MG, McCusker J, Bellavance F, Primeau FJ, Bailey RF, Bonnycastle $\mathrm{MJ}$, et al. Systematic detection and multidisciplinary care of delirium in older medical inpatients: a randomized trial. CMAJ 2002;167:753-9.

(7) InouyeSK, Bogardus Jr ST, CharpentierPA, Leo-Summers L, Acampora D, Holford TR, et al. A multicomponent intervention to prevent delirium in hospitalized older patients. N Engl J Med 1999;340:669-76.

(8) Schuurmans MJ, Duursma SA, Shortridge-Baggett LM. Early recognition of delirium: review of the literature. J Clin Nurs 2001;10:721-9.

(9) Van Rompaey B, Schuurmans MJ, Shortridge-Baggett LM, Truijen S, Bossaert L. Risk factors for intensive care delirium: a systematic review. Intensive Crit Care Nurs 2008;24:98-107.

(10) Inouye SK, van Dyck CH, Alessi CA, Balkin S, Siegal AP, Horwitz RI. Clarifying confusion: the confusion assessment method. A new method for detection of delirium. Ann Intern Med 1990;113:941-8. 
(11) Neelon VJ, Champagne MT, Carlson JR, Funk SG. The NEECHAM Confusion Scale: construction, validation, and clinical testing. Nurs Res 1996;45:324-30.

(12) Schuurmans MJ, Shortridge-Baggett LM, Duursma SA. The Delirium Observation Screening Scale: a screening instrument for delirium. Res Theory Nurs Pract 2003;17:31-50.

(13) Chang YL, Tsai YF, Lin PJ, Chen MC, Liu CY. Prevalence and risk factors for postoperative delirium in a cardiovascular intensive care unit. Am J Crit Care 2008;17:567-75.

(14) Norkiene I, Ringaitiene D, Misiuriene I, Samalavicius R, Bubulis R, Baublys $\mathrm{A}$, et al. Incidence and precipitating factors of delirium after coronary artery bypass grafting. Scand Cardiovasc J 2007;41:180-5.

(15) Rolfson DB, McElhaney JE, Rockwood K, Finnegan BA, Entwistle LM, Wong $\mathrm{JF}$, et al. Incidence and risk factors for delirium and other adverse outcomes in older adults after coronary artery bypass graft surgery. Can J Cardiol 1999;15:771-6.

(16) Milisen K, Foreman MD, Abraham IL, De GS, Godderis J, Vandermeulen E, et al. A nurse-led interdisciplinary intervention program for delirium in elderly hip-fracture patients. J Am Geriatr Soc 2001;49:523-32.

(17) Ely EW, Margolin R, Francis J, May L, Truman B, Dittus R, et al. Evaluation of delirium in critically ill patients: validation of the Confusion Assessment Method for the Intensive Care Unit (CAM-ICU). Crit Care Med 2001;29:1370-9.

(18) American Psychiatric Association. Diagnostic and statistical manual of mental disorders 4th ed. Washington D.C.: American Psychiatric Association; 1994.

(19) BanachM,Kazmierski J,KowmanM,Okonski PK, SobowT,Kloszewska I, et al. Atrial fibrillation as a non psychiatric predictor of delirium after cardiac surgery: a pilot study. Med Sci Monit 2008;14:286-91.

(20) Kazmierski J, Kowman M, Banach M, Pawelczyk T, Okonski P, Iwaszkiewicz A, et al. Preoperative predictors of delirium after cardiac surgery: a preliminary study. Gen Hosp Psychiatry 2006;28:536-8. 
(21) van der Mast RC, van den Broek WW, Fekkes D, Pepplinkhuizen L, Habbema JD. Incidence of and preoperative predictors for delirium after cardiac surgery. J Psychosom Res 1999;46:479-83.

(22) van der Mast RC, van den Broek WW, Fekkes D, Pepplinkhuizen L, Habbema JD. Is delirium after cardiac surgery related to plasma amino acids and physical condition? J Neuropsychiatry Clin Neurosci 2000;12:57-63.

(23) Kalisvaart CJ, Vreeswijk R, de Jonge JF, Milisen K. A systematic review of multifactorial interventions for primary prevention of delirium in the elderly. Tijdschr Gerontol Geriatr 2005;36:224-31.

(24) Schuurmans MJ. Early recognition of delirium. Utrecht: University Medical Center Utrecht, 2001 (Thesis).

(25) Schuurmans MJ, Duursma SA, Shortridge-Baggett LM, Clevers GJ, Pel-Littel R. Elderly hip fracture patients: the risk for delirium. Appl Nurs Res 2003;16:75-84.

(26) Koolhoven I, Tjon ATM, van der Mast RC. Early diagnosis of delirium after cardiac surgery. Gen Hosp Psychiatry 1996;18:448-51.

(27) Skrobik Y. Delirium prevention and treatment. Crit Care Clin 2009;25: 58591.

(28) Marcantonio ER, Flacker JM, Wright RJ, Resnick NM. Reducing delirium after hip fracture: a randomized trial. J Am Geriatr Soc 2001;49:516-22.

(29) Kalisvaart KJ, de Jonge JF, Bogaards MJ, Vreeswijk R, Egberts TC, Burger BJ, et al. Haloperidol prophylaxis for elderly hip-surgery patients at risk for delirium: a randomized placebo-controlled study. J Am Geriatr Soc 2005;53:1658-66.

(30) Inouye SK. Delirium in older persons. N Engl J Med 2006;354: 1157-65.

(31) Vaurio LE, Sands LP, Wang Y, Mullen EA, Leung JM. Postoperative delirium: the importance of pain and pain management. Anesth Analg 2006;102:1267-73.

(32) Walzer T, Herrmann M, Wallesch CW. Neuropsychological disorders after coronary bypass surgery. J Neurol Neurosurg Psychiatry 1997;62: 644-8. 
(33) Rudolph JL, Jones RN, Levkoff SE, Rockett C, Inouye SK, Sellke FW, et al. Derivation and validation of a preoperative prediction rule for delirium after cardiac surgery. Circulation 2009;119:229-36.

(34) Sockalingam S, Parekh N, Bogoch II, Sun J, Mahtani R, Beach C, et al. Delirium in the postoperative cardiac patient: a review. J Card Surg 2005;20:560-7.

(35) Siddiqi N, Stockdale R, Britton AM, Holmes J. Interventions for preventing delirium in hospitalised patients. Cochrane Database Syst Rev 2007:55-63.

(36) Weeks BP, Nilsson U. Music interventions in patients during coronary angiographic procedures: a randomized controlled study of the effect on patients' anxiety and well-being. Eur J Cardiovasc Nurs (Electronic publication ahead of print, 2010 Aug 2). 


\section{Chapter 4}

Delirium after cardiac surgery and predictive validity of a risk checklist

Sandra Koster

Frits G.J. Oosterveld

Ab G. Hensens

Arie Wijma

Job van der Palen

Ann Thorac Surg. 2008 Dec;86(6):1883-7 


\begin{abstract}
Background. Delirium or acute confusion is a temporary mental disorder that occurs frequently among hospitalized elderly patients. Patients who undergo cardiac surgery have an increased risk of delirium, which is associated with many negative consequences. Therefore, prevention or early recognition of delirium is essential.
\end{abstract}

Methods. In this observational study, a risk checklist for delirium was used during the preoperative outpatient screening in 112 patients who underwent elective cardiac surgery. The Delirium Observation Screening (DOS) scale was used before and after cardiac surgery to assess whether delirium had developed in patients. The psychiatrist was consulted to confirm or refute the diagnosis delirium. Results. The incidence of delirium after cardiac surgery was $21 \%$, and the mean duration of delirium was 2.5 days. The time to discharge was 11 days longer in patients with delirium. The delirium risk checklist could accurately predict postoperative delirium in patients who underwent elective cardiac surgery based on a disturbance in the electrolytes sodium and potassium and on EuroSCORE (European System for Cardiac Operative Risk Evaluation). When using a probability of delirium of $50 \%$, the sensitivity of the risk checklist was $25.0 \%$ and specificity was $95.5 \%$. The predictive value of a positive test was $60.0 \%$, and the predictive value of a negative test was $82.4 \%$. The area under the receiveroperating characteristic curve was 0.75 .

Conclusions. With the risk checklist for delirium, patients at an increased risk of delirium after elective cardiac surgery can be identified. 


\section{Introduction}

Delirium is a common temporary mental disorder among hospitalized elderly patients (1). In the literature, the incidence and prevalence of delirium vary widely between different study populations. Patients who undergo cardiac surgery have an increased risk of delirium. The incidence of delirium was $13.5 \%$ after elective cardiac surgery and increased to $20.0 \%$ among patients aged 60 years and older (2). Generally, an incidence of $25 \%$ is assumed among hospitalized elderly patients (1). As a result of demographic aging, the incidence of delirium is likely to increase in the foreseeable future. Early recognition or prevention of delirium is important, because delirium has been related to a prolonged hospital stay, nursing home placement, and reduced cognitive and functional recovery (3-7).

With the Delirium Observation Screening (DOS) scale by Schuurmans and associates (10), delirium can be recognized at an early stage. The likelihood of delirium increases proportionally with the number of existing risk factors. Some of the greatest predisposing risk factors for delirium are the presence of cognitive impairment, sleep deprivation, immobility, visual and hearing impairment, and dehydration (6). If the patient has an increased risk for delirium, preventative interventions can be considered (8).

At this time, there is no model available that is able to predict postoperative delirium. We have developed a delirium risk checklist to identify patients with an increased risk of postoperative delirium after elective cardiac surgery. This study will examine the predictive validity of this risk checklist for delirium. If this is successful, in the future, preventive interventions can be taken for patients at high risk for postoperative delirium, such as providing adequate preoperative information or Haloperidol prophylaxis (9).

\section{Patients and Methods}

Between November 2006 and June 2007, our prospective cohort study included 112 consecutive patients, aged 45 years and older, who underwent elective cardiac surgery with and without cardiopulmonary bypass assistance at the Department of Cardiothoracic Surgery. Excluded were patients who did not 
undergo preoperative outpatient screening and patients with preoperative delirium. Informed consent was obtained in accordance with the hospital's policy.

\section{Procedure}

The delirium risk checklist was completed during the preoperative outpatient screening 2 to 6 weeks before the surgery, and it measured all data concerning the potential predictors of delirium and study outcomes. Patients were followed from the time of admission until the time of discharge from the hospital.

The DOS scale was rated by nurses three times a day at the end of every shift, before and after surgery, to assess whether patients had delirium. The DOS scale describes typical behavioral patterns related to delirium in 13 statements or questions, which the observer has to answer with "never" (score $=0)$ or "sometimes or always" (score $=1$ ) if applicable (Table 1 ).

Table 1. The working method of the DOS scale

\begin{tabular}{l} 
The patient: \\
\hline 1. Dozes during conversation or activities \\
2. Is easy distracted by stimuli from the environment \\
3. Loses attention to conversation or action \\
4. Does not finish question or answer \\
5. Gives answers which do not fit the question \\
6. Reacts slowly to instructions \\
7. Thinks to be somewhere else \\
8. Does not know which part of the day it is \\
9. Does not remember recent event \\
10. Is picking, disorderly, restless \\
11. Pulls intravenous tubes, feeding tubes, catheters etc. \\
12. Is easy or sudden emotional (frightened, angry, irritated) \\
13. Sees persons/things as somebody/something else
\end{tabular}

Never $=0$ points; Sometimes or always $=1$ point. A total score of 3 or more points indicates delirium.

A DOS score of 3 or more indicates delirium (10). When the DOS score was 2 or more, the psychiatrist was consulted to confirm or refute the diagnosis delirium. The psychiatrist was not consulted when the DOS score was 1 or less, as the 
probability of delirium was unlikely (7). The diagnostic criteria of the psychiatrist to confirm or refute the diagnosis delirium were based on the Diagnostic and Statistical Manual of Mental Disorders, Fourth Revision (DSM-IV) criteria for delirium (11) and the nursing documentation. The DSM-IV criteria were based on specific diagnostic criteria to differentiate delirium from other syndromes such as anxiety, depression, and dementia. Table 2 shows the DSM-IV criteria for the diagnosis of delirium.

Data were collected during the day of admission until the fifth postoperative day. If the patient did not have delirium by then, the DOS scale was not rated anymore. If the patient had delirium during the first five postoperative days, the DOS scale was rated until the patient was delirium free for two consecutive days.

The Ethics Committee of Medisch Spectrum Twente was asked whether approval was needed. Because this study was observational only, without invasive procedures, it was not deemed necessary.

Table 2. Diagnostic criteria of Diagnostic and Statistical Manual of Mental Disorders-IV for the diagnosis of delirium

\footnotetext{
A Disturbance of consciousness with reduced ability to focus, sustain, or shift attention

B Changed cognition or the development of a perceptual disturbance

C Disturbance develops in a short period of time and fluctuates over the course of the day

D Evidence from history, physical examination, or laboratory findings that the disturbance is

1. Physiological consequence of general condition

2. Caused by intoxication

3. Caused by medication

4. Caused by more than one etiology
}

\section{Measures}

Predisposing factors for delirium are older age ( $\geq 70$ years), cognitive impairment, history of delirium, dementia, depression, visual and hearing impairment, functional impairment, preoperative use of alcohol or opiates, preoperative anxiety, smoking, poor nutritional status, severe comorbidity, markedly abnormal renal function, history of cerebrovascular disease, peripheral vascular disease, atrial fibrillation, diabetes mellitus, left ventricular function of $30 \%$ or less, preoperative cardiogenic 
shock, urgent operation, intraoperative hemofiltration, operation time of three hours or more, a high perioperative transfusion requirement, and disturbed sodium, potassium, or glucose levels $(2,4,7,8,12)$. Beating-heart surgery, compared to cardiac surgery with cardiopulmonary bypass, was identified as having a significant protective effect against postoperative delirium (4).

In the studies mentioned above, the EuroSCORE (European System for Cardiac Operative Risk Evaluation (range, $0 \%$ to $100 \%$ )) has not been reported as a risk factor for delirium (13). However, because the EuroSCORE is a combination of many of the risk factors described, it has been incorporated as a separate risk factor in the delirium risk checklist. In total, 25 risk factors were selected (Table 3). Validated instruments were used to assess functional impairment (Barthel Index $(14,15)$ ); nutritional status (Short Nutritional Assessment Questionnaire (SNAQ) (16)); cognitive function (Standardized Mini-Mental State Examination (SMMSE) (17)); and hearing and vision (hearing test (18) and visual test (19)).

The DOS scale is a reliable and valid instrument to recognize delirium based on nurses' observations during regular care (20). The predictive validity of the DOS scale in comparison to the DSM-IV criteria of a geriatrician or psychiatrist was good, with a sensitivity of $94.4 \%$ and specificity of $76.6 \%$ (10). In 2007, van Gemert and Schuurmans (21) found a sensitivity of $89 \%$ and a specificity of $86 \%$ for the DOS scale, at four wards of a university hospital.

\section{Statistical Analysis}

The univariate association between each candidate predictor and postoperative delirium was estimated. The independent two-tailed $t$ test was used to compare the means of variables in case of continuous normally distributed data. When data were not distributed normally, Wilcoxon's rank-sum test was utilized. The following risk factors were analyzed as continuous variables: age, EuroSCORE, and operation time. The $\mathrm{x}^{2}$ test was used for the comparison of categorical variables (Table 3). The following cut-off values were used to classify high-risk patients: cognitive impairment, SMMSE less than 23; physical impairment, Barthel index less than 14; visual impairment, Landolt $C$ circles less than 0.5 ; hearing 
Table 3. Distribution and univariate analysis of all candidate predictors

\begin{tabular}{|c|c|c|c|c|c|}
\hline & $\begin{array}{c}\text { Total } \\
\mathrm{N}=112\end{array}$ & $\begin{array}{l}\text { No delirium } \\
\qquad N=88\end{array}$ & $\begin{array}{c}\text { Delirium } \\
\mathrm{N}=24\end{array}$ & $\begin{array}{c}\text { Relative } \\
\text { Risk }\end{array}$ & $p$ Value \\
\hline \multicolumn{6}{|l|}{ Patient Characteristics } \\
\hline \multicolumn{6}{|l|}{ Sex } \\
\hline Male & 71 & 58 & 13 & 0.68 & 0.29 \\
\hline Female & 41 & 30 & 11 & & \\
\hline Age, years & 70 & $69.2(7.0)$ & $73.9(7.6)$ & - & $<0.001$ \\
\hline$\geq 70$ & 65 & 46 & 19 & 2.75 & 0.01 \\
\hline$<70$ & 47 & 42 & 5 & & \\
\hline \multicolumn{6}{|l|}{ Type of operation } \\
\hline CABG & 42 & 38 & 4 & - & 0.04 \\
\hline Valve & 41 & 30 & 11 & - & \\
\hline CABG + valve & 15 & 9 & 6 & - & \\
\hline Other & 14 & 11 & 3 & - & \\
\hline Cognitive impairment & 26 & 18 & 8 & 1.79 & 0.18 \\
\hline Delirium in history & 10 & 6 & 4 & 2.04 & 0.21 \\
\hline Physical impairment & 0 & 0 & 0 & - & - \\
\hline Comorbidity & 21 & 14 & 7 & 1.78 & 0.15 \\
\hline Alcohol use & 8 & 8 & 0 & - & 0.19 \\
\hline Visual/ hearing impairment & 66 & 50 & 16 & 1.39 & 0.38 \\
\hline Opiates use & 2 & 2 & 0 & - & 1.00 \\
\hline Cigarette use & 17 & 14 & 3 & 0.80 & 1.00 \\
\hline Poor nutritional status & 10 & 8 & 2 & 0.93 & 1.00 \\
\hline Anxiety score $\geq 6$ & 50 & 36 & 14 & 1.74 & 0.10 \\
\hline Disturbed sodium/ potassium & 29 & 19 & 10 & 2.04 & 0.04 \\
\hline Elevated creatinine & 28 & 19 & 9 & 1.80 & 0.11 \\
\hline Peripheral vascular disease & 23 & 20 & 3 & 0.55 & 0.39 \\
\hline Diabetes mellitus & 22 & 22 & 0 & - & $<0.001$ \\
\hline Preoperative atrial fibrillation & 20 & 15 & 5 & 1.20 & 0.76 \\
\hline Depression & 2 & 1 & 1 & 2.39 & 0.38 \\
\hline Cerebrovascular accident & 9 & 6 & 3 & 1.63 & 0.40 \\
\hline Moderate LV function & 22 & 15 & 7 & 1.68 & 0.24 \\
\hline Poor LV function & 11 & 9 & 2 & 0.83 & 1.00 \\
\hline Use heart-lung machine & 90 & 67 & 23 & 5.62 & 0.04 \\
\hline EuroSCORE, mean (SD) & & $5.7 \%(5.5)$ & $11.8 \%(10.3)$ & - & $<0.001$ \\
\hline Operation time, minutes (SD) & & $237(99)$ & $263(180)$ & - & 0.35 \\
\hline
\end{tabular}

CABG = coronary artery bypass graft surgery; EuroSCORE = European System for Cardiac Operative Risk Evaluation; $L V=$ left ventricular. 
impairment, mean frequency threshold at $500,1,000$, and $2,000 \mathrm{~Hz}$ greater than 25 $\mathrm{dB}$; poor nutritional status, SNAQ of 2 or more; anxiety score of 6 or more; sodium less than 135 or greater than $145 \mathrm{mmol} / /$; potassium less than 3.5 or greater than $5.0 \mathrm{mmol} / \mathrm{l}$; creatinine, male, greater than $110 \mathrm{micro} \mathrm{mol} / \mathrm{l}$, and creatinine, female greater than $90 \mathrm{micro} \mathrm{mol} / \mathrm{l}$; moderate left ventricular function, $30 \%$ to $50 \%$; and poor left ventricular function, less than $30 \%$. Hereafter, the factors independently associated with postoperative delirium $(p \leq 0.10)$ were all entered in a logistic regression analysis. Subsequently, this model was reduced to remove non significant factors $(p>0.05)$ one by one.

The model's ability to discriminate between patients with and without postoperative delirium was estimated by the area under the receiver-operating characteristic (ROC) curve.

\section{Results}

\section{Study Population}

One hundred and 14 patients were invited to participate in the study, and of those, two refused for personal reasons. The majority of patients were male (63.4\%). The mean age of the total study population was 70 years (SD 7.3; Table 3). There was a significant difference in age in patients with and without delirium. Sixty-five patients $(58.0 \%)$ were older than 70 years. The most commonly performed cardiac operations were coronary artery bypass grafting (37.5\%) and heart valve surgery (36.6\%).

\section{Incidence and Duration of Delirium and Stay in Hospital}

The psychiatrist diagnosed postoperative delirium in 24 patients (21\%). Of these 24 patients, 13 were male with a mean age of 74 years. Almost $30 \%$ of these patients had delirium the first day after cardiac surgery. The mean duration of delirium was 2.5 days (SD 2.1). In the event of delirium, the duration of hospital stay was significantly higher $(p<0.01)$. For patients with postoperative delirium, the mean hospital stay was 22 days (SD 21.0) versus 11 days (SD 5.9) for patients without postoperative delirium. Four patients $(3.6 \%)$, of whom two had postoperative delirium, died during the postoperative stage. 


\section{Validity Risk Checklist for Delirium}

In the univariate analysis, type of operation, EuroSCORE, age, use of heart-lung machine, electrolyte disturbance, anxiety, and diabetes mellitus were associated ( $p$ $\leq 0.10$ ) with a higher risk of postoperative delirium after cardiac surgery (Table 3 ). The overall multivariable model containing all predictors yielded an area under the ROC curve of 0.85 (95\% confidence interval $(\mathrm{Cl})$ : $0.78-0.93 ; p<0.001)$.

Only two predictors were independently associated with postoperative delirium: disturbance in electrolytes and EuroSCORE (Table 4). There was a disturbance in electrolytes when the sodium or the potassium was disturbed. When the EuroSCORE increased by $1 \%$, the risk of having postoperative delirium was 1.5 fold higher.

The sensitivity of this short risk checklist, when using a probability of developing delirium of $50 \%$, amounted to $25.0 \%$ and the specificity was $95.5 \%$. The predictive value of a positive test was $60.0 \%$ and the predictive value of a negative test was $82.4 \%$. An area under the curve of 0.75 was found $(95 \% \mathrm{Cl}: 0.66$ to $0.85 ; p<$ 0.001). To estimate the probability of developing delirium for an individual patient, the prediction formula in Table 4 can be used (22).

Table 4. Predictors from multivariate analysis that independently contributed to the prediction of postoperative delirium after cardiac surgery $(N=112)$

\begin{tabular}{|c|c|c|c|c|c|}
\hline & \multirow[b]{2}{*}{ B } & \multirow[b]{2}{*}{ Odds Ratio } & \multicolumn{2}{|c|}{$95 \% \mathrm{Cl}$} & \multirow[b]{2}{*}{$p$ Value } \\
\hline & & & Low & High & \\
\hline EuroSCORE & 0.11 & 1.12 & 1.05 & 1.19 & 0.001 \\
\hline Electrolytes disturbance & 1.19 & 3.29 & 1.16 & 9.34 & 0.025 \\
\hline
\end{tabular}

Prediction formula: $1 /\left(1+\mathrm{e}^{-\left(-2.59+0.11^{\star} \text { EuroSCORE }+1.19^{\star} \text { disturbed electrolytes }\right)}\right)$

\section{Comment}

Two independent predictors of postoperative delirium after cardiac surgery were found: electrolyte disturbances and EuroSCORE. According to the delirium 
guideline (2), a disturbance in electrolytes (serum concentration of sodium and potassium) is a very plausible precipitating factor for postoperative delirium. In a recently published study, a EuroSCORE of 5 or more was associated with postoperative delirium (23). Considering that the EuroSCORE itself contains relevant risk factors for mortality (age, cognitive impairment, and so forth), a positive correlation between the EuroSCORE and postoperative delirium is not too farfetched. That also explains why other predisposing factors for developing delirium such as age 70 years or more, cognitive impairment, and so forth, no longer appear as independent predictors in the final model. Finally, preoperative anxiety, a common problem among patients undergoing cardiac surgery, is a factor that can influence the development of postoperative delirium $(2,3,24)$. However, it was not mentioned as a risk factor in the delirium guideline. Also, it failed to reach significance in our study, possibly because of a too-small sample size. The incidence of delirium after cardiac surgery was $21 \%$. This corresponds well with the incidence of $25 \%$ reported by the Inspection of Healthcare according to van Blanken and Robben (1) and the study by van der Mast and coworkers (2), who found a postoperative delirium incidence of $20 \%$ among patients aged 60 years and older. The duration of postoperative delirium was 2.5 days, whereas previous studies, and also the delirium guideline (2), have reported delirium duration from several days to a couple of weeks. This discrepancy is possibly due to the use of the DOS scale, which may allow for not only earlier delirium recognition but also earlier resolution of delirium. Furthermore, before the start of the study, nurses were informed about delirium, including risk factors, prevention, and interventions. This informed approach may also have contributed to earlier recognition of delirium and hence to appropriate interventions such as orienting the patient as necessary, correcting fluid balance, providing quiet surroundings, and so forth. In previous studies, it was found that the education of nurses and the initiation of nursing interventions had a positive effect on early delirium recognition (24). Finally, patients with postoperative delirium had a significantly longer hospital stay, which was also observed in earlier studies (3-7).

If a patient has delirium, mobility decreases, so the revalidation period goes up and the stay in hospital increases. If we exempt the patients who had a much longer 
stay in hospital, however, the number of patients we kept is too low for doing statistical analysis.

A number of critical considerations pertaining to our study can be made. We have included a relatively small number of patients. That might result in less stable estimates of the independent associations of the predictors in the final model, as well as the model's discriminative ability. However, with 112 patients, a multivariate analysis with seven variables is very well possible. A second consideration can be made about the fact that we have derived our model from the same set of data that was used for our test set. A model works always better on the test set than on a separate validation set. In further research, we will test the model on a complete separate second data set.

When patients had postoperative delirium, the psychiatrist prescribed Haloperidol, and the nurses created a safe environment and supported the patient mentally and physically (put on their eyeglasses or hearing aid) so patients could orient themselves. We did not review the use of certain drugs after cardiac surgery that could either increase or decrease the incidence of delirium.

The two identified predictors (electrolyte disturbance and EuroSCORE) are relatively easy to measure and can be used to identify patients at greater risk for postoperative delirium after cardiac surgery. In these patients, preventative interventions can be taken, such as providing adequate preoperative information or Haloperidol prophylaxis. Maybe we can raise the prophylactic dose of Haloperidol, as discussed in the study by Kalisvaart and colleagues (9), to $5 \mathrm{mg} /$ day so we can examine if it is possible to prevent delirium. Early recognition of postoperative delirium can be realized by using the Delirium Observation Screening scale.

\section{References}

(1) van Blanken G, Robben PBM. Delirium often not recognized. Medisch Contact 2005;60:1724-7.

(2) van der Mast RC, Huyse FJ, Rosier PF. Guideline delirium. Ned Tijdschr Geneeskd 2005;149:1027-32.

(3) Amador LF, Goodwin JS. Postoperative delirium in the older patient. J Am 
Coll Surg 2005;200:767-73.

(4) Bucerius J, Gummert JF, Borger MA, et al. Predictors of delirium after cardiac surgery delirium: effect of beatingheart (off-pump) surgery. $\mathrm{J}$ Thorac Cardiovasc Surg 2004;127: 57-64.

(5) Cole MG, McCusker J, Bellavance F, et al. Systematic detection and multidisciplinary care of delirium in older medical inpatients: a randomized trial. Can Med Assoc. J 2002;167: 753-9.

(6) Inouye SK, Bogardus ST, Charpentier PA, et al. A multicomponent intervention to prevent delirium in hospitalized older patients. N Engl J Med 1999;340:669 -76.

(7) Schuurmans MJ, Duursma SA, Shortridge-Baggett LM. Early recognition of delirium: review of the literature. J Clin Nurs 2001;10:721-9.

(8) Yildizeli B, Ozyurtkan MO, Batirel HF, Kuscu K, Bekiroglu N, Yuksel M. Factors associated with postoperative delirium after thoracic surgery. Ann Thorac Surg 2005;79:1004 -9.

(9) Kalisvaart KJ, de Jonge JF, Bogaards MJ, et al. Haloperidol prophylaxis for elderly hip-surgery patients at risk for delirium: a randomized placebocontrolled study. J Am Geriatr Soc 2005;53:1658-66.

(10) Schuurmans MJ, Shortridge-Baggett LM, Duursma SA. The delirium observation screening scale: a screening instrument for delirium. Res Theory Nurs Pract 2003;17:31-50.

(11) American Psychiatric Association. Diagnostic and statistical manual of mental disorders. 4th ed. Washington, DC: American Psychiatric Association, 1994.

(12) Dubois MJ, Bergeron N, Dumont M, Dial S, Skrobik Y. Delirium in an intensive care unit: a study of risk factors. Intens Care Med 2001;27:1297304.

(13) Roques F, Nashef SA, Michel P, et al. Risk factors and outcome in European cardiac surgery: analysis of the EuroSCORE multinational database of 19030 patients. Eur J Cardiothorac Surg 1999;15:816-22. 
(14) Haan R, Limburg M, Schuling J, Broeshart J, Jonkers L, van Zuylen P. Clinimetric evaluation of the Barthel index, a measure of limitations in daily activities. Ned Tijdschr Geneeskd 1993;137:917-21.

(15) Mahoney FI, Barthel DW. Functional evaluation: the Barthel index. Md State Med J 1965;14:61-5.

(16) Kruizenga HM, Seidell JC, de Vet HC, Wierdsma NJ, Van Bokhorst-de van der Schueren MA. Development and validation of a hospital screening tool for malnutrition: the Short Nutritional Assessment Questionnaire (SNAQ). Clin Nutr 2005;24:75- 82.

(17) Molloy DW, Alemayehu E, Roberts R. Reliability of a standardized MiniMental State Examination compared with the traditional Mini-Mental State Examination. Am J Psychiatry 1991;148:102-5.

(18) Katz J. Handbook of clinical audiology. Baltimore: Williams \& Wilkins, 1985.

(19) Bredewoud RA. Medical requirements regarding the ability to drive. Dutch institution governing licensing of drivers (CBR). Guidelines for driving ability. 2000, 2004.

(20) Timmers J, Kalisvaart K, Schuurmans M, de Jonge J. A review of delirium rating scales. Tijdschr Gerontol Geriatr 2004;35:5-14.

(21) van Gemert LA, Schuurmans MJ. The Neecham confusion scale and the delirium observation screening scale: capacity to discriminate and ease of use in clinical practice. BMC Nurs 2007;6:3.

(22) Szklo M, Nieto FJ. Epidemiology beyond the basics. Sudbury, UK: Jones and Bartlett, 2008:303- 4.

(23) Norkiene I, Ringaitiene D, Misiuriene I, et al. Incidence and precipitating factors of delirium after coronary artery bypass grafting. Scand Cardiovasc J 2007;41:180 -5.

(24) Lundstrom M, Edlund A, Karlsson S, Brannstrom B, Bucht G, Gustafson Y. A multifactorial intervention program reduces the duration of delirium, length of hospitalization, and mortality in delirious patients. J Am Geriatr Soc 2005;53: 622-8. 


\title{
Chapter 5
}

\section{Prediction of delirium after cardiac surgery with a risk checklist}

\author{
Sandra Koster \\ Ab G. Hensens \\ Marieke J. Schuurmans \\ Job van der Palen
}

Submitted 


\begin{abstract}
Background. Delirium is a temporary mental disorder, which occurs frequently among patients who undergo cardiac surgery. Prediction and with that connected prevention of delirium, is essential. In a previous study a prediction model was developed. Objective. The present study validated the model in a new, larger study population, and also investigated new predictors. Methods. The delirium risk checklist was used during the preoperative outpatient screening in 300 patients who underwent elective cardiac surgery. The Delirium Observation Screening scale was used pre- and post operatively to assess delirium. Results. The incidence delirium was $17.3 \%$. Compared to the previously prediction model, the Euroscore was confirmed as a predictor of postoperative delirium, but a disturbance in electrolytes was not. When using a predicted probability of delirium of $20 \%$, the original model had a sensitivity of $40.4 \%$ with a specificity of $82.7 \%$. The Area Under the Receiver Operating Curve of the original model was 0.71 . Based on this new study a new prediction model was constructed with the following risk factors: Euroscore, older age ( $\geq 70$ years), cognitive impairment, the number of comorbidities, history of delirium, alcohol use, and type of surgery. When using a probability of delirium of $20 \%$, as predicted by the model, the sensitivity was $80.8 \%$, the specificity $82.2 \%$. The Area Under the Curve was 0.89 . Conclusions. Patients with a higher Euroscore, have an increased risk of developing delirium following elective cardiac surgery. Next, with the added predictors patients with an increased risk of developing delirium can be identified much more accurately.
\end{abstract}




\section{Introduction}

Delirium is a common temporary mental disorder among hospitalized elderly patients (1). According to the American Psychiatric Association's Diagnostic and Statistical Manual of Mental Disorders (DSM-IV), delirium is defined as "a disturbance of consciousness with reduced ability to focus, sustain, or shift attention; a change in cognition; or the development of a perceptual disturbance that occurs over a short period of time and tends to fluctuate over the course of the day" (2). In the literature, the incidence and prevalence of delirium vary widely between different studies. The wide range in reported incidences could be explained by the different study designs, a difference in the method of assessing delirium and the differences in the study population. Given the demographic changes the incidence of delirium will increase in the foreseeable future.

Patients who undergo cardiac surgery have an increased risk of developing delirium.

In an earlier study in the same department, the incidence of delirium following cardiac surgery was found to be $21 \%$ (3).

The likelihood of developing delirium increases proportionally with the number of existing risk factors. Some of the most important general predisposing risk factors for developing delirium are the presence of cognitive impairment, sleep deprivation, immobility, visual and hearing impairment, and dehydration (4). Also, anesthesia and analgesic are mentioned as probable risk factors of delirium. In a recent study the choice of intraoperative analgesic is a risk factor for postoperative delirium, and the authors state that modification provides a promising approach to reduce the incidence of postoperative delirium (5). In another study there was no effect of the anesthesia type on developing postoperative delirium. However, general anesthesia was marginally non significantly associated with postoperative cognitive decline (6).

In an earlier study of cardiac surgery patients, the Euroscore, a method of calculating predicted operative mortality for patients undergoing cardiac surgery, and a disturbance in electrolytes could help predict a postoperative delirium in patients who underwent elective cardiac surgery (3). 
Early recognition or prevention of delirium is important, because in general delirium has been related to a prolonged hospital stay, nursing home placement and reduced cognitive and functional recovery $(4 ; 7 ; 8)$. In patients who undergo cardiac surgery, a delirium is associated with more postoperative complications (7). After 11.5 years after cardiac surgery a postoperative delirium seems to be associated with increased mortality and re-admissions to the hospital, as well as poorer cognitive and functional outcomes (9).

With the Delirium Observation Screening (DOS) scale by Schuurmans et al. a delirium can be recognized at an early stage. In several studies the DOS scale was tested in hip fracture patients and patients admitted to the Department of geriatric medicine. In these studies the DOS scale showed high internal consistency (0.93$0.96)(10-13)$. The predictive validity against the diagnosis of delirium made by a geriatrician was also good in the above mentioned studies. The sensitivity of the DOS scale was $89-100 \%$ with a specificity of $68-88 \%(10-12)$. In a recent study in cardiac surgery patients, the sensitivity and specificity of the DOS scale was $100 \%$ and $96.6 \%$ respectively. The Area Under the Receiver Operating Curve (AUC) was 0.98 , so the DOS scale is a very good instrument to facilitate early recognition of delirium by nurses' observation of patients who undergo cardiac surgery (14). If a patient has an increased risk of developing delirium, preventative interventions can be considered (15). At this time, there is no definitive model available that is able to predict postoperative delirium. In an earlier study we developed a first delirium risk checklist to identify patients with an increased risk of postoperative delirium following elective cardiac surgery and examined the predictive validity of this risk checklist. The present study will validate the model in a new, larger study population, and will investigate new predictors as well.

\section{Materials and Methods}

\section{Patients}

Between October 2008 and January 2010300 consecutive patients, of 45 years or older, who underwent elective cardiac surgery with and without cardiopulmonary bypass (CPB) assistance were included at the Department of Cardiothoracic Surgery. Excluded were patients that did not undergo preoperative outpatient 
screening and patients with a preoperative delirium. Informed consent was obtained in accordance with the hospital's policy. The Ethics Committee of Medisch Spectrum Twente was asked whether approval was needed. Because this is an observational study, without invasive procedures, approval was not deemed necessary.

\section{Procedure}

The delirium risk checklist that was used in the present study, was also used in the earlier study (3) but contained new predictors as well. The checklist was completed during the preoperative outpatient screening one day to maximum six weeks prior to the surgery. Patients were followed from the time of admission until the time of discharge from the hospital. The diagnosis of delirium was based on the DOS scale; nurses rated their observation three times a day at the end of every shift, pre- and post operatively. If the patient had not developed a delirium by day four, the DOS scale was not rated anymore. This was done because in our earlier study most of the patients (33\%) developed a delirium on the first postoperative day and only $3 \%$ on day four or five (3).

\section{Measures}

Predisposing factors, described in the literature as suspected risk factors for delirium, are older age ( $\geq 70$ years), cognitive impairment, history of delirium, dementia, depression, visual and hearing impairment, functional impairment, preoperative use of alcohol or opiates, preoperative anxiety, smoking, poor nutritional status, severe co-morbidity, markedly abnormal renal function, history of cerebrovascular disease, peripheral vascular disease, atrial fibrillation, diabetes mellitus, left ventricular function of $30 \%$ or less, Euroscore, preoperative cardiogenic shock, urgent operation, intraoperative hemofiltration, operation time of three hours or more, a high perioperative transfusion requirement, and disturbed sodium, potassium and/or glucose levels (3;7;8;15-17). Beating heart surgery, compared to cardiac surgery with cardiopulmonary bypass (CPB), was identified as having a significant protective effect against postoperative delirium (7). In total 27 risk factors were selected (Table 1). 
Table 1. Distribution and univariate analysis of all candidate predictors in the overall population and among patients with and without delirium

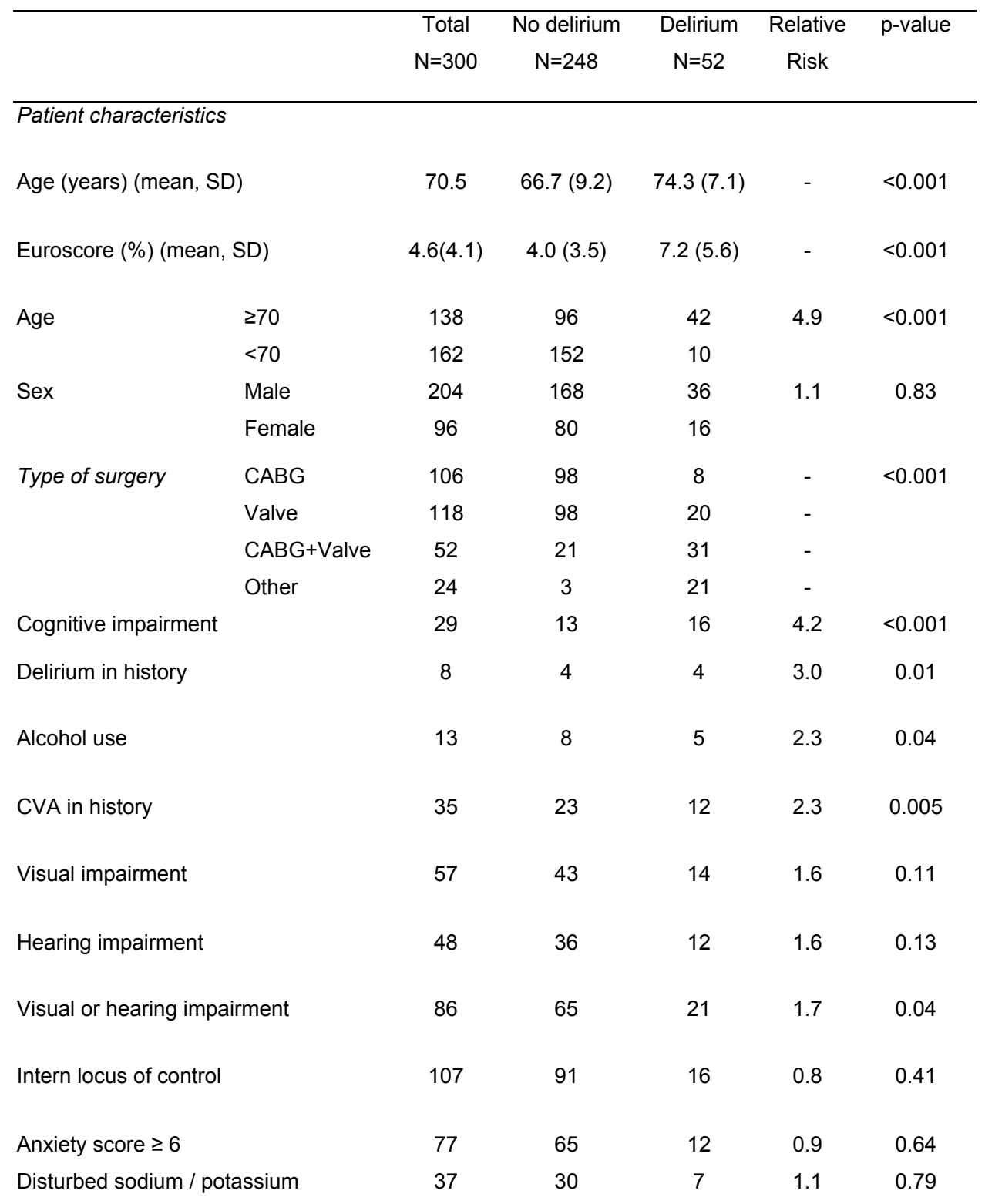




\begin{tabular}{|c|c|c|c|c|c|c|}
\hline & & $\begin{array}{c}\text { Total } \\
\mathrm{N}=300\end{array}$ & $\begin{array}{l}\text { No delirium } \\
\qquad N=248\end{array}$ & $\begin{array}{c}\text { Delirium } \\
\mathrm{N}=52\end{array}$ & $\begin{array}{c}\text { Relative } \\
\text { Risk }\end{array}$ & $p$-value \\
\hline Elevated creatinine & & 43 & 29 & 14 & 2.2 & 0.005 \\
\hline Anxiety HADS & & 24 & 19 & 5 & 1.2 & 0.58 \\
\hline Depression HADS & & 19 & 15 & 4 & 1.2 & 0.75 \\
\hline \multirow[t]{4}{*}{ Nr. of co-morbidities } & 1 & 146 & 138 & 8 & - & $<0.001$ \\
\hline & 2 & 112 & 90 & 22 & - & \\
\hline & 3 & 29 & 15 & 4 & - & \\
\hline & 4 & 13 & 5 & 8 & - & \\
\hline Dementia & & 1 & 0 & 1 & - & 0.17 \\
\hline COPD & & 32 & 18 & 14 & 3.1 & $<0.001$ \\
\hline Diabetes mellitus & & 57 & 43 & 14 & 1.6 & 0.11 \\
\hline Use of heart-lung machine & & 214 & 168 & 46 & 3.1 & 0.003 \\
\hline Distress 4DKL & & 55 & 44 & 11 & 1.2 & 0.56 \\
\hline Depression 4DKL & & 23 & 17 & 6 & 1.6 & 0.25 \\
\hline Somatisation $4 \mathrm{DKL}$ & & 55 & 47 & 8 & 0.8 & 0.55 \\
\hline Anxiety $4 \mathrm{DKL}$ & & 15 & 10 & 5 & 2.0 & 0.15 \\
\hline
\end{tabular}

$\mathrm{CABG}=$ Coronary Artery Bypass Grafting; $\mathrm{COPD}=$ Chronic Obstructive Pulmonary Disease $; \mathrm{CVA}=$ Cerebro Vascular Accident; HADS = Hospital Anxiety and Depression Scale; GDS = Geriatric Depression Scale; $4 \mathrm{DKL}=$ four dimensional complaints list.

Validated instruments were used to assess nutritional status (Short Nutritional Assessment Questionnaire (SNAQ)- list (18)), cognitive function (Short Mini Mental State Examination (SMMSE)- scale (19)), anxiety (Hospital Anxiety and Depression (HADS) scale (20) and four dimensional complaints list (4DKL) (21)), depression (Geriatric Depression Scale (GDS) (22), HADS, and 4DKL), locus of control (Intern Extern locus of control - 18 (IE 18) (23)), somatisation (4DKL), and distress (4DKL). 
As already mentioned, the diagnosis of delirium was based on the DOS scale. This is a reliable and valid instrument to recognize delirium based on nurses' observations during regular care (10). The DOS scale describes typical behavioral patterns related to delirium in 13 statements or questions, which the observer has to answer with "never" (score $=0$ ) or "sometimes or always" (score $=1$ ) if applicable (see Table 2).

Table 2. The working method of the DOS scale

The patient:

1. Dozes off during conversation or activities

2. Is easily distracted by stimuli from the environment

3. Loses attention to conversation or action

4. Does not finish question or answer

5. Gives answers that do not fit the question

6. Reacts slowly to instructions

7. Thinks to be somewhere else

8. Does not know which part of the day it is

9. Does not remember recent event

10. Is picking, disorderly, restless

11. Pulls IV tubes, feeding tubes, catheters etc.

12. Is easy or sudden emotional (frightened, angry, irritated)

13. Sees/hears things which are not there

Never $=0$ points; Sometimes or always $=1$ point.

A total score of three or more points indicate a delirium.

The DOS score is calculated by dividing the total score by 3 . The DOS score is between 0 and 13. A DOS score of $\geq 3$ indicates delirium (10). Nurses were informed about delirium including risk factors, prevention, interventions, and using the DOS scale.

\section{Statistical analysis}

The univariate association between each candidate predictor and postoperative delirium was estimated. The independent two-tailed $t$ test was used to compare the means of variables in case of continuous normally distributed data. When data was not distributed normally, Wilcoxon's Rank Sum Test was utilized. The following risk 
factors were analyzed as continuous variables: age and Euroscore. The Chisquare test was used for the comparison of categorical variables (see Table 1). The following cut-off values, based on the literature, were used to classify high risk patients: cognitive impairment: MMSE $<23$; Poor nutritional status: $S N A Q \geq 2$; Anxiety score $\geq 6$; Anxiety according to HADS: anxiety score $>8$; Depression according to HADS: depression score > 8; Intern locus of control: score < 52.5; Depression according to GDS: depression score >7; Somatisation moderate: 4DKL somatisation score $>10$; Somatisation severe: $4 \mathrm{DKL}$ somatisation score $>20$; Distress moderate: $4 \mathrm{DKL}$ distress score $>10$; Distress severe: $4 \mathrm{DKL}$ distress score $>20$; Anxiety moderate: $4 \mathrm{DKL}$ anxiety score $>8$; Anxiety severe: $4 \mathrm{DKL}$ anxiety score > 12; Depression moderate: 4DKL depression score $>10$; Depression severe: 4DKL depression score $>20$; Sodium < 135 or $>145 \mathrm{mmol} / \mathrm{l}$; Potassium < 3.5 or $>5.0 \mathrm{mmol} / \mathrm{l}$; Creatinine male $>110 \mathrm{micro} \mathrm{mol} / \mathrm{l}$, female $>90 \mathrm{micro} \mathrm{mol} / \mathrm{l}$. Alcohol use is defined as an intake of more than three glasses of alcohol per day.

First we validated the earlier model in a new, larger study population with 300 patients to see whether the Euroscore and a disturbance in electrolytes could again predict a postoperative delirium in patients who underwent elective cardiac surgery. The model's ability to discriminate between patients with and without postoperative delirium was estimated by the area under the receiver operating characteristic curve (ROC- curve). Secondly, the model was tested in a new population with 300 patients, but with the added predictors. The factors independently associated with postoperative delirium ( $p \leq 0.10)$ were all entered in a logistic regression analysis. Subsequently, this model was reduced to remove non significant factors ( $p$ - value $>0.05$ ) one by one. Also in this model the ROCcurve was estimated.

\section{Results}

\section{Study population}

450 patients were invited to participate in the study of which $1 / 3$ refused for personal reasons. Of the included patients the majority were male (68.6\%). The mean age was 74 years $(S D=7.1)$ (Table 1$)$. There was a significant difference in 
age in patients with and without delirium. 138 patients (46\%) were older than 70 years. The most commonly performed cardiac surgery included heart valve surgery (39.3\%) and Coronary Artery Bypass Grafting (CABG) (35.3\%).

\section{Incidence delirium}

Based on the DOS scale, in 52 patients (17\%) there was a postoperative delirium. Of these 52 patients, 36 were male with a mean age of 74 years.

\section{Validity risk checklist for delirium}

Compared to the previously developed prediction model, the Euroscore was confirmed as a predictor of a postoperative delirium, but a disturbance in electrolytes was not. When using a predicted probability of delirium of $20 \%$, the original model with Euroscore and a disturbance in electrolytes, but now with 300 patients, had a sensitivity of $40.4 \%$ and a specificity of $82.7 \%$. The predictive value of a positive test was $32.8 \%$ and of a negative test $86.9 \%$ (Table 3). The Area Under the Receiver Operating Curve (AUC) of the original model was 0.71 (Figure 1).

Table 3. Predictive validity of the original delirium risk checklist and the extended risk checklist delirium $(N=300)$ with a probability of delirium of $20 \%$ according to the risk model

\begin{tabular}{lcccc}
\hline & & $\begin{array}{l}\text { Delirium } \\
\text { Yes }\end{array}$ & No & Total \\
\hline $\begin{array}{l}\text { Risk for delirium with original } \\
\text { risk checklist }\end{array}$ & Yes & 21 & 43 & 64 \\
& No & 31 & 205 & 236 \\
$\begin{array}{l}\text { Risk for delirium with } \\
\text { extended risk checklist }\end{array}$ & Yes & 42 & & 86 \\
& No & 10 & 44 & 214 \\
Total & & 52 & 204 & 300 \\
\hline
\end{tabular}




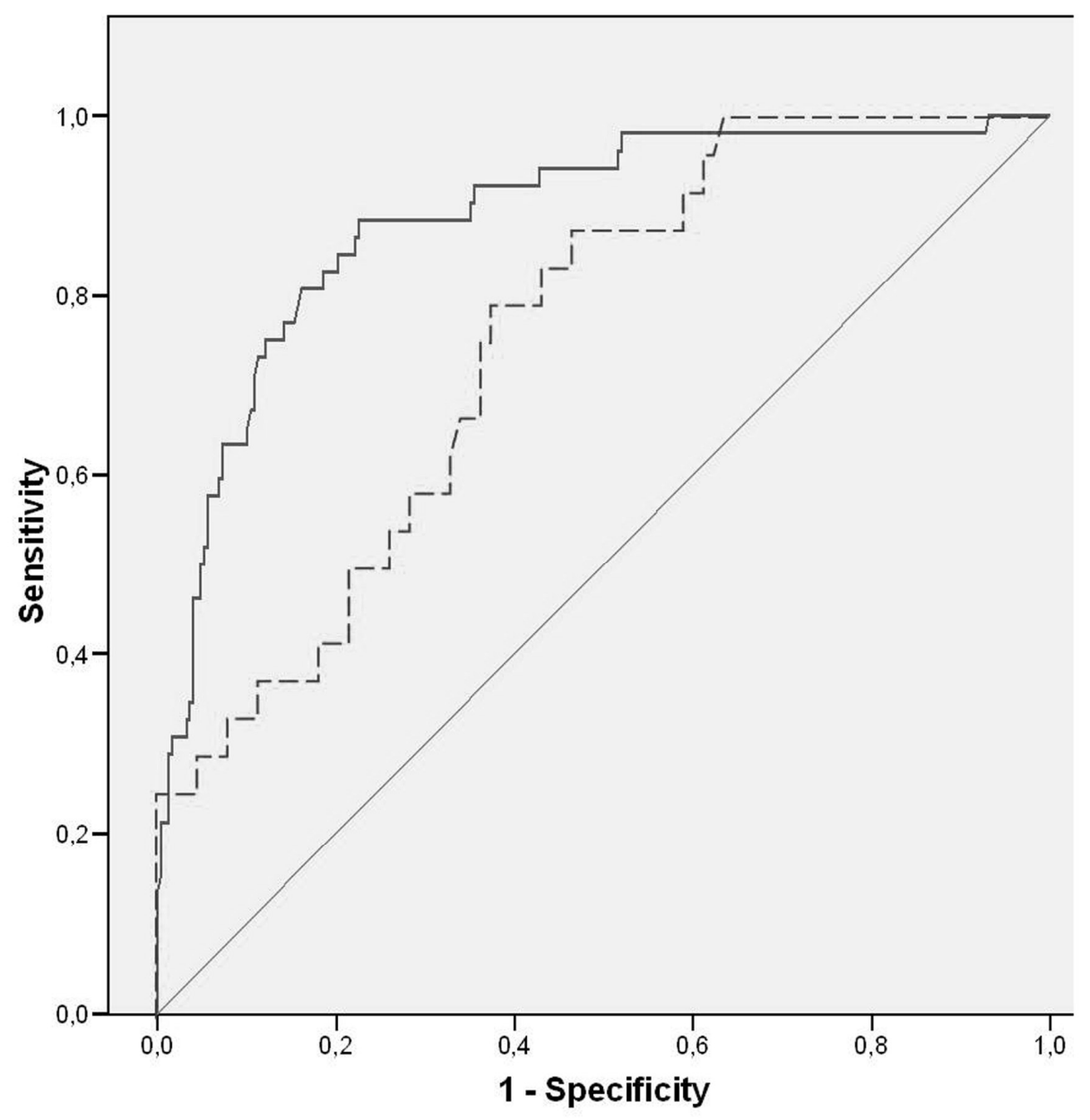

Figure 1. ROC-curve of the original delirium risk checklist including Euroscore and disturbance in electrolytes (dashed line) and ROC- curve of the extended delirium risk checklist including: older age $(\geq$ 70 years), cognitive impairment, number of co-morbidities, history of delirium, alcohol use, type of surgery and Euroscore (continuous line). The diagonal line is the reference line indicating pure chance.

Risk checklist for delirium with added predictors In the univariate analysis the following variables: Euroscore, number of comorbidities, higher age, type of surgery, use of heart-lung machine, cognitive impairment, elevated creatinine, COPD, CVA in history, visual- and hearing impairment, alcohol use, and delirium in history were associated $(p \leq 0.10)$ with a higher risk of postoperative delirium after cardiac surgery (Table 1). 
The full multivariable model containing all predictors yielded an area under the ROC curve of 0.90 (95\% BI $=0.85-0.94 ; p<0.001)$.

Seven predictors were independently associated with postoperative delirium: older age ( $\geq 70$ years), cognitive impairment, number of co-morbidities, history of delirium, alcohol use, type of surgery, and Euroscore (Table 4). When using a probability of delirium of $20 \%$, as predicted by the model, the sensitivity was $80.8 \%$, while the specificity was $82.2 \%$. The predictive value of a positive test was $48.8 \%$ and the predictive value of a negative test was $95.3 \%$ (Table 3). An area under the curve of 0.89 was found $(95 \% \mathrm{BI}=0.83-0.94 ; \mathrm{p}<0.001)$ (Figure 1). To estimate the probability of developing delirium for an individual patient the prediction formula in Table 4 can be used.

Table 4. Predictors from multivariate analysis that independently contributed to the prediction of postoperative delirium after cardiac surgery $(N=300)$

\begin{tabular}{|c|c|c|c|c|c|}
\hline & \multirow[t]{2}{*}{ B } & \multirow[t]{2}{*}{ Odds Ratio } & \multicolumn{2}{|c|}{$95 \% \mathrm{Cl}$} & \multirow[t]{2}{*}{$p$-value } \\
\hline & & & Low & High & \\
\hline Age $\geq 70$ & 1.59 & 4.9 & 1.9 & 13.0 & $p=0.001$ \\
\hline Cognitive impairment & 1.51 & 4.5 & 1.6 & 12.7 & $p=0.004$ \\
\hline Comorbidity & 0.82 & 2.3 & 1.4 & 3.5 & $p<0.001$ \\
\hline Delirium in history & 1.70 & 5.5 & 0.8 & 36.4 & $p=0.077$ \\
\hline Alcohol use & 2.38 & 10.8 & 2.2 & 53.6 & $p=0.003$ \\
\hline Euroscore & 0.10 & 1.1 & 1.0 & 1.2 & $p=0.030$ \\
\hline Type of surgery & & & & & $p=0.043$ \\
\hline CABG & & 1.0 & & & \\
\hline Valve & 0.67 & 1.9 & 0.7 & 5.4 & $p=0.200$ \\
\hline CABG + valve & 1.38 & 4.0 & 1.3 & 11.7 & $p=0.012$ \\
\hline Other & 0.44 & 0.6 & 0.1 & 4.9 & $p=0.672$ \\
\hline
\end{tabular}

Prediction formula:

$1+\mathrm{e}^{-\left(-5.73+1.59^{*} \text { age } \geq 70+1.51^{*} \text { cognitive impairment }+0.82^{*} \text { comorbidity + }\right.}$

$1.70^{*}$ delirium in history $+2.38^{*}$ alcohol use $+0.10^{*}$ Euroscore $+0.67^{*}$ Valve + $\left.1.38^{*}(\mathrm{CABG}+\mathrm{valve})+0.44^{*} \mathrm{Other}\right)$ 


\section{Discussion}

\section{Risk factors delirium}

In the extended model, seven independent predictors of postoperative delirium after cardiac surgery were found. In comparison with the earlier study the sensitivity of the new, larger prediction model is much better $(40.4 \%$ versus $80.8 \%)$, the specificity is almost comparable $(82.7 \%$ versus $82.2 \%$ ) and the Area Under the Receiver Operating Curve (AUC) is much better ( 0.71 versus 0.89 ). The Euroscore could again predict a postoperative delirium in patients who underwent elective cardiac surgery, so the Euroscore seems to be a stable predictor of postoperative delirium in cardiac surgery patients. Also in a recently published study, a Euroscore $\geq 5$ was associated with postoperative delirium (24). Considering that the Euroscore itself contains relevant risk factors for mortality (sex, urgent operation, re-operation etc.), a positive correlation between the Euroscore and postoperative delirium is not too farfetched. This also explains why other predisposing factors for developing delirium such as use of a heart-lung machine, disturbed creatinine etc. no longer appear as independent predictors in the final model.

A disturbance in electrolytes could not again predict a postoperative delirium in patients who underwent elective cardiac surgery. The study population in the present study was comparable with the study population of the earlier study, so therefore, it might have been a chance finding in the earlier study. This underlines the importance of true validation studies in prognostic research.

According to the present study a delirium in the patient's history is a relevant risk factor. Although the incidence of a delirium in history is low, it is a very relevant predictor leading to a 5.5 fold increased risk. Dementia and a poor nutritional status failed to reach significance in our study, because of a too small number of patients with dementia (one patient) or a poor nutritional status (two patients). However, if patients have dementia or a poor nutritional status they seem to have a very high risk for developing delirium; the three patients with dementia or a poor nutritional status all developed delirium after cardiac surgery.

Preoperative anxiety, a common problem in patients undergoing cardiac surgery, is a factor that according to the literature can influence the development of 
postoperative delirium $(17 ; 25)$. However, it was not mentioned as a risk factor in the delirium guideline. In our first study anxiety failed to reach significance, possibly because the sample size was too small; but in 300 patients anxiety is still not an independent risk factor of a postoperative delirium. Probably anxiety is a common problem in most of the patients undergoing cardiac surgery, and not only in patients who develop a postoperative delirium. Anxiety was also a common reason of refusing to participate in the study. Dealing with the upcoming cardiac surgery was enough for the patients and participating in a study, although it was only observational, was too much.

Next, the use of the heart-lung machine increases the relative risk of delirium 3.6 fold $(p=0.003)$ in a univariate analysis, and yet in multivariate analysis fails to rise to the level of an independent predictor of delirium. This is an important issue in the controversy surrounding off-pump versus on-pump cardiac surgery and the avoidance of "neuropsychiatric injury" purported to be more common when extracorporeal circulation is used (26).

\section{Incidence delirium}

The incidence of delirium after cardiac surgery was $17 \%$. This incidence is somewhat lower in comparison with the incidence of $25 \%$ reported by the Dutch Inspection of Healthcare according van Blanken and Robben (1), the study by van der Mast et al. (27) who found a postoperative delirium incidence of $20 \%$, and our earlier study with an incidence delirium of $21 \%$ (3). This discrepancy is possibly due to the nurses who were well informed about delirium including risk factors, prevention, and interventions. This may contribute to appropriate preventive interventions such as orientating the patient as necessary, correcting fluid balance, and providing quiet surroundings that probably had a positive effect on the incidence of delirium. The incidence of delirium in studies among cardiac surgery patients shows a broad range anyway, from $3 \%(24)$ to $52 \%(28)$. The number of patients, the methods of the studies, and the diagnostic criteria used influence the results reported. Because the DOS scale is a very good instrument to facilitate early recognition of delirium by nurses' observation we do not expect an underestimation of the incidence delirium. Generally, an incidence of $25 \%$ is 
assumed among hospitalized elderly patients (1). The incidence of $52 \%$ in a recent study in patients after cardiac surgery is very high. Probably the Confusion Assessment Method (CAM) measures a higher incidence of delirium.

\section{Limitations}

A number of critical considerations pertaining to our study can be made. A psychiatrist was not consulted to diagnose delirium, but the diagnosis delirium was based on the DOS scale. Only in patients in whom the treatment of delirium was not successful or the delirium was very severe (DOS score $>6$ ), a psychiatrist was consulted. In all these patients the psychiatrist diagnosed delirium. With a DOS score $<3$ we assumed that there was no delirium. It is very unlikely that a delirium was present in patients with a DOS score $<3$ because of the similarity between the DOS scale items and the diagnostic criteria for delirium. Also in our earlier study the validity of the DOS scale was very good with a sensitivity of $100 \%$ and a specificity of $96.6 \%$ (14). Therefore, using the DOS scale has probably not influenced the results of the study. Because of the fluctuating nature of delirium and the frequent contact of nurses with patients, nurses are in a strategic position to observe changes in patients' behavior at an early stage. Therefore, the choice was made for a screening instrument based on nurses' observations and on that account the DOS scale was regarded as a suitable instrument. In intensive care patients we also used the DOS scale according to the hospital's policy, but in these patients the DOS scale is probably not the best instrument, because patients are intubated most of the time. In intubated patients the DOS score is zero oftentimes, and a delirium can be missed. Another screening instrument, like the NEECHAM Confusion Scale ICU or the CAM-ICU, is therefore more recommended in intubated patients $(29 ; 30)$.

Poor nutritional status was not found as an independent predictor. The reason for that was probably the small number of patients (two patients) with a poor nutritional status but also the assessment of the nutritional status seems to be relevant. To assess the nutritional status the SNAQ list was used. Probably in cardiac surgery patients this instrument is not the best instrument. Because many patients have 
edema, loss of weight is not the most suitable parameter. Perhaps a more comprehensive instrument that looks at more factors than loss of weight only, like the Mini Nutritional Assessment short-form (MNA sf) (31), is more suitable in cardiac surgery patients.

Also dementia was not found as an independent predictor because we only included one patient with dementia. However, the method of assessing dementia is relevant. The diagnosis dementia was taken from patient's file, but was not assessed with a preoperative cognitive assessment. Perhaps this can contribute to an underestimation in the number of patients with dementia.

In our study the use of opiates is not an independent predictor, because the number of patients that uses opiates pre operatively is very low. We could not study the possible effect of the use of opiate analgesics in the early postoperative period because all patients have the same anesthetic and postoperative analgesic control by an epidural or intravenous catheter. Because in an earlier study the choice of the intraoperative analgesic was a risk factor for postoperative delirium (5), it would be very interesting to investigate what kind of intraoperative analgesic could reduce the incidence of delirium.

We did not study the preoperative medications like statins and beta blockers. The results of studies on preoperative cardiac medication contradict each other. Katznelson et al. found that the preoperative use of statins is associated with reduced early delirium rates after cardiac surgery (32) whereas Drummond et al. found that statins might contribute to postoperative delirium (33). Because of the contradiction in outcomes and the fact that it is difficult in practice to change medication pre operatively, we did not study preoperative medication as a risk factor.

There are more studies concerning prediction of delirium in cardiac surgery (28). Because we felt it was important to validate the results of our first study we repeated it. Also, we used important risk factors like Euroscore and history of delirium that other studies did not use. 


\section{Implications for practice and further research}

Euroscore and the other six identified predictors are relatively easy to measure and can be used to identify patients at greater risk of developing postoperative delirium following cardiac surgery. With the prediction formula in Table 4 the risk of delirium can be calculated straightforwardly.

In practice it is difficult to alleviate or eliminate the risk factors or markers of delirium. Firstly, it is not always possible because the surgery can not be delayed, and secondly, at present there is a paucity of data to support that elimination of these risk factors or markers has any effect on the incidence of postoperative delirium. On the other hand, in patients with a high risk of developing delirium it may not be possible to prevent delirium, but early recognition of postoperative delirium can be realized. However, it was not possible to determine whether any of the risk factors were true independent causal variables or only markers that reflected the general medical condition of the patient and also the clinical pathway to delirium is at present unknown. In patients with the identified markers, preventative interventions, to reduce the number, severity or duration of episodes of delirium, can be taken, such as a program of proactive geriatric consultation or Haloperidol prophylaxis $(34 ; 35)$. Maybe it it is time to consider prospective studies to test interventions for the prevention of delirium, such as pharmacological treatment. To conduct this type of study, a reliable risk scoring system such as ours is very important. For the preoperative intervention program we have to focus on the predisposing factors, because we cannot influence precipitating factors pre operatively. So an intervention program could pay attention to the cognitive function, co-morbidities, for example to improve the inspiratory muscle force in patients with COPD, and the use of alcohol.

The first aim of this study was to validate the delirium risk checklist of the earlier study. Next, we added new risk factors. Because this is the first study with these new added risk factors, this model needs external validation as well. 


\section{References}

(1) van Blanken G, Robben PBM. Delirium vaak niet herkend. Medisch Contact. 2005;60:1724-1727.

(2) American Psychiatric Association. Diagnostic and Statistical Manual of Mental Disorders. 4th ed. Washington: 1994.

(3) Koster S, Oosterveld FG, Hensens AG, Wijma A, van der Palen J. Delirium After Cardiac Surgery and Predictive Validity of a Risk Checklist. Ann Thorac Surg. 2008;86(6):1883-1887.

(4) Inouye SK, Bogardus ST, Jr., Charpentier PA, Leo-Summers L, Acampora $D$, Holford TR, et al. A multicomponent intervention to prevent delirium in hospitalized older patients. N Engl J Med. 1999; 4;340(9):669-676.

(5) Radtke FM, Franck M, MacGuill M, Seeling M, Lutz A, Westhoff S, et al. Duration of fluid fasting and choice of analgesic are modifiable factors for early postoperative delirium. Eur J Anaesthesiol. 2010;27(5):411-416.

(6) Mason SE, Noel-Storr A, Ritchie CW. The impact of general and regional anesthesia on the incidence of post-operative cognitive dysfunction and post-operative delirium: a systematic review with meta-analysis. $J$ Alzheimers Dis. 2010;22(3):67-79.

(7) Bucerius J, Gummert JF, Borger MA, Walther T, Doll N, Falk V, et al. Predictors of delirium after cardiac surgery delirium: effect of beating-heart (off-pump) surgery. J Thorac Cardiovasc Surg. 2004;127(1):57-64.

(8) Schuurmans MJ, Duursma SA, Shortridge-Baggett LM. Early recognition of delirium: review of the literature. J Clin Nurs 2001;10(6):721-729.

(9) Koster S, Hensens AG, van der Palen J. The long-term cognitive and functional outcomes of postoperative delirium after cardiac surgery. Ann Thorac Surg. 2009;87(5):1469-1474.

(10) Schuurmans MJ, Shortridge-Baggett LM, Duursma SA. The Delirium Observation Screening Scale: a screening instrument for delirium. Res Theory Nurs Pract. 2003;17(1):31-50.

(11) Timmers J, Kalisvaart K, Schuurmans M, de Jonge J. A review of delirium rating scales. Tijdschr Gerontol Geriatr. 2004;35(1):5-14. 
(12) Schuurmans MJ, Donders ART, Shortridge-Baggett LMS, Duursma SA. Early symptoms of delirium observed by nurses in hip fracture patients. In: Early recognition of delirium. 1th ed. Gent, Belgium: Academia Press; 1999.

(13) Schuurmans MJ, Donders ART, Shortridge-Baggett LM, Duursma SA. Delirium case finding: pilot testing of a new screening scale for nurses. Journal of the American Geriatric Society. 2002;50(4):S3.

(14) Koster S, Hensens AG, Oosterveld FG, Wijma A, van der Palen J. The delirium observation screening scale recognizes delirium early after cardiac surgery. Eur J Cardiovasc Nurs. 2009;8(4):309-314.

(15) Yildizeli B, Ozyurtkan MO, Batirel HF, Kuscu K, Bekiroglu N, Yuksel M. Factors associated with postoperative delirium after thoracic surgery. Ann Thorac Surg. 2005;79(3):1004-1009.

(16) Dubois MJ, Bergeron N, Dumont M, Dial S, Skrobik Y. Delirium in an intensive care unit: a study of risk factors. Intensive Care Med. 2001;27(8):1297-1304.

(17) van der Mast RC, Huyse FJ, Rosier PF. Guideline 'Delirium. Ned Tijdschr Geneeskd. 2005;149(19):1027-1032.

(18) Kruizenga HM, Seidell JC, de Vet HC, Wierdsma NJ, Van Bokhorst-de van der Schueren MA. Development and validation of a hospital screening tool for malnutrition: the short nutritional assessment questionnaire (SNAQ). Clin Nut.r 2005;24(1):75-82.

(19) Molloy DW, Alemayehu E, Roberts R. Reliability of a Standardized MiniMental State Examination compared with the traditional Mini-Mental State Examination. Am J Psychiatry. 1991;148(1):102-105.

(20) de Croon EM, Nieuwenhuijsen K, Hagenholtz NIR, van Dijk FJH. Drie vragenlijsten voor diagnostiek van depressie en angststoornissen. Tijdschrift voor Bedrijfs- en Verzekeringsgeneeskunde. 2005;13(4):98-103.

(21) Terluin B, van Marwijk HW, Ader HJ, de Vet HC, Penninx BW, Hermens ML, et al. The Four-Dimensional Symptom Questionnaire (4DSQ): a validation study of a multidimensional self-report questionnaire to assess distress, depression, anxiety and somatization. BMC Psychiatry. 2006;6:34. 
(22) Lesher EL, Berryhill JS. Validation of the Geriatric Depression Scale--Short Form among inpatients. J Clin Psychol. 1994;50(2):256-260.

(23) Den Hertog PC. De 'IE-18 locus of control'-vragenlijst: betrouwbaarheid en validiteit van een gewijzigde versie. Nederlands Tijdschrift voor de Psychologie; 1992;47:82-87.

(24) Norkiene I, Ringaitiene D, Misiuriene I, Samalavicius R, Bubulis R, Baublys $\mathrm{A}$, et al. Incidence and precipitating factors of delirium after coronary artery bypass grafting. Scand Cardiovasc J. 2007;41(3):180-185.

(25) Lundstrom M, Edlund A, Karlsson S, Brannstrom B, Bucht G, Gustafson Y. A multifactorial intervention program reduces the duration of delirium, length of hospitalization, and mortality in delirious patients. J Am Geriatr Soc. 2005;53(4):622-628.

(26) Shroyer AL, Grover FL, Hattler B, Collins JF, McDonald GO, Kozora E, et al. On-pump versus off-pump coronary-artery bypass surgery. N Engl J Med; 2009;5;361(19):1827-1837.

(27) van der Mast RC, van den Broek WW, Fekkes D, Pepplinkhuizen L, Habbema JD. Incidence of and preoperative predictors for delirium after cardiac surgery. J Psychosom Res; 1999;46(5):479-483.

(28) Rudolph JL, Jones RN, Levkoff SE, Rockett C, Inouye SK, Sellke FW, et al. Derivation and validation of a preoperative prediction rule for delirium after cardiac surgery. Circulation; 2009;119(2):229-236.

(29) Immers HE, Schuurmans MJ, van de Bijl JJ. Recognition of delirium in ICU patients: a diagnostic study of the NEECHAM confusion scale in ICU patients. BMC Nurs. 2005;4:7.

(30) Ely EW, Margolin R, Francis J, May L, Truman B, Dittus R, et al. Evaluation of delirium in critically ill patients: validation of the Confusion Assessment Method for the Intensive Care Unit (CAM-ICU). Crit Care Med; 2001;29(7):1370-1379.

(31) Kaiser MJ, Bauer JM, Ramsch C, Uter W, Guigoz Y, Cederholm T, et al. Validation of the Mini Nutritional Assessment short-form (MNA-SF): a practical tool for identification of nutritional status. J Nutr Health Aging. 2009;13(9):782-788. 
(32) Katznelson R, Djaiani GN, Borger MA, Friedman Z, Abbey SE, Fedorko L, et al. Preoperative use of statins is associated with reduced early delirium rates after cardiac surgery. Anesthesiology. 2009;110(1):67-73.

(33) Drummond JC, Head BP, Patel PM. Statins might contribute to postoperative delirium. Anesthesiology. 2010;113(2):500-501.

(34) Kalisvaart KJ, de Jonge JF, Bogaards MJ, Vreeswijk R, Egberts TC, Burger BJ, et al. Haloperidol prophylaxis for elderly hip-surgery patients at risk for delirium: a randomized placebo-controlled study. J Am Geriatr Soc. 2005;53(10):1658-1666.

(35) Marcantonio ER, Flacker JM, Wright RJ, Resnick NM. Reducing delirium after hip fracture: a randomized trial. J Am Geriatr Soc. 2001;49(5):516-522. 


\section{Chapter 6}

The long-term cognitive and functional outcomes of postoperative delirium after cardiac surgery

Sandra Koster

Ab G. Hensens

Job van der Palen

Ann Thorac Surg. 2009 May;87(5):1469-74 


\section{Abstract}

Background. Delirium or acute confusion is a temporary mental disorder, which occurs frequently among hospitalized elderly patients. Patients who undergo cardiac surgery have an increased risk of developing delirium. This is associated with many negative consequences such as prolonged hospital stay, nursing home placement, and reduced cognitive and functional recovery.

Methods. In this prospective follow-up study, a questionnaire was used 1 to 1.5 years after cardiac surgery in our earlier cohort of 112 patients who underwent elective cardiac surgery, of which 24 patients (21\%) developed postoperative delirium as diagnosed by a single psychiatrist.

Results. Postoperative delirium after cardiac surgery may be associated with increased mortality $(12.5 \%$ in patients with delirium versus $4.5 \%$ in patients without delirium; $p=0.16)$, more readmissions to the hospital $(47.6 \%$ vs $32.6 \% ; p=0.19)$, dysfunction in memory (31.6\% vs $22.6 \% ; p=0.39$ ), and concentration problems ( $36.8 \%$ vs $20.2 \% ; p=0.13)$; and is associated with sleep disturbance $(47.4 \%$ vs $23.8 \% ; p=0.03$ ).

Conclusions. Postoperative delirium after cardiac surgery may be associated with increased mortality and readmissions to the hospital, as well as poorer cognitive and functional outcomes. Therefore, prevention and (or) early recognition of delirium must be improved. In addition, patients and caregivers (family and general practitioner) must be better informed about the long-term consequences of delirium and what they can do about it. 


\section{Introduction}

Delirium is a common temporary mental disorder among hospitalized elderly patients (1). In the literature the incidence and prevalence of delirium vary widely among different study populations. Patients who undergo cardiac surgery have an increased risk of developing delirium. In our observational cohort study the incidence of delirium after elective cardiac surgery was $21 \%$ (2). As a result of demographic aging, the incidence of delirium is likely to increase in the foreseeable future. Generally, delirium has been related to a prolonged hospital stay, nursing home placement, and reduced cognitive and functional recovery (3-7). Francis and Kapoor (8) found that delirium identifies older patients at risk for mortality, loss of independence, and cognitive decline two years after an episode of delirium in general medical wards (8). Rockwood and colleagues (9) observed in older patients without prior cognitive or functional impairment, that the incidence of dementia was $5.6 \%$ per year over three years for those without delirium and $18.1 \%$ per year for those with delirium. In addition, mortality was also increased for those with delirium. Of the 38 patients with delirium, only eight (21\%) were alive at followup, compared with 94 (57\%) of those without delirium (9).

In cardiac surgery little is known about mortality, morbidity, and cognitive and functional outcomes of postoperative delirium. This study will examine mortality after discharge, readmission rate, and the long-term cognitive and functional outcomes of delirium after cardiac surgery.

\section{Patients and Methods}

Design and Sample

Between November 2006 and June 2007 our earlier prospective cohort study included 112 consecutive patients, of 45 years and older, who underwent elective cardiac surgery at the Department of Cardiothoracic Surgery. The Ethics Committee of Medisch Spectrum Twente was asked whether approval was needed. Because this was an observational study, without invasive procedures, approval was not necessary. Informed consent was obtained in accordance with the policy of the hospital. 
Of these 112 patients, $24(21 \%)$ developed postoperative delirium as diagnosed by a single psychiatrist. The diagnostic criteria used by the psychiatrist to diagnose delirium were based on the nursing documentation and the Diagnostic and Statistical Manual of Mental Disorders, Fourth Revision (DSM-IV) criteria (10). The DSM-IV criteria were based on specific diagnostic criteria to differentiate delirium from other syndromes (like anxiety, depression, and dementia). Table 1 shows the DSM-IV criteria for the diagnosis of delirium.

\section{Procedure}

Initially we ascertained whether patients had died. In June 2008 a questionnaire was sent to all 103 surviving patients to evaluate readmission rates and cognitive and functional outcomes 1 to 1.5 years after the cardiac surgery. When patients had not responded after two months, they were contacted by telephone and were asked to complete the questionnaire.

\section{Table 1. Diagnostic criteria of DSM-IV for the diagnosis of delirium}
A Disturbance of consciousness with reduced ability to focus, sustain
D There is evidence from history, physical examination or laboratory findings that the disturbance is:
1. Physiological consequence of general condition
2. Caused by intoxication
3. Caused by medication
4. Caused by more than one etiology

C Disturbance develops in a short period of time and fluctuates over the course of the day

DSM-IV = Diagnostic and Statistical Manual of Mental Disorders.

There is no standard or validated questionnaire available to examine cognitive and functional outcomes; therefore, we designed one. The questionnaire was made, together with an epidemiologist and two delirium experts, to at least obtain face validity. Before we used the questionnaire for the study we did a pilot with the questionnaire to see whether the questionnaire was clear and understandable. After peer review and the pilot study, the questionnaire contained questions on readmission to the hospital, memory, concentration, confusion, sleep pattern, 
emotions, activities of daily living, mobility, and in case of a postoperative delirium the experience of the episode of confusion (see Appendix 1 for the questionnaire). We defined problems about memory, concentration, confusion, etc., to be present when the patient feels, thinks, or believes he has a problem in this area. The Medical Computer System (MCS) of the Hospital was used to ascertain the readmissions and whether patients had died.

\section{Statistical Analysis}

The univariate association between postoperative delirium and cognitive or functional outcomes was estimated. The independent 2-tailed $t$ test was used to compare the means of variables in case of continuous normally distributed data. When data were not distributed normally, the Wilcoxon rank sum test was utilized. The following outcomes were analyzed as continuous variables: readmission rate to the hospital, memory, concentration, confusion, sleep pattern, emotions, activities of daily living, mobility, and in case of a postoperative delirium the experience of the episode of confusion. The $\mathrm{x}^{2}$ test was used for the comparison of categorical variables between those with and without delirium.

\section{Results}

\section{Study Population}

One hundred and twelve patients were invited to participate in the study. All 103 non deceased patients returned the questionnaire.

\section{Long-term Outcomes of Delirium After Cardiac Surgery}

MORTALITY. Seven patients $(6.3 \%)$ died during the follow- up period: three $(12.5 \%)$ among those who had experienced a postoperative delirium and four (4.5\%) among those who had not experienced a delirium $(p=0.16)$. Four of the seven patients $(57.1 \%)$ died during the hospital period after cardiac surgery, of which two patients had developed a postoperative delirium (Table 2).

READMISSION. In the event of delirium, the number of readmissions to the hospital was higher. In 21 patients (19.6\%) there was a readmission to the hospital for 
several reasons. The most commonly mentioned reason for readmission was a cardiac problem (32.4\%) (Table 2).

Table 2. Mortality and re-admission to the hospital after cardiac surgery with and without a postoperative delirium ( $N=112$ for mortality and $N=107$ for re-admissions)

\begin{tabular}{lllll}
\hline & & Delirium & No delirium & $p$ Value \\
\hline Died & Yes & $3(12.5 \%)$ & $4(4.5 \%)$ & \\
& No & $21(87.5 \%)$ & $84(95.5 \%)$ & 0.167 \\
Readmission & Yes & $10(47.6 \%)$ & $28(32.6 \%)$ & \\
& No & $11(52.4 \%)$ & $58(67.4 \%)$ & 0.196
\end{tabular}

\section{Experience of Delirium in the Hospital}

Patients' experience of delirium during hospitalization varies widely. Seven patients $(36.8 \%)$ remembered having been confused and described anxiety, fear, and helplessness. A third of them experienced disorientation, especially in place and time, while one quarter reported seeing or hearing things that did not exist. In 12 patients $(63.2 \%)$ the psychiatrist had diagnosed postoperative delirium, but these patients did not remember the postoperative delirium. Four patients $(4.9 \%)$ remembered having been confused, in whom the psychiatrist had not diagnosed delirium.

\section{Cognitive and Functional Outcomes}

After discharge from the hospital 25 patients (24.3\%) had memory problems and $24(23.3 \%)$ had concentration problems. The higher incidence of memory problems and concentration problems in those with delirium seems to be relevant, but is not significant. Eleven patients (10.7\%) were confused after discharge with no difference between patients with or without delirium. Twenty-nine patients $(28.2 \%)$ experienced sleep disturbance after discharge from the hospital; $51.9 \%$ reported "fall asleep" problems and 48.1\% "sleep on" problems. In those who had experienced delirium, the incidence of sleep disturbance was significantly higher. Eleven patients (10.8\%) experienced nightmares or bad dreams after discharge, of 
which two patients (28.6\%) still experienced nightmares at the time of our study (Table 3).

Table 3. Cognitive and functional outcomes after cardiac surgery with and without a postoperative delirium $(N=103)$

\begin{tabular}{|c|c|c|c|c|}
\hline Outcome & & Delirium & No delirium & $p$ Value \\
\hline \multirow[t]{2}{*}{ Memory problems } & Yes & $6(31.6 \%)$ & $19(22.6 \%)$ & \\
\hline & No & $13(68.4 \%)$ & $65(77.4 \%)$ & 0.393 \\
\hline \multirow[t]{2}{*}{ Concentration problems } & Yes & $7(36.8 \%)$ & $17(20.2 \%)$ & \\
\hline & No & $12(63.3 \%)$ & $67(79.8 \%)$ & 0.139 \\
\hline \multirow[t]{2}{*}{ Confusion } & Yes & $2(10.5 \%)$ & $9(10.7 \%)$ & \\
\hline & No & $17(89.5 \%)$ & $75(89.3 \%)$ & 1.000 \\
\hline \multirow[t]{2}{*}{ Sleep disturbance } & Yes & $9(47.4 \%)$ & $20(23.8 \%)$ & \\
\hline & No & $10(52.6 \%)$ & $64(76.2 \%)$ & 0.039 \\
\hline \multirow[t]{2}{*}{ Dependency in ADL } & Yes & $13(68.4 \%)$ & $62(74.7 \%)$ & \\
\hline & No & $6(31.6 \%)$ & $21(25.3 \%)$ & 0.576 \\
\hline \multirow[t]{2}{*}{ Dependency in mobility } & Yes & $4(21.1 \%)$ & $14(17.1 \%)$ & \\
\hline & No & $15(78.9 \%)$ & $68(82.9 \%)$ & 0.741 \\
\hline \multirow[t]{2}{*}{ Emotional problems } & Yes & $7(36.8 \%)$ & $29(34.9 \%)$ & \\
\hline & No & $12(63.2 \%)$ & $54(65.1 \%)$ & 1.000 \\
\hline
\end{tabular}

$\overline{\mathrm{ADL}}=$ activities of daily living.

Almost all patients (92.2\%) were independent in activities of daily living before they underwent cardiac surgery. After discharge from the hospital 27 patients $(26.5 \%)$ were in some way dependent in activities of daily living. The most commonly mentioned dependency was taking a shower (64.3\%), followed by help with preparing meals $(21.4 \%)$. In the event of delirium, the incidence of dependency in activities of daily living was higher, but not significant.

Almost all patients (96.1\%) were mobile before cardiac surgery. After discharge 18 patients $(17.8 \%)$ were in some way less mobile in comparison with the period before cardiac surgery. Most commonly mentioned were the use of a walking-stick 
or a walker $(36.8 \%)$. In the event of delirium, the number of patients who reported to be less mobile was not significantly higher. Thirty-six patients $(35.3 \%)$ had emotional problems after discharge with no difference between patients with or without delirium.

\section{Comment}

A postoperative delirium after cardiac surgery seems to be associated with increased mortality and a higher readmission rate to the hospital, as well as longterm cognitive and functional effects. Cognitive and functional effects included the following: negative experience of delirium, memory and concentration problems, sleep disturbance, and dependency in activities of daily living.

These findings correspond well with the literature, which shows that delirium is related to nursing home placement and reduced cognitive and functional recovery (3-7). Also, other negative effects of delirium have been described. Patients with postoperative delirium were more prone to have postoperative respiratory insufficiency, had a higher prevalence of sternum instability, were more likely to require surgical revision of the sternal wound, and had a significantly longer intensive care stay and longer postoperative hospitalization (4). Another study (9) found that the incidence of dementia was $5.6 \%$ per year over three years for those without delirium and $18.1 \%$ per year for those with delirium. In a longitudinal study by Francis and Kapoor (8) of patients admitted to general medical wards it was found that after two years only one-third of individuals who had experienced delirium still lived independently in the community. The two-year mortality was significantly higher in the case of delirium ( $39 \%$ vs $23 \%)$. They concluded that delirium identifies older patients at risk for mortality and loss of independence. Rockwood and colleagues (9) followed 38 older patients with delirium and demonstrated that delirium is an important marker of the risk for death, even in those without prior cognitive and functional impairment. The median follow-up of this cohort was 32.5 months. Only eight patients $(21 \%)$ with delirium in hospital were alive at follow-up, compared with 94 patients (57\%) of those without delirium. The median survival time was significantly shorter for those with delirium (510 days vs 1,122 days). In comparison with these mortality rates, our mortality of $6.3 \%$ in 
patients with delirium is relatively low. A number of reasons for this are the shorter follow-up period, the younger age of the patients, and the reason for admission to the hospital (elective versus non elective) in our study. The study of Rockwood and colleagues also included patients with dementia, which is a marker of the risk for death.

There was no significant relation between emotional problems, confusion, and dependency in mobility in relation with a postoperative delirium. Emotional problems, confusion, and dependency in mobility are apparently a result of cardiac surgery, no matter if the patients developed a postoperative delirium or not. A number of patients indicated that the emotional difficulties they experienced were considered by them as a normal reaction after cardiac surgery. Emotional problems are common in patients with coronary heart disease. Many studies showed the relation between depressive symptoms and coronary heart disease. For example, Whooley and colleagues (11) found a significant relation between depressive symptoms and patients with coronary heart disease. Also, Detroyer and colleagues (12) found a high prevalence of preoperative anxiety and depressive symptoms in older patients with cardiac surgery. According to Wang and colleagues (13), depressive disorders occurred in $42.7 \%$ of the patients pre operatively and in $23.1 \%$ of the patients six months after cardiac surgery. Murphy and colleagues (14) concluded that although initial anxiety and depression resolved or lessened for most patients, some patients experienced persistent or worsening depression after coronary artery bypass grafting.

In cardiac surgery little is known about the cognitive and functional outcomes of postoperative delirium. Only health-related quality of life has been evaluated six to 12 months after cardiac surgery (15). A postoperative delirium may exert negative influence on health-related quality of life during the first six months after coronary artery bypass grafting (15). It is likely that the observed negative cognitive and functional outcomes exert a negative influence on health-related quality of life.

A number of critical considerations pertaining to our study can be made. First we did not see the patient face to face, but we used a questionnaire. The use of an interview might have rendered more specific information. Another point is that 
although we sent the questionnaire to the patients, we cannot be sure whether the questionnaire was completed by the patients themselves. It is possible that spouses or significant others completed the questionnaire or influenced the answers of the patient. When patients completed the questionnaire by themselves, there is a possibility of a confounding effect of depression on self-reported cognitive symptoms.

Second, because quite some time had passed after the cardiac surgery, patients could perhaps not remember the whole period since the surgery. This might be the reason why some patients with a confirmed delirium did not remember delirium, or remembered delirium when none was diagnosed.

Finally, due to the low number of patients it is not possible to draw far-reaching conclusions. Only the incidence of sleep disturbance was significantly higher in those who had experienced delirium. For the other outcomes like mortality, readmission, memory, and concentration problems, and dependency in activities of daily living we only see a consistent negative tendency in patients with delirium. Therefore, we only can say a postoperative delirium after cardiac surgery seems to be associated with increased mortality and a higher readmission rate to the hospital, as well as long-term cognitive and functional effects. Repeating the study with a higher number of patients is recommended.

Prevention and (or) early recognition of delirium must be improved. Early recognition of delirium symptoms enables the underlying cause to be diagnosed and treated and can prevent negative outcomes (7). Systematic interventions regarding medical, nurse-led, environmental, and educational items are effective in preventing delirium (16). The approach to delirium has shifted from ad hoc treatment to systematic screening and prevention. Management may be improved with primary prevention, early detection, and prompt management (17). In patients who develop postoperative delirium, interventions are needed to improve delirium treatment; providing adequate information to patients, their family, and their general practitioner, including the fact that these problems are very common. Possibly, interventions can be designed to stimulate cognitive functioning after delirium in cardiac surgery patients. 


\section{References}

(1) van Blanken G, Robben PBM. Delirium vaak niet herkend. Medisch Contact 2005;60:1724 -7.

(2) Koster S, Oosterveld FG, Hensens AG, Wijma A, van der Palen J. Delirium after cardiac surgery and predictive validity of a risk checklist. Ann Thorac Surg 2008;86:1883-7.

(3) Amador LF, Goodwin JS. Postoperative delirium in the older patient. J Am Coll Surg 2005;200:767-73.

(4) Bucerius J, Gummert JF, Borger MA, et al. Predictors of delirium after cardiac surgery delirium: effect of beatingheart (off-pump) surgery. J Thorac Cardiovasc Surg 2004;127: 57-64.

(5) Cole MG, McCusker J, Bellavance F, et al. Systematic detection and multidisciplinary care of delirium in older medical inpatients: a randomized trial. CMAJ 2002;167:753-9.

(6) Inouye SK, Bogardus ST Jr, Charpentier PA, et al. A multicomponent intervention to prevent delirium in hospitalized older patients. N Engl J Med 1999;340:669 -76.

(7) Schuurmans MJ, Duursma SA, Shortridge-Baggett LM. Early recognition of delirium: review of the literature. J Clin Nurs 2001;10:721-9.

(8) Francis J, Kapoor WN. Prognosis after hospital discharge of older medical patients with delirium. J Am Geriatr Soc 1992;40:601-6.

(9) Rockwood K, Cosway S, Carver D, Jarrett P, Stadnyk K, Fisk J. The risk of dementia and death after delirium. Age Ageing 1999;28:551- 6 .

(10) American Psychiatric Association. Diagnostic and statistical manual of mental disorders. 4th ed. Washington, DC; 1994.

(11) Whooley MA, de Jonge $P$, Vittinghoff $E$, et al. Depressive symptoms, health behaviors, and risk of cardiovascular events in patients with coronary heart disease. JAMA 2008; 300:2379-88.

(12) Detroyer E, Dobbels F, Verfaillie E, Meyfroidt G, Sergeant P, Milisen K. Is preoperative anxiety and depression associated with onset of delirium after 
cardiac surgery in older patients? A prospective cohort study. J Am Geriatr Soc 2008; 56:2278-84.

(13) Wang XS, Mei YQ, Li AP, et al. Depression before and after operation in patients undergoing coronary artery bypass grafting and the effect thereof on quality of life. Zhonghua Yi Xue Za Zhi (in Chinese)2008;88:3283- 6.

(14) Murphy BM, Elliott PC, Higgins RO, et al. Anxiety and depression after coronary artery bypass graft surgery: most get better, some get worse. Eur $\mathrm{J}$ Cardiovasc Prev Rehabil 2008;15:434-40.

(15) Loponen P, Luther M, Wistbacka JO, et al. Postoperative delirium and health related quality of life after coronary artery bypass grafting. Scand Cardiovasc J 2008;42;337-44.

(16) Kalisvaart CJ, Vreeswijk R, de Jonge JF, Milisen K. A systematic review of multifactorial interventions for primary prevention of delirium in the elderly. Tijdschr Gerontol Geriatr 2005;36:224 -31.

(17) Shah M, Jan F, Sule A. Approach is now screening, prevention, and recognition. BMJ 2007;334(7601):968. 


\section{Questionnaire follow-up study delirium}

1 Was there a re-admission to the hospital after the discharge from the hospital after your cardiac surgery?

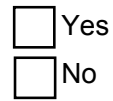

2 If yes, what was the reason for the re-admission to the hospital?

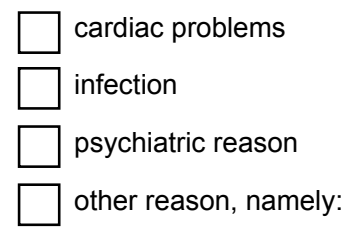

3 Did you have, more than in the time before you underwent the cardiac surgery, memory problems after discharge from the hospital?

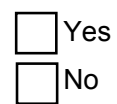

4 If yes, for how long did you have memory problems?

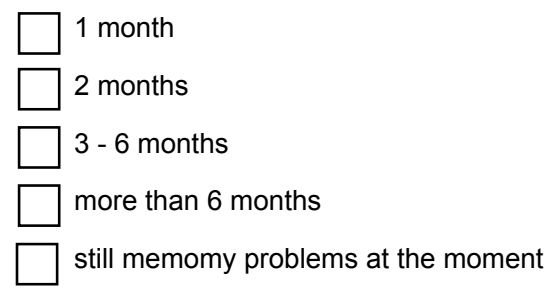

5 Did you have, more than in the time before you underwent the cardiac surgery, concentration problems after discharge from the hospital?

6 If yes, for how long did you have concentrations problems?

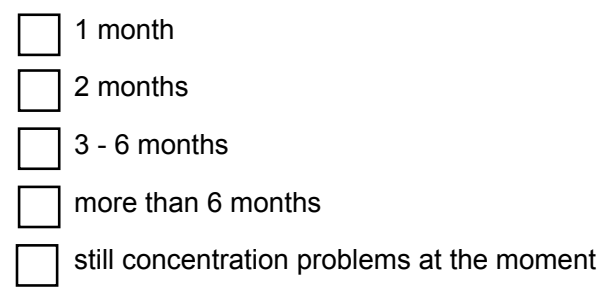

7 Have you been confused after discharge from the hospital?

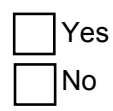

8 If yes, for how long have you been confused? 
9 Did you have sleep problems after discharge from the hospital?

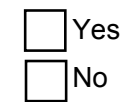

10 If yes, what kind of sleep problems did you have?

$$
\begin{array}{|l}
\square \\
\hline \square \text { "fall asleep" problems } \\
\text { "sleep on" problems }
\end{array}
$$

11 For how long did these sleep problems persist?

$$
\begin{aligned}
& \square 1 \text { month } \\
& \square 2 \text { months } \\
& \square 3 \text { - } 6 \text { months } \\
& \square \text { more than } 6 \text { months } \\
& \square \text { still sleep problems at the moment }
\end{aligned}
$$

12 Did you have bad dreams or nightmares after discharge from the hospital?

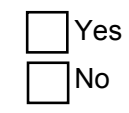

13 If yes, for how long did you have these bad dreams or nightmares?

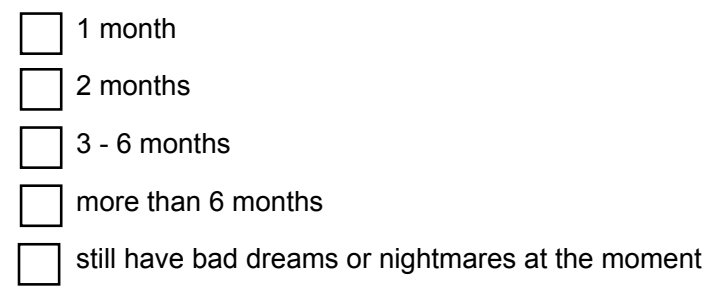

14 Did you have emotional problems (suddenly and / or often emotional like crying) after discharge from the hospital?

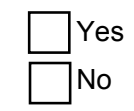

15 If yes, for how long did these emotional problems exist?

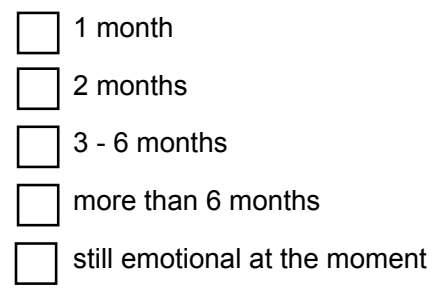

16 Were you independent in activities of daily living before the cardiac surgery (like bathing, dressing, going to the toilet)?

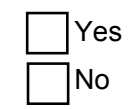

17 If not, what kind of help did you need?

$\square$ bathing and/or taking a shower
$\square$ dressing
$\square$ going to the toilet
$\square$ preparing meals


$\square$ other activity in daily living, namely:

18 Were you independent in activities of daily living after the cardiac surgery (bathing, dressing, going to the toilet)?

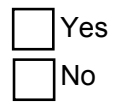

19 If not, what kind of help did you need?

$\square$ bathing and/or taking a shower
$\square$ dressing
$\square$ going to the toilet
$\square$ preparing meals
$\square$ other activity in daily living, namely:

20 For how long did you need help for activities in daily living?

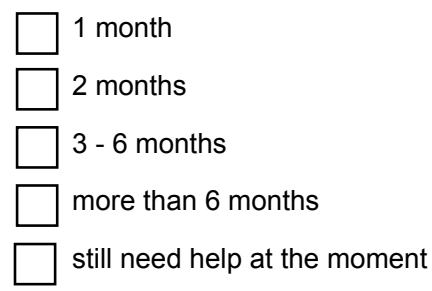

21 Were you mobile before the cardiac surgery (able to move yourself, eventual with help of a walking-stick, walker or wheelchair)?

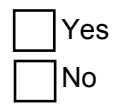

22 Were you less mobile after discharge from the hospital?

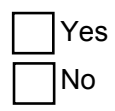

23 If yes, what was the reason why you were less mobile?

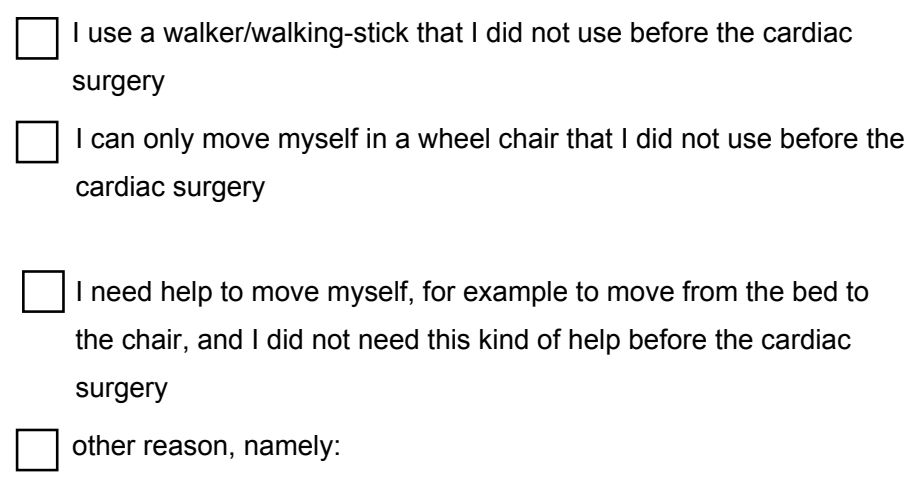

24 For how long did you need this help to be mobile?

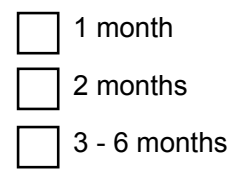




$$
\begin{aligned}
& \square \text { more than } 6 \text { months } \\
& \square \text { still need help at the moment }
\end{aligned}
$$

25 Have you been confused during your stay in the hospital because of the cardiac surgery?

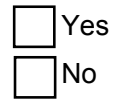

26 If yes, what do you remember of this confusion period?

$\square$ I saw and heard things that did not exist (for example animals or people)

$\square$ I did not know where I was

$\square$ I was anxious and very frightened

$\square$ I was very suspicious and did not trust anybody

other things, namely: 


\title{
Chapter 7
}

\section{Consequences of delirium after cardiac surgery}

\author{
Sandra Koster \\ Ab G. Hensens \\ Marieke J. Schuurmans \\ Job van der Palen
}

Accepted for publication in Ann Thorac Surg. 


\begin{abstract}
Background. Delirium is a transient mental syndrome characterized by disturbances in consciousness, cognition, and perception. Patients who undergo cardiac surgery, especially the elderly, have an increased risk of developing delirium. Generally, delirium during hospital admission is independently associated with many negative consequences such as higher mortality, increased length of hospital stay, nursing home placement after admission, and cognitive and functional decline. Methods. In this prospective follow-up study the short-form health survey with 36 questions (SF-36), the cognitive failure questionnaire (CFQ), and a purpose designed questionnaire were used six months after cardiac surgery in a cohort of 300 patients who underwent elective cardiac surgery, of which 52 patients $(17 \%)$ developed a postoperative delirium. Also mortality and readmission were assessed. Results. Postoperative delirium after cardiac surgery is associated with increased mortality (13.5\% in patients with postoperative delirium versus $2.0 \%$ in patients without postoperative delirium), more re- admissions to the hospital (45.7\% versus $26.5 \%$ ), and reduced quality of life. It is also associated with reduced cognitive functioning including failures in attention, memory, perception, and motor function, and finally delirium is associated with functional dysfunction such as independency in activities of daily living and mobility. Conclusions. A postoperative delirium after cardiac surgery is associated with many important consequences. These findings provide justification for intervention studies to evaluate whether delirium prevention, early recognition or treatment strategies, might improve postoperative functional and cognitive function.
\end{abstract}




\section{Introduction}

Delirium or acute confusion, is a transient mental syndrome characterized by disturbances in consciousness, cognition and perception (1). Patients who undergo cardiac surgery, especially the elderly, have an increased risk of developing delirium. The reported incidence of delirium in patients after cardiac surgery ranged from $3 \%$ (2) to $52 \%$ (3). In our observational cohort study the incidence of delirium following elective cardiac surgery was $21 \%$ (4). Developments in operative and anesthetic techniques have enabled older patients to undergo cardiac surgery (5), which, together with ageing of the population will lead to an increase in the incidence of delirium in the near future.

Delirium has been related to higher mortality, increased length of hospital stay, nursing home placement after admission, reduced quality of life, and cognitive and functional decline, in older general medical patients as well as in surgical patients (6-10).

In cardiac surgery specific, however, little is known about the consequences of postoperative delirium. Gottesman et al. recently found that delirium after cardiac surgery is a strong independent predictor of mortality up to 10 years post operatively (11). In our earlier cohort study of 112 elective cardiac surgery patients we found that a postoperative delirium after cardiac surgery seemed to be associated with increased mortality and re-admissions to the hospital, as well as poorer cognitive and functional outcomes (12). Due to the low number of patients it was not possible to draw firm conclusions. Therefore, we repeated the study in a larger cohort of patients and added new outcomes. The present study will examine the consequences of delirium, such as mortality after discharge, re-admission rate, cognitive and functional outcomes, and quality of life, after cardiac surgery.

\section{Materials and Methods}

Design and sample

Between October 2008 and January 2010 our study included 300 consecutive patients, 45 years and older, who underwent elective cardiac surgery at the Department of Cardiothoracic Surgery (see Table 1). 
Table 1. Baseline characteristics of the patients $(N=300)$

\begin{tabular}{|c|c|c|c|c|c|c|}
\hline & $\begin{array}{c}\text { Total } \\
N=300\end{array}$ & $\begin{array}{l}\text { No delirium } \\
\qquad N=248\end{array}$ & $\begin{array}{l}\text { Delirium } \\
\qquad \mathrm{N}=52\end{array}$ & $\begin{array}{c}\text { Relative } \\
\text { Risk }\end{array}$ & $95 \% \mathrm{Cl}$ & $\mathrm{p}$-value \\
\hline $\begin{array}{l}\text { Age (years) } \\
\text { (mean, SD) }\end{array}$ & 70.5 & $66.7(9.2)$ & $74.3(7.1)$ & & & $<0.001$ \\
\hline Age $\geq 70$ & 138 & $96(70 \%)$ & $42(30 \%)$ & 4.9 & $2.8-9.5$ & $<0.001$ \\
\hline$<70$ & 162 & $152(94 \%)$ & $10(6 \%)$ & & & \\
\hline Sex Male & 204 & $168(82 \%)$ & $36(18 \%)$ & 1.1 & $0.6-1.8$ & 0.83 \\
\hline Female & 96 & $80(83 \%)$ & $16(17 \%)$ & & & \\
\hline \multicolumn{7}{|l|}{ Type of surgery } \\
\hline CABG & 106 & $98(92 \%)$ & $8(8 \%)$ & & & $<0.001$ \\
\hline Valve & 118 & $98(83 \%)$ & $20(17 \%)$ & & & \\
\hline CABG+Valve & 52 & $21(40 \%)$ & $31(60 \%)$ & & & \\
\hline Other & 24 & $3(13 \%)$ & $21(87 \%)$ & & & \\
\hline
\end{tabular}

The Ethics Committee of Medisch Spectrum Twente was asked whether approval was needed. Because this was an observational study, without invasive procedures, approval was not necessary. Informed consent was obtained in accordance with the hospital's policy.

\section{Procedure}

Patients were followed from the time of admission until the time of discharge from the hospital. During hospitalization all patients were screened daily for delirium with the use of the DOS scale. Nurses rated their observation three times a day at the end of every shift, pre- and post operatively. Patients with a preoperative delirium according to the DOS scale were excluded. If the patient had not developed a postoperative delirium by day four, the DOS scale was not rated anymore. The DOS scale is a reliable and valid instrument to recognize delirium based on nurses' 
observations during regular care (13). The DOS scale describes typical behavioral patterns related to delirium in 13 statements or questions, which the observer has to answer with "never" (score $=0$ ) or "sometimes or always" (score $=1)$ if applicable (see Table 2). A DOS score of $\geq 3$ indicates delirium (13).

Six months after discharge we first ascertained whether patients had died. The 288 surviving patients were sent a purpose designed questionnaire (www.mst.nl/thoraxcentrum/appendix.pdf), the short form health survey questionnaire (SF-36) (14) and the cognitive failure questionnaire (CFQ) (15) to evaluate re-admission rates, quality of life, and cognitive and functional outcomes. When patients had not responded after one month, they were contacted by telephone and were asked to complete the three questionnaires.

Table 2. The working method of the DOS scale

The patient:
1. Dozes off during conversation or activities
2. Is easily distracted by stimuli from the environment
3. Loses attention to conversation or action
4. Does not finish question or answer
5. Gives answers that do not fit the question
6. Reacts slowly to instructions
7. Thinks to be somewhere else
8. Does not know which part of the day it is
9. Does not remember recent event
10. Is picking, disorderly, restless
11. Pulls IV tubes, feeding tubes, catheters etc.
12. Is easy or sudden emotional (frightened, angry, irritated)
13. Sees/hears things which are not there

Never $=0$ points; Sometimes or always $=1$ point.

A total score of three or more points indicate a delirium.

The purpose designed questionnaire to assess cognitive and functional outcomes contained questions on re-admission to the hospital, memory, concentration, confusion, sleep patterns, emotions, activities of daily living, mobility, and in case of a postoperative delirium the experience of the episode of confusion. We defined 
problems about memory, concentration, confusion etc. to be present when the patient felt, thought or believed to have a problem in this area. The hospital's Medical Computer System (MCS) was used to ascertain the mortality and readmission rates. The SF-36 is a multipurpose, 36-item survey that measures eight domains of health: physical functioning, role limitations due to physical health, bodily pain, general health perceptions, vitality, social functioning, role limitations due to emotional problems, and mental health. It yields scale scores for each of these eight health domains. The CFQ is a measure of self-reported deficits in the completion of simple everyday tasks that a person should normally be capable of completing without error and includes failures in attention, memory, perception, and motor function. The patient can answer the questions with "never", "rarely", "sometimes, "frequent" and "most of the time; the range of the scores is 0-100.

\section{Statistical Analysis}

The univariate association between postoperative delirium and mortality, readmission, quality of life and cognitive and functional outcomes was estimated. The independent two-tailed $t$ test was used to compare the means of variables in case of continuous normally distributed data. When data was not distributed normally, Wilcoxon's Rank Sum Test was used. The Chi-square test was used for the comparison of categorical variables between those with and without delirium and Relative Risks (RR) are presented. A correction for age was done using logistic regression analysis (with Odds Ratio's (OR)) or linear regression analysis, as appropriate.

\section{Results}

\section{Study population}

Three hundred patients were included in the study. Of these 300 patients, 52 $(17 \%)$ developed postoperative delirium as diagnosed with the Delirium Observation Screening (DOS) scale. The mean duration of delirium was in most of the patients 1-3 days, sometimes 4-7 days, and in two patients 11 and 14 days. In some patients the duration of delirium could not be estimated, because the patients were transferred to another hospital for further recovery after cardiac surgery. 
Almost all patients were treated with a low dose of Haloperidol (1-3 mg per day) and some patients with a dose of 5-15 mg per day. In two patients Haloperidol did not have any effect and in these patients the psychiatrist prescribed Quetiapine (XR 300 once a day, or 100-150 mg per day). 264 of the 288 non deceased patients returned the questionnaire, so the response rate was $91.7 \%$.

\section{Long-term outcomes of delirium after cardiac surgery}

Mortality (see Table 3)

Twelve patients (4\%) died during the follow-up period of six months: seven (13.5\%) of those developed a postoperative delirium and five $(2.0 \%)$ of those did not experience a postoperative delirium (Relative Risk (RR) 6.7; $p=0.001$ ). After correction for age the OR was $5.1(p=0.011)$.

\section{Re-admission (see Table 3)}

In 82 patients (29.7\%) there was a re- admission to the hospital: $21(45.7 \%)$ in the delirium group and $61(26.5 \%)$ in the non delirium group $(R R=1.72 ; p=0.010)$. Of 24 patients, of whom six patients developed delirium, we did not have information about the re-admission. Therefore, in Table 3 the number of patients with delirium is only 46 . In the 12 patients who died there was a re-admission to the hospital. The most commonly mentioned reason for re-admission was a cardiac problem $(52.2 \%)$. Correction for age led to an OR of $2.16(p=0.028)$.

Table 3. Mortality and re-admission to the hospital within six months following cardiac surgery in patients with and without a postoperative delirium ( $N=300$ for mortality and $N=276$ for re-admissions)

\begin{tabular}{|c|c|c|c|c|c|c|}
\hline & \multicolumn{3}{|c|}{ Died } & \multicolumn{3}{|c|}{ Re-admission } \\
\hline \multirow{5}{*}{ Delirium } & & Yes & No & & Yes & No \\
\hline & Yes & $7(13.5 \%)$ & $45(86.5 \%)$ & Yes & $21(45.7 \%)$ & $25(54.3 \%)$ \\
\hline & No & $5(2.0 \%)$ & $243(98.0 \%)$ & No & $61(26.5 \%)$ & $169(73.5 \%)$ \\
\hline & \multicolumn{3}{|c|}{$\mathrm{RR}=6.7(95 \% \mathrm{Cl} 2.2-20.2)$} & & \multicolumn{2}{|c|}{$\mathrm{RR}=1.72(95 \% \mathrm{Cl} 1.2-2.5)$} \\
\hline & \multicolumn{3}{|c|}{$P=0.001$} & & \multicolumn{2}{|c|}{$P=0.010$} \\
\hline
\end{tabular}

Cognitive and functional outcomes (see Table 4)

According to the questionnaire, there were no significant differences between patients with and without a postoperative delirium in memory, concentration, 
confusion, sleep disturbance, and emotions. When results were corrected for age, in the event of delirium the incidence of dependency in activities of daily living was not significantly higher anymore. The results of the other cognitive and functional outcomes remained largely unchanged after correction for age.

Table 4. Cognitive and functional outcomes six months after cardiac surgery in patients with and without a postoperative delirium $(N=264)$

\begin{tabular}{|c|c|c|c|c|c|c|c|}
\hline & & Delirium & No delirium & $\mathrm{OR}^{1}$ & p-value ${ }^{2}$ & $\mathrm{OR}^{3}$ & p-value ${ }^{4}$ \\
\hline \multirow[t]{2}{*}{ Memory problems } & Yes & $17(43.6 \%)$ & $68(30.2 \%)$ & 1.78 & 0.136 & 1.92 & 0.080 \\
\hline & No & $22(56.4 \%)$ & $157(69.8 \%)$ & & & & \\
\hline \multirow[t]{2}{*}{ Concentration problems } & Yes & $13(33.3 \%)$ & $66(29.5 \%)$ & 1.20 & 0.627 & 1.56 & 0.263 \\
\hline & No & $26(66.7 \%)$ & $158(70.5 \%)$ & & & & \\
\hline \multirow[t]{2}{*}{ Confusion } & Yes & $7(17.9 \%)$ & $29(12.9 \%)$ & 1.47 & 0.402 & 1.41 & 0.472 \\
\hline & No & $32(82.1 \%)$ & $195(87.1 \%)$ & & & & \\
\hline \multirow[t]{2}{*}{ Sleep disturbance } & Yes & $14(35.9 \%)$ & $88(39.3 \%)$ & 0.87 & 0.689 & 1.02 & 0.968 \\
\hline & No & $25(64.1 \%)$ & $136(60.7 \%)$ & & & & \\
\hline \multirow[t]{2}{*}{ Having nightmares } & Yes & $10(25.6 \%)$ & $26(11.6 \%)$ & 2.64 & 0.018 & 2.62 & 0.032 \\
\hline & No & $29(74.4 \%)$ & $199(88.4 \%)$ & & & & \\
\hline \multirow[t]{2}{*}{ Emotional problems } & Yes & $17(43.6 \%)$ & $95(42.2 \%)$ & 1.06 & 0.873 & 1.29 & 0.490 \\
\hline & No & $22(56.4 \%)$ & $130(57.8 \%)$ & & & & \\
\hline \multirow[t]{2}{*}{ Dependency in ADL } & Yes & $19(48.7 \%)$ & $62(27.6 \%)$ & 2.50 & 0.008 & 1.90 & 0.084 \\
\hline & No & $20(51.3 \%)$ & $163(72.4 \%)$ & & & & \\
\hline \multirow[t]{2}{*}{ Dependency in mobility } & Yes & $18(46.2 \%)$ & $40(17.8 \%)$ & 3.96 & $<0.001$ & 2.61 & 0.014 \\
\hline & No & $21(53.8 \%)$ & $185(82.2 \%)$ & & & & \\
\hline
\end{tabular}

${ }^{1}$ Unadjusted Odds Ratio; ${ }^{2}$ Unadjusted p-value; ${ }^{3}$ Odds Ratio adjusted for age; ${ }^{4}$ P-value adjusted for age.

After discharge from the hospital 85 patients (32.2\%) had memory problems and many of them $(32.9 \%)$ still had memory problems after six months. Seventy nine patients $(30.0 \%)$ had concentration problems at discharge, and $26.6 \%$ had these problems 3-6 months after discharge or still had concentration problems at the time 
of the questionnaire. Thirty-six patients $(13.7 \%)$ were disorientated after discharge of which $13.9 \%$ still exhibited these problems at six months. Hundred and two patients (38.8\%) experienced sleep disturbances after discharge from the hospital. Hundred and twelve patients (42.4\%) had emotional problems after discharge. There was a significant difference in the duration of the emotional problems in patients with and without a delirium. In those with a postoperative delirium $58.8 \%$ still had emotional problems at six months compared to $23.2 \%$ of the patients without a postoperative delirium $(p=0.03)$.

There were statistically significant differences between patients with and without a postoperative delirium with regard to experiencing nightmares or bad dreams, the activities of daily living, and dependency in mobility. Thirty six patients (13.6\%) experienced nightmares or bad dreams after discharge of which sixteen patients (44.4\%) still experienced nightmares at six months. Almost all patients (94\%) were independent in activities of daily living before they underwent cardiac surgery. After discharge from the hospital 81 patients $(30.7 \%)$ were in some way dependent in activities of daily living. The most commonly mentioned dependency was taking a shower $(67.5 \%)$; most of the patients $(40.3 \%)$ were independent within one month after discharge from the hospital. In the event of delirium, the incidence of dependency in activities of daily living was significantly higher $(p=0.008)$. When corrected for age, dependency in activities of daily living was no longer significantly higher $(p=0.084)$. Almost all patients $(95 \%)$ were mobile before cardiac surgery. After discharge 58 patients (22.0\%) were in some way less mobile in comparison with the period before cardiac surgery. Most commonly mentioned was the use of a walking-stick or a walker (57.6\%). In the event of delirium, the number of patients that reported to be less mobile was significantly higher $(p<0.001)$ and also the duration of the "less mobile period" was significantly longer in the event of delirium. When corrected for age the number of patients with mobility problems was still significantly higher in patients with postoperative delirium $(p=0.014)$.

\section{Subjective cognitive function (See Table 5)}

The mean total score on the CFQ was $31.8(S D=14.6)$ in patients with a postoperative delirium and $25.3(\mathrm{SD}=12.2)$ in those without a postoperative 
delirium (difference 6.5 (95\% Confidence Interval $(95 \% \mathrm{Cl}) 2.2-10.8 ; \mathrm{p}=0.003)$. When corrected for age the difference was $5.7(95 \% \mathrm{Cl} 1.3-10.2 ; \mathrm{p}=0.012)$. In eight questions there was a significant difference between patients with and without delirium with regard to the domains of memory, concentration, acting, and observation.

\section{Quality of life (See Table 6)}

Only two domains of the SF-36 were normally distributed: vitality and general health perceptions. In seven of the eight domains of the SF-36 patients with a postoperative delirium had significantly lower scores: physical functioning, role limitations due to physical health, bodily pain, general health perceptions, vitality, social functioning, and role limitations due to mental health. Only in role limitations due to emotional problems there was no significant difference. No correction for age was done because only in the domain of physical functioning there was a very weak correlation between age and physical functioning (Spearman's Rho -0.33). All other correlations were smaller than 0.2 and not significant.

\section{Discussion}

A postoperative delirium after cardiac surgery is associated with increased mortality and a higher re-admission rate to the hospital, lower quality of life, as well as cognitive failure as measured with the $C F Q$, and functional dysfunction like dependency in ADL and reduced mobility. Because we assumed age could be a confounder, we corrected the outcomes for age. When we corrected for age, in the event of delirium only the incidence of dependency in activities of daily living was no longer significantly higher, but in the other consequences the correction for age did not influence the results. There was a very weak correlation between age and the domain physical functioning of the SF-36, but because physical functioning was not distributed normally, it was not possible to do a correction for age.

These findings correspond well with the literature that shows that in general delirium is related to nursing home placement and reduced cognitive and functional recovery $(6-10)$. 
Table 5. Cognitive failure scores (Mean (SD)) as measured with the cognitive failure questionnaire (CFQ) (scale 0-100), six months after cardiac surgery in patients with $(N=40)$ and without $(N=223)$ a postoperative delirium $(\mathrm{N}=263)$

\begin{tabular}{|c|c|c|c|c|}
\hline & Delirium & & & \\
\hline & Yes & No & $\begin{array}{l}\text { Difference } \\
(95 \% \mathrm{Cl})\end{array}$ & p-value \\
\hline Cognitive failure total score & $31.8(14.6)$ & $25.3(12.2)$ & $6.5(2.2 ; 10.8)$ & 0.003 \\
\hline Reading & $1.75(1.03)$ & $1.39(0.87)$ & $0.36(0.06 ; 0.66)$ & 0.020 \\
\hline Forgetting things at home & $1.40(0.90)$ & $1.13(0.81)$ & $0.27(-0.01 ; 0.55)$ & 0.057 \\
\hline Missing signposts & $1.15(1.05)$ & $0.85(0.76)$ & $0.30(-0.05 ; 0.65)$ & 0.088 \\
\hline Confuse left and right & $0.80(0.91)$ & $0.55(0.79)$ & $0.25(-0.02 ; 0.53)$ & 0.069 \\
\hline Hit someone accidentally & $0.53(0.75)$ & $0.29(0.54)$ & $0.23(-0.02 ; 0.48)$ & 0.066 \\
\hline $\begin{array}{l}\text { Don't remember to turn off the gas } \\
\text { etc. }\end{array}$ & $1.20(0.82)$ & $0.96(0.81)$ & $0.25(-0.03 ; 0.52)$ & 0.080 \\
\hline Do not listen at people's names & $1.58(1.04)$ & $1.30(1.02)$ & $0.28(-0.07 ; 0.62)$ & 0.119 \\
\hline Blurting & $1.00(0.64)$ & $0.94(0.76)$ & $0.06(-0.19 ; 0.31)$ & 0.648 \\
\hline $\begin{array}{l}\text { Not notice someone during an } \\
\text { activity }\end{array}$ & $1.60(0.78)$ & $1.26(0.86)$ & $0.34(0.06 ; 0.63)$ & 0.018 \\
\hline Being anxious and later regret it & $1.13(0.88)$ & $1.16(0.76)$ & $-0.03(-0.30 ; 0.23)$ & 0.811 \\
\hline $\begin{array}{l}\text { Leave important letters unanswered } \\
\text { for several days }\end{array}$ & $1.15(1.03)$ & $0.70(0.88)$ & $0.46(0.15 ; 0.76)$ & 0.004 \\
\hline Not remembering usual streets & $0.95(0.88)$ & $0.55(0.71)$ & $0.40(0.15 ; 0.65)$ & 0.002 \\
\hline Not finding things in the supermarket & $1.35(0.95)$ & $1.02(0.87)$ & $0.33(0.03 ; 0.63)$ & 0.029 \\
\hline
\end{tabular}




\begin{tabular}{|c|c|c|c|c|}
\hline & Delirium & & & \\
\hline & Yes & No & $\begin{array}{l}\text { Difference } \\
(95 \% \mathrm{Cl})\end{array}$ & $p$-value \\
\hline Not knowing how to use words & $1.18(0.81)$ & $0.92(0.82)$ & $0.25(-0.03 ; 0.53)$ & 0.076 \\
\hline Difficulties in making a decision & $1.60(0.98)$ & $1.14(0.84)$ & $0.46(0.17 ; 0.75)$ & 0.002 \\
\hline Forgetting appointments & $1.28(1.06)$ & $0.89(0.78)$ & $0.39(0.03 ; 0.74)$ & 0.033 \\
\hline Not remember where things were put & $1.58(0.81)$ & $1.37(0.86)$ & $0.20(-0.09 ; 0.49)$ & 0.167 \\
\hline Throwing things away, unintended & $0.90(0.74)$ & $0.67(0.68)$ & $0.23(-0.02 ; 0.49)$ & 0.072 \\
\hline Daydreaming & $1.13(0.79)$ & $0.93(0.82)$ & $0.19(-0.08 ; 0.47)$ & 0.172 \\
\hline Forgetting names & $2.05(0.99)$ & $1.90(0.98)$ & $0.15(-0.19 ; 0.49)$ & 0.369 \\
\hline Not finishing jobs & $1.23(1.00)$ & $0.92(0.75)$ & $0.31(-0.03 ; 0.64)$ & 0.072 \\
\hline Not finding the right words & $2.03(0.66)$ & $1.88(0.86)$ & $0.14(-0.14 ; 0.42)$ & 0.322 \\
\hline Forgetting what to buy & $1.00(0.96)$ & $0.73(0.78)$ & $0.27(-0.01 ; 0.54)$ & 0.055 \\
\hline Dropping things & $0.95(0.88)$ & $0.77(0.79)$ & $0.18(-0.09 ; 0.45)$ & 0.195 \\
\hline Having no topics to talk about & $1.30(0.82)$ & $1.08(0.89)$ & $0.22(-0.07 ; 0.52)$ & 0.140 \\
\hline
\end{tabular}

In our earlier study we concluded that a postoperative delirium after cardiac surgery seems to be associated with increased mortality and re-admissions to the hospital, as well as poorer cognitive and functional outcomes. Due to the low number of patients it was not possible to draw far-reaching conclusions; we only saw a consistent negative tendency in patients with delirium. In our current study the follow-up was only six months compared to the earlier study where the followup was after one year.

There was no significant difference in the level of emotional problems between patients with or without a postoperative delirium as measured with the SF-36 and the purpose designed questionnaire. Emotional problems might 
Table 6. Quality of life (with SF-36 ${ }^{1}$ ) six months after cardiac surgery in patients with and without a postoperative delirium $(N=264)$

\begin{tabular}{|c|c|c|c|c|}
\hline Domain & Delirium & Mean (SD) & Median $\left(\mathrm{IQR}^{2}\right)$ & $p$-value ${ }^{3}$ \\
\hline \multirow[t]{2}{*}{ Physical functioning } & Yes & & $65(35-80)$ & \\
\hline & No & & $85(65-100)$ & 0.000 \\
\hline \multirow[t]{2}{*}{ Social functioning } & Yes & & $75(50-88)$ & \\
\hline & No & & $88(75-100)$ & 0.001 \\
\hline \multicolumn{5}{|l|}{ Role limitations due } \\
\hline \multirow[t]{2}{*}{ to physical health } & Yes & & $50(0-100)$ & \\
\hline & No & & $75(25-100)$ & 0.050 \\
\hline \multicolumn{5}{|l|}{ Role limitations due } \\
\hline \multirow[t]{2}{*}{ to emotional problems } & Yes & & $100(33-100)$ & \\
\hline & No & & $100(67-100)$ & 0.106 \\
\hline \multirow[t]{2}{*}{ Mental health } & Yes & & $80(60-84)$ & \\
\hline & No & & $84(72-92)$ & 0.003 \\
\hline \multirow[t]{2}{*}{ Vitality } & Yes & $58(23)$ & & \\
\hline & No & $67(19)$ & & 0.006 \\
\hline \multirow[t]{2}{*}{ Bodily pain } & Yes & & $78(57-100)$ & \\
\hline & No & & $90(67-100)$ & 0.035 \\
\hline \multicolumn{5}{|l|}{ General health } \\
\hline \multirow[t]{2}{*}{ perceptions } & Yes & $56(21)$ & & \\
\hline & No & $66(21)$ & & 0.008 \\
\hline
\end{tabular}

${ }^{1}$ SF-36= short form health survey questionnaire. ${ }^{2}$ IQR: Inter Quartile Range ${ }^{3}$ The T-test was used for vitality and general health perceptions and the Wilcoxon's Rank Sum Test was used for: physical functioning, social functioning, role limitations due to physical health, role limitations due to emotional problems, mental health, and bodily pain.

be more a result of cardiac surgery or may pre-exist in patients with cardiac diseases, and may not be dependent on having a postoperative delirium or not. Emotional problems such as anxiety and depression are common in patients with coronary heart disease. Recently, Spezzaferri et al. found that 8-12 days after CABG a high prevalence of depression and state anxiety was observed (16). In another recent study the authors found that cardiac surgery patients who undergo long procedures, commonly have postoperative anxiety and tension (17). In cardiac surgery little is known about the cognitive and functional outcomes following a postoperative delirium. It may exert a negative influence on health related quality of life during the first six months after coronary artery bypass 
grafting (18). Rudolph et al. found that functional decline occurred in $36.3 \%$ at one month and in $14.6 \%$ at 12 months (19). In our earlier study a consistent negative tendency concerning cognitive and functional outcomes was found in patients with delirium (12), but it was not possible to draw firm conclusions.

To examine the cognitive function we used two instruments: our own purpose designed questionnaire and the CFQ. In the questionnaire one question addressed concentration, and in the CFQ five questions are about concentration. In the questionnaire there was no significant difference in concentration between patients with and without delirium, whereas in three of the six questions of the CFQ there was a significant relationship between concentration and postoperative delirium. The results of our questionnaire concerning the cognitive function and CFQ are difficult to compare, because the CFQ is a more specific and comprehensive list. Because the questionnaire is not a valid instrument to measure the cognitive function and the CFQ is a valid instrument, the outcome of the questionnaire concerning the cognitive function can be questioned.

In contrast to findings of other studies we did not find a difference in patients with and without delirium in confusion six months after cardiac surgery. Although we have no data to support this, we hypothesize that in our patient group the presurgery cognitive status was relatively good compared to other studies.

A number of critical considerations pertaining to our study can be made. A psychiatrist was not consulted to diagnose delirium, but the diagnosis delirium was based on the DOS scale. Only in patients in whom the treatment of delirium was not successful or the delirium was very severe, a psychiatrist was consulted. In all these patients the psychiatrist diagnosed delirium. With a DOS score $<3$ we assumed that there was no delirium. It is very unlikely that a delirium was present in patients with a DOS score $<3$ because of the similarity between the DOS scale items and the diagnostic criteria for delirium. Also, in an earlier study the validity of the DOS scale was very accurate with a sensitivity of $100 \%$ and a specificity of $96.6 \%(20)$. Therefore, using the DOS scale has probably not influenced the results of the study. Another limitation of our study is the fact that we did not see the patient face to face, but we used a questionnaire. The use of an interview might 
have rendered more specific information. Another point is that although we sent the questionnaire to the patients, we cannot be sure whether the questionnaire was completed by the patients themselves. It is possible that spouses or significant others completed the questionnaire or influenced the answers of the patient. When patients completed the questionnaire by themselves, there is a possibility of a confounding effect of depression on self-reported cognitive symptoms.

Our findings provide justification for intervention studies to evaluate whether delirium prevention, early recognition or treatment strategies might improve postoperative functional and cognitive function and thereby the quality of life. To prevent delirium it is important to identify the risk factors for delirium in patients when they present themselves to the hospital and observe any changes in these risk factors during the admission (21). The initial management of delirium according to the National Institute for Health and Clinical Excellence (NICE) guideline is to identify and manage the possible underlying cause(s) of delirium. Next it is important to ensure effective communication and reorientation, consider involving family, friends, and other caregivers to help with this and provide a suitable care environment (21). Finally, possibly interventions can be designed to stimulate cognitive and functional functioning following delirium in cardiac surgery patients.

\section{References}

(1) van Blanken G, Robben PBM: Delirium vaak niet herkend. Medisch Contact. 2005; 60:1724-7.

(2) Norkiene I, Ringaitiene D, Misiuriene I, Samalavicius R, Bubulis R, Baublys A, Uzdavinys $G$ : Incidence and precipitating factors of delirium after coronary artery bypass grafting. Scand Cardiovasc J. 2007; 41:180-5.

(3) Rudolph JL, Jones RN, Levkoff SE, Rockett C, Inouye SK, Sellke FW, Khuri SF, Lipsitz LA, Ramlawi B, Levitsky S, Marcantonio ER: Derivation and validation of a preoperative prediction rule for delirium after cardiac surgery. Circulation. 2009; 119:229-36. 
(4) Koster S, Oosterveld FG, Hensens AG, Wijma A, van der Palen J: Delirium After Cardiac Surgery and Predictive Validity of a Risk Checklist. Ann Thorac Surg; 2008; 86:1883-7.

(5) Yildizeli B, Ozyurtkan MO, Batirel HF, Kuscu K, Bekiroglu N, Yuksel M: Factors associated with postoperative delirium after thoracic surgery. Ann Thorac Surg. 2005; 79:1004-9.

(6) Amador LF, Goodwin JS: Postoperative delirium in the older patient. J Am Coll Surg. 2005; 200:767-73.

(7) Bucerius J, Gummert JF, Borger MA, Walther T, Doll N, Falk V, Schmitt DV, Mohr FW: Predictors of delirium after cardiac surgery delirium: effect of beating-heart (off-pump) surgery. J Thorac Cardiovasc Surg. 2004; 127:5764.

(8) Cole MG, McCusker J, Bellavance F, Primeau FJ, Bailey RF, Bonnycastle MJ, Laplante J: Systematic detection and multidisciplinary care of delirium in older medical inpatients: a randomized trial. CMAJ. 2002; 167:753-9.

(9) Inouye SK, Bogardus ST, Jr., Charpentier PA, Leo-Summers L, Acampora D, Holford TR, Cooney LM Jr: A multicomponent intervention to prevent delirium in hospitalized older patients. N Engl J Med. 1999; 340:669-76.

(10) Schuurmans MJ, Duursma SA, Shortridge-Baggett LM: Early recognition of delirium: review of the literature. J Clin Nurs. 2001; 10:721-9.

(11) Gottesman RF, Grega MA, Bailey MM, Pham LD, Zeger SL, Baumgartner WA, Selnes OA, McKhann JM: Delirium after coronary artery bypass graft surgery and late mortality. Ann Neurol. 2010; 67:338-44.

(12) Koster S, Hensens AG, van der Palen J: The long-term cognitive and functional outcomes of postoperative delirium after cardiac surgery. Ann Thorac Surg. 2009; 87:1469-74.

(13) Schuurmans MJ, Shortridge-Baggett LM, Duursma SA: The Delirium Observation Screening Scale: a screening instrument for delirium. Res Theory Nurs Pract. 2003; 17:31-50.

(14) Aaronson NK, Muller M, Cohen PD, Essink-Bot ML, Fekkes M, Sanderman $\mathrm{R}$, Sprangers MA, te Velde A, Verrips E: Translation, validation, and norming 
of the Dutch language version of the SF-36 Health Survey in community and chronic disease populations. J Clin Epidemiol. 1998; 51:1055-68.

(15) Broadbent DE, Cooper PF, FitzGerald P, Parkes KR: The Cognitive Failures Questionnaire (CFQ) and its correlates. Br J Clin Psychol. 1982; 21:1-16.

(16) Spezzaferri R, Modica M, Racca V, Ripamonti V, Tavanelli M, Brambilla G, Ferratini M: Psychological disorders after coronary artery by-pass surgery: a one-year prospective study. Monaldi Arch Chest Dis. 2009; 72:200-5.

(17) Bauer BA, Cutshall SM, Wentworth LJ, Engen D, Messner PK, Wood CM, Brekke KM, Kelly RF, Sundt TM: Effect of massage therapy on pain, anxiety, and tension after cardiac surgery: a randomized study. Complement Ther Clin Pract. 2010; 16:70-5.

(18) Loponen P, Luther M, Wistbacka JO, Nissinen J, Sintonen H, Huhtala H, Tarkka MR: Postoperative delirium and health related quality of life after coronary artery bypass grafting. Scand Cardiovasc J. 2008; 4:1-8.

(19) Rudolph JL, Inouye SK, Jones RN, Yang FM, Fong TG, Levkoff SE, Marcantonio ER: Delirium: an independent predictor of functional decline after cardiac surgery. J Am Geriatr Soc. 2010; 58:643-9.

(20) Koster S, Hensens AG, Oosterveld FG, Wijma A, van der Palen J: The delirium observation screening scale recognizes delirium early after cardiac surgery. Eur J Cardiovasc Nurs. 2009; 8:309-14.

(21) Young J, Murthy L, Westby M, Akunne A, O'Mahony R: Diagnosis, prevention, and management of delirium: summary of NICE guidance. BMJ. 2010; 341:3704. 


\section{Chapter 8}

Discussion 


\section{Introduction}

This thesis describes the results of studies on the recognition, risk factors, and consequences of delirium in cardiac surgery patients. Delirium is one of the most frequent forms of psychopathology in elderly patients. Patients who undergo cardiac surgery have an increased risk of developing delirium (1). Given the far reaching consequences of delirium and the increasing incidence of delirium in the foreseeable future this topic has a major importance.

Delirium was first reported in cardiac surgery over forty years ago (2). Within the last decade not much research was done in the field of delirium. In the Netherlands van der Mast is one of the latest researchers who studied delirium in cardiac surgery patients (3-8). At the moment much emphasis is given to delirium on the ICU, however on delirium in patients in general wards still much is unknown. Despite studies about independent risk factors for delirium $(9 ; 10)$ there is no validated preoperative prediction model to identify patients at risk for delirium after cardiac surgery. The risk model developed in our study, including seven risk factors: older age ( $\geq 70$ years), cognitive impairment, number of co-morbidities, history of delirium, alcohol use, type of surgery, and Euroscore, will aid nurses, doctors and other clinicians caring for cardiac surgery patients to improve the care and cure of cardiac surgery patients and their caregivers.

The Inspection of Healthcare in the Netherlands reported in 2005 that a delirium is often overlooked or misdiagnosed in hospitalized patients (11). They recommended in their report to introduce protocols or guidelines to recognize a delirium in an earlier stage and start earlier with the treatment. In 1999 Inouye already stated that delirium is a symptom of how hospital care fails in older persons and also is a window to improve quality of hospital care (12). A delirium can serve as a marker of the quality of hospital care and nowadays we do use delirium as a marker of the quality of hospital care. Last year the government has introduced "frail elderly" at risk for functional decline as one of the 10 themes of the safety management system (VMS) that underlines the importance of this topic. Functional decline is a common and serious problem in older hospitalized patients, resulting in a change in quality of life and lifestyle. Studies have shown that $30-60 \%$ of older 
people develop new dependencies in activities of daily living (ADL) during their hospital stay. Adverse health outcomes such as mortality, a prolonged hospital stay, nursing home placement, and increased dependency of older people at home are the results. Not only the personal costs are high but, in a rapid growing older population, the impact on health-care costs is also high (13). Delirium is an important part of the safety management program.

The studies presented in this thesis were designed to study the possibility to develop a delirium risk checklist to identify patients with an increased risk of postoperative delirium following elective cardiac surgery. All studies were conducted in cardiac surgery patients and one systematic review was done. In order to identify patients with an increased risk of postoperative delirium following cardiac surgery we first studied the Delirium Observation Screening (DOS) scale in cardiac surgery patients. After that two studies examined the predictive validity of a risk checklist for delirium and finally two studies regarded the consequences of delirium after cardiac surgery.

This final chapter puts the studies in a broader perspective. The methodological issues are discussed, the main conclusions are further outlined and implications for clinical practice and further research are described.

\section{Methodological issues}

Design and samples

In order to identify patients with an increased risk of postoperative delirium following cardiac surgery two prospective observational studies with elective cardiac surgery patients were performed. Based on other studies, the expectation of the incidence delirium was $20 \%(5 ; 11)$. The first study with 112 patients showed an incidence of delirium of $21 \%$, while the second study with 300 patients showed an incidence of $17 \%$. The incidence in the first study corresponds well with the incidence of $25 \%$ reported by the Inspection of Healthcare according to van Blanken and Robben (11), and the study by van der Mast et al. (5) who found a postoperative delirium incidence of $20 \%$ in patients 60 years and older who underwent cardiac surgery. The incidence in the second study was somewhat lower. This discrepancy is possibly due to the nurses who were well informed about 
delirium including risk factors, prevention, and interventions. This may have contributed to appropriate preventive interventions that probably had a positive effect on the incidence of delirium. Another explanation can be the use of only the Delirium Observation Screening (DOS) scale in the second study, whereas in the first study also the psychiatrist was consulted. This might have led to some under diagnosis.

The mean duration of postoperative delirium was only two and a half days, where previous studies, and also the delirium guideline (3) have reported delirium duration from several days to several weeks. This discrepancy is possibly due to the use of the DOS scale, which may allow earlier delirium recognition, and combined with earlier consultation of the psychiatrist, also for earlier resolution of delirium. Furthermore, prior to the start of the study, nurses were informed about delirium including risk factors, prevention, and interventions. This may also have contributed to earlier recognition of delirium and hence appropriate interventions such as orientating the patient as necessary, correcting fluid balance, and providing quiet surroundings, et cetera. In previous studies it was found that the education of nurses and the initiation of nursing interventions had a positive effect on early delirium recognition and reduces the duration of delirium (14).

All the patients included in the studies were elective patients, since the focus of our studies was on preoperative risk factor identification, which is not feasible in non elective patients. It is possible that the incidence of delirium in non elective patients is higher. However, it is likely that the risk checklist can also be used in non elective patients to recognize delirium in an early stage after cardiac surgery.

\section{Procedures}

Before the first study the nurses of the ICU and general wards were informed about delirium, the risk factors, prevention, and treatment. This can have influenced the low duration of delirium in comparison with the literature.

In the first study the DOS scale was used pre- and post operatively to assess whether patients had developed delirium. In several studies the DOS scale was tested in hip fracture patients and patients admitted to the Department of geriatric medicine. In these studies the DOS scale showed high internal consistency (0.93- 
0.96) (15-18). The predictive validity against the diagnosis of delirium made by a geriatrician was also good in the above mentioned studies. The sensitivity of the DOS scale was $89-100 \%$ with a specificity of $68-88 \%(15 ; 16 ; 18)$.

The psychiatrist was consulted when the DOS score was 2 or more to confirm or refute the diagnosis delirium, so since there was a potential for delirium, this might have biased the psychiatrist to expect delirium. Also the diagnosis by a single psychiatrist can be discussed because of the personal interpretation. However, in practice, it was not possible to consult two or more psychiatrists to assess delirium at the same time. Internationally, the most common used instrument to diagnose delirium is the Confusional Assessment Method (CAM) (19), but this instrument also does not have a $100 \%$ sensitivity and specificity. There is a lack of a uniform gold standard to diagnose delirium.

\section{Validity issues}

This thesis contains two studies about the delirium risk checklist. The first study was intentional performed in a relative small population to gain a first idea on delirium, the risk factors of delirium, and consequences of delirium in cardiac surgery patients.

We repeated our first study to validate our delirium risk checklist not only statistically, but also in real life practice. Most of the time researchers do not repeat a study or validate their model only statistically, for example with bootstrapping. Because we want to use the risk checklist to identify patient at risk for delirium it is important to be sure the risk factors are true independent risk factors. For example we found a disturbance in electrolytes as a potential risk factor in the first study. If we had not repeated our study we would have identified patients at risk for delirium who are not really at risk for delirium. When we use the risk checklist for an intervention study, especially for a medical intervention, it is important to only treat patients who are really at risk for delirium. To ensure that the risk factors are true independent risk factors it is necessary to repeat studies concerning prognostic research. 
There is no simple singular clinical pathway of delirium, it is a complex syndrome. But with the outcomes of prognostic studies it is possible to make one step further ahead.

\section{Assessment}

\section{Diagnosis of delirium}

In the first study the DOS scale was used to assess delirium and the psychiatrist was consulted to confirm or refute the diagnosis delirium. In the same study the DOS scale was validated. The sensitivity and specificity of the DOS scale was $100 \%$ and $96.6 \%$ respectively, so the outcome of the DOS scale and the psychiatrist were almost the same. Only on the operation day there were some patients who experienced a delirium according to the DOS scale, whereas the psychiatrist did not find one. After the first day the outcome of the DOS scale and the psychiatrist were identical. According to the hospital's policy, also in the ICU we used the DOS scale to assess delirium. In three patients there was a delirium according to the DOS scale, but the psychiatrist did not find one. It is plausible that delirium according to the DOS scale was influenced by the side effects of the recent narcosis. In intubated intensive care patients the DOS scale is probably not the best instrument. The NEECHAM Confusion Scale ICU or the CAM-ICU are probably more suitable for this kind of patients $(20 ; 21)$. In further studies we will use these instruments and compare them with the DOS scale.

\section{Risk checklist of delirium}

Prior to our studies, there was no model available that was able to predict postoperative delirium. Therefore, based on finding on a literature review, the delirium risk checklist was developed to identify patients with an increased risk of postoperative delirium after elective cardiac surgery. With the risk checklist preventive interventions, such as a program of proactive geriatric consultation, complement nurture and fluid if necessary, or Haloperidol prophylaxis, can be taken for patients at high risk for postoperative delirium and/or early recognition of delirium can be realized. 
Some of the predisposing risk factors were collected from medical records. For example the diagnosis dementia was taken from the patient's file, but was not assessed with a preoperative cognitive assessment, so it is possible that patients with dementia or a depression were missed.

To assess the nutritional status the Short Nutritional Assessment Questionnaire (SNAQ) was used. Probably in cardiac surgery patients this instrument is not the best instrument. Because many patients have edema, loss of weight is not the most suitable parameter and it is possible there were more patients with a poor nutritional status than we have found.

In the first study two independent predictors of postoperative delirium after cardiac surgery were found: electrolyte disturbance and Euroscore. Considering that the Euroscore itself contains relevant risk factors for mortality (age, cognitive impairment, etc.), a positive correlation between the Euroscore and postoperative delirium is not too farfetched. In the second study the Euroscore could again predict a postoperative delirium in patients who underwent elective cardiac surgery. This relation was also observed in a recently published study (22), so the Euroscore seems to be a stable predictor of postoperative delirium in cardiac surgery patients. In the second study, a disturbance in electrolytes could not again predict a postoperative delirium in patients who underwent elective cardiac surgery. It underlines the importance of true validation studies in prognostic research. Rudolph et al. developed in $\mathbf{2 0 0 9}$ a prediction rule based on preoperative factors for the development of delirium after cardiac surgery. Multivariate analysis identified four variables independently associated with delirium: prior stroke or transient ischemic attack, Mini Mental State Examination score, abnormal serum albumin, and the Geriatric Depression Scale (9). In this study also urgent cardiac surgical procedures were included generating a much higher incidence delirium of $52 \%$. Therefore the results are not comparable with ours. Also the cut-off values of some of the risk factors, for example the GDS and SMMSE score, are not the same. In our study the cut-off values were based on the literature, however the base of the cut-off values used by Rudolph et al. are unclear. 


\section{Consequences of delirium}

An important issue is the discussion about cause and consequence. Are the cognitive and functional dysfunction really a cause of delirium or is delirium a symptom of already fragile patients who have a high risk of cognitive and functional dysfunction after cardiac surgery. From the studies it was not possible to determine whether any of the risk factors were true independent causal variables or only markers that reflected the general medical condition of the patient. Besides a delirium, also functional decline is a common problem in older hospitalized patients, resulting in a lower quality of life, new dependency in activities of daily living, higher mortality, prolonged hospital stay, nursing home placement, and increased dependency of older people at home (13). In 2010 Rudolph et al. studied the consequences of delirium (10). In their study, delirium was independently associated with functional decline at one month after cardiac surgery and had a trend toward association at 12 months after cardiac surgery. The researchers also concluded that intervention trials to evaluate whether delirium prevention or treatment strategies might improve postoperative functional recovery are recommended (10). Although the study design is not comparable, these findings corresponds well with our results.

The clinical pathway to delirium is at present unknown. Although it is not possible to determine whether risk factors are the cause of delirium or not, with these risk factors patients at an increased risk of delirium can be identified and preventative interventions and early recognition can be realized. This gives an opportunity for doing intervention studies to prevent delirium. For example a preoperative intervention program could pay attention to the nutritional status, inspiratory muscle force, and cognitive function to improve the patient's condition and with that reduce the risk of delirium. Next it is important to inform the patient and their caregivers preoperative about delirium and the consequences. To conduct this type of studies a prediction model such as ours is necessary.

\section{Final conclusions and recommendations}

In summary, the main conclusions with regard to the questions studied and recommendations can be described as follows: 
- "Is the Delirium Observation Screening scale a valid instrument to detect delirium in cardiac surgery patients?"

Yes, the Delirium Observation Screening scale can be considered as a valid instrument in cardiac surgery patients to rate nurses' observations during regular care. In 27 of the 112 patients a DOS score of $\geq 3$ was found, which indicates delirium. In 24 of these patients the psychiatrist also declared the diagnosis delirium. The sensitivity and specificity of the DOS scale was $100 \%$ and $96.6 \%$ respectively. The AUC was 0.98 . The DOS scale is a very good instrument to facilitate early recognition of delirium by nurses' observation of patients who undergo cardiac surgery.

- "Is it possible to develop a risk checklist to identify patients with an increased risk of postoperative delirium following elective cardiac surgery?"

Yes, it is possible to develop a risk checklist to identify patients with an increased risk of postoperative delirium following elective cardiac surgery. The risk checklist contains the following risk factors: Euroscore, older age ( $\geq 70$ years), cognitive impairment, the number of co-morbidities, history of delirium, alcohol use, and type of surgery. When using a probability of delirium of $20 \%$, as predicted by the model, the sensitivity was $80.8 \%$, while the specificity was $82.2 \%$. The predictive value of a positive test was $48.8 \%$ and the predictive value of a negative test was $95.3 \%$. An area under the curve of 0.89 was found $(95 \% \mathrm{BI}=0.83-0.94 ; \mathrm{p}<0.001)$. To estimate the probability of developing delirium for an individual patient the following prediction formula can be used:

$$
1
$$

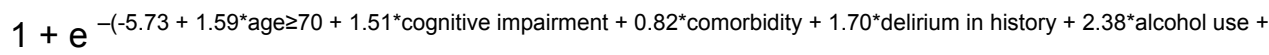
$0.10^{\star}$ Euroscore $+0.67^{\star}$ Valve $+1.38^{\star}(\mathrm{CABG}+$ valve $)+0.44^{\star}$ Other $)$ 
- What are the long-term cognitive and functional consequences of delirium after cardiac surgery?"

- What are the consequences of delirium, including mortality, re-admission, quality of life and cognitive and functional function, six months after cardiac surgery?"

In the first study about the long-term consequences of delirium it was not possible to draw far reaching conclusions, because the number of patients was relatively small and we did not use validated instruments to assess the cognitive function and quality of life. In the second study with more patients we used validated instruments and therefore can draw stronger conclusions.

Postoperative delirium after cardiac surgery is associated with increased mortality (13.5\% in patients with postoperative delirium versus $2.0 \%$ in patients without postoperative delirium), more re- admissions to the hospital ( $45.7 \%$ versus $26.5 \%$ ), and reduced quality of life. Next, postoperative delirium is associated with cognitive failure including failures in attention, memory, perception, and motor function and finally delirium is associated with functional dysfunction like independency in activities of daily living and mobility.

\section{Implications for clinical practice}

Delirium is a common and frequent problem in cardiac surgery patients. Findings of the studies described in this thesis showed relevant predictors of postoperative delirium in cardiac surgery patients. Although the clinical pathway is unknown at present, the use of the risk checklist in clinical practice will nevertheless be helpful in daily care. Patients at an increased risk of delirium after elective cardiac surgery can be identified and early recognition can be realized. Nurses have a key position in this, because of their ability to observe and to guide the patients 24 hours a day and the overall view they have. Screening is a first step to identify patients at risk for delirium and this will make it possible to treat patient to perhaps prevent delirium. Research in this area is urgently needed. The implementation of the risk checklist in cardiac surgery patients is easy to implement during regular care. The DOS scale is already introduced in Medisch Spectrum Twente. Based on this 
thesis, it is important to identify patients at risk for delirium as soon as possible. In elective patients this can be done at the Outpatient Preoperative Screening and for the non elective patients, the assessment can be done shortly after admission to the cardiac surgery ward. As described in the introduction the intention of the studies was to improve the care and cure of cardiac surgery patients with a postoperative delirium. With the delirium risk checklist and better information to the patient and their caregivers about delirium and the consequences, it is possible to improve the care and cure around delirium. In the future it might be possible to prevent delirium by improving patient's general condition before cardiac surgery.

\section{Implications for further research}

Further research should focus on the prevention of delirium. The environment of the patient is not included as a risk factor of delirium in the studies of this thesis. In clinical practice and also in some studies (12;23), however, the environment appears to play a significant role in the development of delirium. Intervention studies paying attention to the environment to prevent delirium are therefore recommended. It is important to orient the patient carefully and to encourage a normal sleep-wake cycle. Avoiding noise and promoting sleep hygiene seems to be helpful in preventing delirium (12). Also music therapy can be used (23). The preoperative intervention program could pay attention to the cognitive function, comorbidities, nutritional status, and dehydration and complement nurture and fluid if necessary. A study of costeffectiveness of the Hospital Elder Life Program (HELP) (12), in Dutch hospital care is in preparation by Nursing Science Utrecht. HELP provides methods of early recognition combined with standardized protocols targeting six delirium risk factors (cognitive impairment, sleep deprivation, immobility, visual impairment, hearing impairment, and dehydration). The introduction of a Nurse Practitioner Elderly Care and the introduction of trained volunteers are also part of the program. Research findings from the USA support show its (cost-) effectiveness in reducing the incidence, duration and severity of delirium in a population at risk.

If these non pharmacological interventions cannot prevent delirium or reduce the severity or duration of delirium, an intervention with medication should be 
considered. In a study by Kalisvaart et al. in hip fracture patients a preoperative low-dose of Haloperidol showed a positive effect on the duration and severity of delirium (24). It could be interesting to repeat this study and raise the prophylactic dose of Haloperidol, for example to $5 \mathrm{mg} /$ day, to examine if it is possible to prevent delirium. Rivastigmine was not found to be effective in preventing postoperative delirium in elderly patients undergoing elective cardiac surgery with cardiopulmonary bypass (25). According to Tabet et al. well designed and appropriately powered RCT's are now needed to justify the routine clinical prophylactic use of any pharmacological agent in the prevention of delirium (26).

In summary, the main conclusions and recommendations for further research are as follows:

- Early recognition of postoperative delirium can be realized with the Delirium Observation Screening (DOS) scale, so the DOS scale should be implemented in cardiac surgery patients;

- The delirium risk checklist can be used to identify patients at an increased risk of developing postoperative delirium following cardiac surgery;

- A delirium is associated with many negative consequences. Therefore, prevention or early recognition of delirium is essential;

- In patients with the identified markers, preventative interventions, to attempt a reduction in the number, severity or duration of episodes of delirium, can be taken, such as a program of proactive geriatric consultation, a Hospital Elder Life Program, or Haloperidol prophylaxis.

\section{References}

(1) Bucerius J, Gummert JF, Borger MA, Walther T, Doll N, Falk V, et al. Predictors of delirium after cardiac surgery delirium: effect of beating-heart (off-pump) surgery. J Thorac Cardiovasc Surg 2004 Jan;127(1):57-64.

(2) Gilman S. Cerebral disorders after open-heart operations. N Engl J Med 1965;272:489-98.

(3) van der Mast RC, Huyse FJ, Rosier PF. Guideline 'Delirium'. Ned Tijdschr Geneeskd 2005 May 7;149(19):1027-32. 
(4) van der Mast RC. Postoperative delirium. Dement Geriatr Cogn Disord 1999 Sep;10(5):401-5.

(5) van der Mast RC, van den Broek WW, Fekkes D, Pepplinkhuizen L, Habbema JD. Incidence of and preoperative predictors for delirium after cardiac surgery. J Psychosom Res 1999 May;46(5):479-83.

(6) van der Mast RC, Roest FH. Delirium after cardiac surgery: a critical review. J Psychosom Res 1996 Jul;41(1):13-30.

(7) van der Mast RC, van den Broek WW, Fekkes D, Pepplinkhuizen L, Habbema JD. Is delirium after cardiac surgery related to plasma amino acids and physical condition? J Neuropsychiatry Clin Neurosci 2000;12(1):57-63.

(8) van der Mast RC. Pathophysiology of delirium. J Geriatr Psychiatry Neurol 1998;11(3):138-45.

(9) Rudolph JL, Jones RN, Levkoff SE, Rockett C, Inouye SK, Sellke FW, et al. Derivation and validation of a preoperative prediction rule for delirium after cardiac surgery. Circulation 2009 Jan 20;119(2):229-36.

(10) Rudolph JL, Inouye SK, Jones RN, Yang FM, Fong TG, Levkoff SE, et al. Delirium: an independent predictor of functional decline after cardiac surgery. J Am Geriatr Soc 2010 Apr;58(4):643-9.

(11) van Blanken G, Robben PBM. Delirium vaak niet herkend. Medisch Contact 2005;60:1724-7.

(12) Inouye SK, Bogardus ST, Jr., Charpentier PA, Leo-Summers L, Acampora $D$, Holford TR, et al. A multicomponent intervention to prevent delirium in hospitalized older patients. N Engl J Med 1999 Mar 4;340(9):669-76.

(13) Hoogerduijn JG, Schuurmans MJ, Duijnstee MS, de Rooij SE, Grypdonck MF. A systematic review of predictors and screening instruments to identify older hospitalized patients at risk for functional decline. J Clin Nurs 2007 Jan;16(1):46-57.

(14) Lundstrom M, Edlund A, Karlsson S, Brannstrom B, Bucht G, Gustafson Y. A multifactorial intervention program reduces the duration of delirium, length of hospitalization, and mortality in delirious patients. J Am Geriatr Soc 2005 Apr;53(4):622-8. 
(15) Schuurmans MJ, Shortridge-Baggett LM, Duursma SA. The Delirium Observation Screening Scale: a screening instrument for delirium. Res Theory Nurs Pract 2003;17(1):31-50.

(16) Schuurmans MJ, Rogier ADTS-BLM, Duursma SA. Early symptoms of delirium observed by nurses in hip fracture patients. Early recognition of delirium. 2001. p. 91-108.

(17) Schuurmans MJ, Donders ART, Shortridge-Baggett LM, Duursma SA. Delirium case finding: pilot testing of a new screening scale for nurses. Journal of the American Geriatric Society 2002;50(4):S3.

(18) Timmers J, Kalisvaart K, Schuurmans M, de Jonge J. A review of delirium rating scales. Tijdschr Gerontol Geriatr 2004 Feb;35(1):5-14.

(19) Inouye SK, van Dyck CH, Alessi CA, Balkin S, Siegal AP, Horwitz RI. Clarifying confusion: the confusion assessment method. A new method for detection of delirium. Ann Intern Med 1990 Dec 15;113(12):941-8.

(20) Immers HE, Schuurmans MJ, van de Bijl JJ. Recognition of delirium in ICU patients: a diagnostic study of the NEECHAM confusion scale in ICU patients. BMC Nurs 2005;4:7.

(21) Ely EW, Margolin R, Francis J, May L, Truman B, Dittus R, et al. Evaluation of delirium in critically ill patients: validation of the Confusion Assessment Method for the Intensive Care Unit (CAM-ICU). Crit Care Med 2001 Jul;29(7):1370-9.

(22) Norkiene I, Ringaitiene D, Misiuriene I, Samalavicius R, Bubulis R, Baublys $A$, et al. Incidence and precipitating factors of delirium after coronary artery bypass grafting. Scand Cardiovasc J 2007 Jun;41(3):180-5.

(23) Weeks BP, Nilsson U. Music interventions in patients during coronary angiographic procedures: A randomized controlled study of the effect on patients' anxiety and well-being. Eur J Cardiovasc Nurs 2010 Aug 2.

(24) Kalisvaart KJ, de Jonge JF, Bogaards MJ, Vreeswijk R, Egberts TC, Burger BJ, et al. Haloperidol prophylaxis for elderly hip-surgery patients at risk for delirium: a randomized placebo-controlled study. J Am Geriatr Soc 2005 Oct;53(10):1658-66. 
(25) Gamberini M, Bolliger D, Lurati Buse GA, Burkhart CS, Grapow M, Gagneux $A$, et al. Rivastigmine for the prevention of postoperative delirium in elderly patients undergoing elective cardiac surgery--a randomized controlled trial. Crit Care Med 2009 May;37(5):1762-8.

(26) Tabet N, Howard R. Pharmacological treatment for the prevention of delirium: review of current evidence. Int J Geriatr Psychiatry 2009 Oct;24(10):1037-44. 


\section{Summary}

In this thesis the main theme is the identification of patients with a high risk of developing a postoperative delirium; in particular, the focus is on identifying patients who undergo cardiac surgery. Chapter 1 talks about the background of delirium and the rationale of the study. Delirium is a common temporary mental disorder among hospitalized elderly patients. Generally, an incidence of $25 \%$ is assumed among hospitalized elderly patients. Given the demographic changes the incidence of delirium will increase in the foreseeable future. Prevention or early recognition of delirium is important since delirium correlates with a prolonged hospital stay, nursing home placement, reduced cognitive and functional recovery, and increased morbidity and mortality. In this study we have developed a delirium risk checklist to try to identify patients with an increased risk of postoperative delirium following elective cardiac surgery, so early recognition of delirium and probably prevention of delirium becomes possible. Chapter 2 describes the validation of the Delirium Observation Screening (DOS) scale in accordance with the diagnosis of the psychiatrist, using the DSM-IV criteria as the gold standard. In 27 of the 112 patients a DOS score of $\geq 3$, indicating a delirium, was found, and was largely comparable with the diagnosis delirium made by the psychiatrist. The sensitivity and specificity of the DOS scale was $100 \%$ and $96.6 \%$ respectively. The AUC was 0.98 . The DOS scale is a very good instrument to facilitate early recognition of delirium by nurses' observation of patients who undergo cardiac surgery. Early recognition will expedite good postoperative management such as implementation of appropriate interventions, and may decrease negative consequences caused by postoperative delirium. Chapter 3 gives an overview of studies about risk factors of delirium, especially in cardiac surgery patients. The review revealed 27 risk factors; 12 predisposing and 15 precipitating factors for delirium after cardiac surgery. The most established predisposing risk factors were atrial fibrillation, cognitive impairment, depression, history of stroke, older age, and peripheral vascular disease. The most established precipitating risk factor was a red blood cell transfusion. An abnormal albumin level was reported as the most established precipitating risk factor among blood values tested. A multifactorial risk model should be applied to identify patients at an increased risk of developing 
delirium following elective cardiac surgery. In these patients, if possible, preventative interventions can be taken and early recognition of delirium can be realized. This could potentially decrease the incidence of delirium and negative consequences caused by a postoperative delirium. Chapter $\mathbf{4}$ examines the predictive validity of a risk checklist for delirium. The incidence of delirium following cardiac surgery was $21 \%$ and the mean duration of delirium was two and a half days. The time to discharge was 11 days longer in patients with delirium. The delirium risk checklist could accurately predict a postoperative delirium in patients who underwent elective cardiac surgery based on a disturbance in electrolytes sodium and potassium and Euroscore. When using a probability of delirium of $50 \%$, the sensitivity of the risk checklist was $25.0 \%$ with a specificity of $95.5 \%$. The predictive value of a positive test was $60.0 \%$ and the predictive value of a negative test was $82.4 \%$. The Area Under the Receiver Operating Curve (AUC) was 0.75 . In conclusion, with the delirium risk checklist patients at an increased risk of developing delirium following elective cardiac surgery can be identified. Chapter 5 examines the predictive validity of the risk checklist for delirium again in a larger population and with more risk factors. The incidence of delirium was $17.3 \%$. Compared to the previously prediction model, the Euroscore was confirmed as a predictor of postoperative delirium, but a disturbance in electrolytes was not. When using a predicted probability of delirium of $20 \%$, the original model had a sensitivity of $40.4 \%$ with a specificity of $82.7 \%$. The Area Under the Receiver Operating Curve of the original model was 0.71 . Based on this new study a new prediction model was constructed with the following risk factors: Euroscore, older age ( $\geq 70$ years), cognitive impairment, the number of co-morbidities, history of delirium, alcohol use, and type of surgery. When using a probability of delirium of $20 \%$, as predicted by the model, the sensitivity was $80.8 \%$, the specificity $82.2 \%$. The Area Under the Curve was 0.89 . Patients with a higher Euroscore, have an increased risk of developing delirium following elective cardiac surgery. Next, with the added predictors patients with an increased risk of developing delirium can be identified much more accurately. Chapter 6 describes the cognitive and functional outcomes of delirium 1-1.5 years after cardiac surgery. A postoperative delirium after cardiac surgery seems to be associated with increased mortality, more re- admissions to 
the hospital, dysfunction in memory, concentration problems, and sleep disturbance. Therefore, prevention and/or early recognition of delirium should be improved. In addition, patients and their caregivers (family and general practitioner) must be better informed about the long-term consequences of delirium and what they can do about it. Chapter 7 describes the consequences of delirium six months after cardiac surgery with more patients and with validated instruments to assess the cognitive function and quality of life. Mortality and readmission were assessed too. Postoperative delirium after cardiac surgery turns out to be associated with increased mortality, more re- admissions to the hospital, reduced quality of life and cognitive functioning, and functional dysfunction like independency in activities of daily living and mobility. In concluding, a postoperative delirium after cardiac surgery is associated with many important consequences. These findings provide justification for future intervention studies to evaluate whether delirium prevention, early recognition or treatment strategies, might improve postoperative functional and cognitive functioning. 


\section{Samenvatting}

In dit proefschrift staat het identificeren van patiënten met een verhoogd risico op een delirium centraal, in het bijzonder wordt het risico op een delirium bij de cardiochirurgische patiënt onderzocht. Hoofdstuk 1 gaat in op de achtergrondinformatie van een delirium en beschrijft de aanleiding tot het onderzoek. Een delirium is een veelvoorkomend psychiatrisch ziektebeeld bij vooral oudere patiënten die opgenomen zijn in het ziekenhuis. Gemiddeld wordt een incidentie van $25 \%$ aangenomen bij oudere patiënten die zijn opgenomen in het ziekenhuis. Als gevolg van de vergrijzing zal de incidentie delirium in de toekomst toenemen. Een delirium gaat gepaard met veel negatieve gevolgen zoals verlengde opnameduur, opname in een verpleeghuis, verminderd cognitief en functioneel herstel en een verhoogde morbiditeit en mortaliteit. Preventie of vroegtijdige identificatie van een delirium is daarom van groot belang. In dit onderzoek wordt met het ontwikkelen van een eerste delirium risicochecklist getracht om patiënten met een verhoogd risico op een postoperatief delirium na een hartoperatie te identificeren, zodat vroegtijdige herkenning en wellicht preventie van een delirium mogelijk is. Hoofdstuk 2 beschrijft de validatie van de Delirium Observatie Screening (DOS) schaal door de uitkomst van de DOS schaal te vergelijken met de gouden standaard: het oordeel van de psychiater die de DSM-IV criteria hanteert. Bij 27 van de 112 patiënten werd een DOS score van $\geq 3$ gevonden, wat duidt op een delirium. Deze uitkomst was nagenoeg vergelijkbaar met het oordeel van de psychiater. De sensitiviteit en specificiteit van de DOS schaal waren respectievelijk 100\% en $96.6 \%$. De AUC was 0.98 . Geconcludeerd wordt dat de DOS schaal een zeer goed instrument is om vroegtijdige herkenning van een delirium door verpleegkundigen te bewerkstelligen bij patiënten die een hartoperatie moeten ondergaan. Vroegtijdige herkenning zal bijdragen aan een goed postoperatief management, zoals implementatie van interventies en zal zo de negatieve gevolgen die gepaard gaan met een delirium kunnen verminderen. Hoofdstuk 3 geeft een overzicht van de onderzoeken die zijn verricht op het gebied van risicofactoren en delirium, en dan hoofdzakelijk binnen de cardio-thoracale chirurgie. De review kwam tot 27 risicofactoren, waarvan 12 predisponerende en 15 precipiterende risicofactoren. De meest voorkomende predisponerende risicofactoren van een delirium bij de 
cardiochirurgische patiënt zijn atriumfibrilleren, cognitieve disfunctie, depressie, een CVA in de voorgeschiedenis, oudere leeftijd en perifeer vaatlijden. De meest voorkomende precipiterende risicofactor is een bloedtransfusie. Onder de laboratoriumwaarden was een afwijkende albumine waarde de meest voorkomende precipiterende risicofactor. Een model bestaande uit meerdere risicofactoren zou toegepast moeten worden om patiënten met een verhoogd risico op een delirium na een hartoperatie mee te kunnen identificeren. Bij deze patiënten zouden, indien mogelijk, preventieve maatregelen genomen kunnen worden en vroege identificatie van een delirium zou zo mogelijk worden. Dit zou wellicht kunnen bijdragen aan het verminderen van de incidentie delirium en de negatieve gevolgen die gepaard gaan met een delirium. Hoofdstuk 4 onderzoekt de predictieve validiteit van een delirium risicochecklist. De incidentie delirium na een hartoperatie was $21 \%$ en de gemiddelde duur van een delirium was twee en een halve dag. De opnameduur in het ziekenhuis was in geval van een delirium 11 dagen langer. De delirium risicochecklist, bestaande uit een afwijkende natrium- en kalium waarde en Euroscore, kan goed voorspellen welke patiënten een verhoogd risico hebben op een delirium na een electieve hartoperatie. Bij een mogelijkheid van een delirium van $50 \%$, was de sensitiviteit van de risicochecklist delirium $25.0 \%$ en de specificiteit $95.5 \%$. De predictieve waarde van een positieve testuitslag was $60 \%$ en de predictieve waarde van een negatieve testuitslag 82.4\%. De Area Under the Receiver Operating Curve (AUC) was 0.75 . Geconcludeerd wordt dat met de delirium risicochecklist electieve hartoperatie patiënten met een verhoogd risico op een delirium kunnen worden geïdentificeerd.

Hoofdstuk 5 onderzoekt opnieuw de predictieve validiteit van de delirium risicochecklist in een grotere populatie en met meer risicofactoren. De incidentie delirium was $17.3 \%$. Vergeleken met het eerdere voorspellingsmodel, bleek de Euroscore opnieuw een risicofactor te zijn van een postoperatief delirium, maar afwijkende waarden van de elektrolyten natrium en kalium niet. Bij een mogelijkheid van een delirium van $20 \%$ in het oorspronkelijke model, was de sensitiviteit van de risicochecklist delirium $40.4 \%$ en de specificiteit $82.7 \%$. De Area Under the Receiver Operating Curve (AUC) was 0.71 . Gebaseerd op deze nieuwe studie werd een nieuw voorspellingsmodel opgesteld bestaande uit de volgende 
risicofactoren: Euroscore, oudere leeftijd ( $\geq 70$ jaar), cognitieve achteruitgang, comorbiditeit, delirium in de voorgeschiedenis, gebruik van alcohol en de soort hartoperatie. Bij een mogelijkheid van een delirium van $20 \%$ in het nieuwe model, was de sensitiviteit van de risicochecklist delirium $80.8 \%$ en de specificiteit $82.2 \%$. De Area Under the Receiver Operating Curve (AUC) was 0.89. Patiënten met een hogere Euroscore hebben een verhoogd risico op het ontwikkelen van een delirium na een hartoperatie. Met de toegevoegde voorspellers kunnen patiënten met een verhoogd risico op een postoperatief delirium nauwkeuriger worden geïdentificeerd. Hoofdstuk 6 beschrijft de cognitieve en functionele gevolgen van een delirium, 1-1.5 jaar na een hartoperatie. Een delirium na een hartoperatie lijkt geassocieerd met een verhoogde mortaliteit, meer heropnames, geheugen- en concentratieproblemen en een verstoord slaappatroon. Daarom moeten preventie en/of vroege herkenning van een delirium worden verbeterd. Patiënten en hun zorgverleners (familie en/of huisarts) zouden bijvoorbeeld beter geïnformeerd moeten worden over de lange termijn gevolgen van een delirium en wat ze hier eventueel aan kunnen doen. Hoofdstuk 7 beschrijft de gevolgen van een delirium zes maanden na een hartoperatie met meer patiënten en met gebruik van gevalideerde meetinstrumenten om de cognitieve functie en kwaliteit van leven te bepalen. Ook mortaliteit en heropnames in het ziekenhuis werden bepaald. Een delirium na een hartoperatie gaat gepaard met verhoogde mortaliteit, meer heropnames in het ziekenhuis, verminderde kwaliteit van leven en cognitieve functie en functionele achteruitgang, zoals afhankelijkheid in het dagelijkse leven en mobiliteit. Een delirium na een hartoperatie gaat gepaard met vele ingrijpende gevolgen. Deze bevindingen rechtvaardigen de uitvoer van interventiestudies om te beoordelen of het voorkómen, de vroege herkenning en de behandeling van een delirium de postoperatieve functionele en cognitieve functies kunnen verbeteren. 


\section{Dankwoord}

Al tijdens mijn loopbaan als verpleegkundige kwam ik in aanraking met delirium. Vooral tijdens de nachtdienst was het intrigerend om te zien dat patiënten van het ene op het andere moment psychisch ontregelden als gevolg van lichamelijk lijden. Het ziektebeeld delirium boeide me enorm en ik wilde er meer over weten. Dit begon met het lezen van artikelen en het bijwonen van presentaties over delirium. Tijdens mijn studie Master Advanced Nursing Practice (MANP) kwam ik in aanraking met wetenschappelijk onderzoek. Al snel had ik de overtuiging me te gaan verdiepen in delirium, omdat hier nog veel winst te behalen viel (en valt). Het doen van onderzoek beviel me zo goed, dat dit onverwachts leidde tot een promotieonderzoek. Nu, vier jaar later, is dit proefschrift een feit. Gedurende deze jaren hebben diverse mensen een belangrijke bijdrage geleverd die ik hiervoor heel graag wil bedanken. Als eerste gaat mijn dank uit naar de twee personen die mij de afgelopen periode hebben begeleid: prof. dr. Job van der Palen en prof. dr. Marieke Schuurmans. Job, je hebt me de hele onderzoeksperiode vanaf de opleiding tot en met de totstandkoming van dit proefschrift op een zeer prettige en professionele wijze begeleid. Je betrokkenheid en grote inzet, met zelfs beantwoording van mails in de weekenden of late avonduren en vanuit diverse windstreken, heb ik altijd enorm gewaardeerd. De artikelen van eerste aanzetten tot definitieve versies heb je altijd goed gelezen en van zinvol commentaar voorzien. Je kennis op het gebied van statistische bewerkingen en analyses is enorm. Je bezit de gave om op eenvoudige wijze ingewikkelde materie duidelijk te maken en daar heb ik veel van kunnen leren. Ik hoop dat dit in de toekomst zeker een vervolg gaat krijgen. Daarnaast heb ik genoten van de vele koppen thee die bijna bij elk bezoekje werden ingeschonken (de laatste jaren zelfs bijzondere kruidenthee in een echt theeglas) en van je goochelkunsten. Marieke, als tweede promotor was je, mede op advies van Marianne Lensink, na het verschijnen van de eerste twee artikelen actief betrokken bij mijn onderzoek. Mede door het bijwonen van jouw lezingen over delirium is mijn interesse in delirium sterk aangewakkerd en was en ben je een belangrijke inspiratiebron voor mij. Je vakkennis op het gebied van ouderenzorg en delirium in het bijzonder is enorm, maar ook je wetenschappelijke inzicht is groot. Ik heb bewondering voor je scherpe, kritische, 
maar opbouwende manier van feedback geven op mijn artikelen en proefschrift. Daar heb ik veel van geleerd. Hartelijk dank daarvoor en ik hoop in de toekomst nog veel met je samen te kunnen werken. Alle thoraxchirurgen, cardiologen en cardio-anesthesiologen wil ik bedanken voor de mogelijkheid om het onderzoek binnen de thoraxchirurgie uit te kunnen voeren. In het bijzonder wil ik de thoraxchirurgen Ab Hensens en Jan Grandjean bedanken. Ab, jij was als mijn zogenoemde "leermeester" bij de opleiding tot nurse practitioner betrokken. Vervolgens ben je betrokken geweest bij alle gepubliceerde artikelen. Mede door jou was het mogelijk om na de opleiding één dag per week aan onderzoek te besteden, zodat deze promotie mogelijk was. Ik waardeer het enorm dat ik deze kans heb gekregen en dat we op deze manier de zorg aan hartchirurgische patiënten nog verder hebben kunnen verbeteren. Ik hoop dat we dit kunnen voortzetten en dat onderzoek een belangrijke plaats blijt behouden binnen de thoraxchirurgie. Jan, als commissielid heb je het proefschrift zeer goed doorgenomen en van zinvol commentaar voorzien (en dat tijdens je vakantie!). Daarnaast kan ik het waarderen dat je meedenkt over hoe we de interventies om een delirium te voorkómen verder vorm kunnen gaan geven. Je denkt buiten de kaders en dat kan vast mooie resultaten opleveren. Van de cardio-anesthesiologen wil ik in het bijzonder Jan Diephuis bedanken voor zijn interesse in het onderzoek en zijn mentale steun tijdens mijn $1^{\mathrm{e}}$ internationale presentatie tijdens een congres in Wenen van the European Association of Cardiothoracic Anaesthesiologists (EACTA). Daarnaast wil ik mede de Raad van Bestuur, in het bijzonder Marianne Lensink, en destijds de bedrijfskundig manager van het thoraxcentrum Henny Voss en het afdelingshoofd van de thoraxchirurgie Elly Huiskes bedanken voor de mogelijkheid om een onderzoeksdag per week te realiseren. En ook de verdere voortgang is goed verlopen mede dankzij Irma Wolters, het huidige teamhoofd van de A2 en Mark Vos, de bedrijfskundig manager van het thoraxcentrum. Zonder een onderzoeksdag was deze promotie niet mogelijk geweest. Ik hoop dat in de toekomst nog vele verpleegkundigen zich bezig mogen gaan houden met wetenschappelijk onderzoek; er valt nog veel te onderzoeken en er is nog veel winst te behalen. Speciale dank gaat uit naar Arie Wijma, de psychiater die gedurende het ontwikkelen van de delirium risicochecklist een belangrijk aandeel 
heeft gehad in het diagnosticeren van delirium. Arie, heel erg bedankt voor je grote inzet en de vele extra kilometers en uren die je voor het onderzoek hebt moeten maken. Daarnaast wil ik de verpleegkundigen en andere disciplines van het thoraxcentrum bedanken die een bijdrage hebben geleverd aan mijn onderzoek. In het bijzonder de verpleegkundigen met als aandachtsgebied de patiëntenvoorlichting hebben veel werk verzet door het afnemen van vragenlijsten en het includeren van patiënten. En niet te vergeten gaat mijn dank uit naar het planningssecretariaat van de thoraxchirurgie die de vragenlijsten naar alle patiënten heeft verzonden. Ook de Saxion Hogeschool, in het bijzonder Alice Bomers, Frits Oosterveld en Joy Notter, wil ik bedanken voor de eerste aanzet tot het doen van onderzoek en de achtergrondinformatie daar omheen. Bedankt ook Frits voor je aandeel in de eerste twee artikelen. Daarnaast mogen de patiënten die hebben deelgenomen aan het onderzoek niet ongenoemd voorbij gaan. Zonder de patiënten, met ondersteuning van hun familieleden, was dit onderzoek niet tot stand gekomen. Vooral de grote respons op de enquêtes was hartverwarmend. Alle patiënten en hun familie die hebben deelgenomen wil ik dan ook hartelijk danken voor hun medewerking. Mijn eerste onderzoek zou ik nooit alleen hebben kunnen uitvoeren. Met hulp van, destijds nog, studente psychologie Amrah Schotanus is het mogelijk geworden om de uitgebreide vragenlijsten en testen af te nemen op de preoperatieve screening. Amrah, bedankt voor je bijdrage aan mijn onderzoek. Mijn collega nurse practitioners wil ik ook bedanken. Als ik op vakantie was, hebben jullie waar nodig voor de gegevensverzameling van mijn onderzoek gezorgd. Ook jullie extra inzet in verband met mijn afwezigheid op de afdeling gedurende mijn onderzoeksdagen kan ik erg waarderen. Heel erg bedankt hiervoor en ik hoop dat we met zijn allen wetenschappelijk onderzoek een belangrijk onderdeel van onze werkzaamheden kunnen laten zijn. Voor het beoordelen van mijn artikelen op de Engelse taal wil ik Rik Klarenbeek en Annette Hensens bedanken. Aangezien de Engelse taal niet mijn sterkste kant is, was het heel prettig om de artikelen voor indiening te laten corrigeren. Heel erg bedankt daarvoor.

Mijn laatste woorden van dank gaan uit naar mijn familie en vrienden. In het bijzonder mijn lieve ouders en schoonouders, Jaap \& Rita en Tjeert \& Henny. 
Bedankt voor jullie interesse in mijn onderzoek en ondersteuning als het nodig was. Zeker het jaar waarin Jort geboren werd en we de eerste maanden 's nachts vaak in touw waren, was het erg prettig om in de weekenden af en toe even bij te tanken in Emmen en weer nieuwe energie op te doen om weer verder te gaan met het schrijven van artikelen en het invoeren van alle data in de computer. Ook heb ik veel steun gehad van Erik en Marloes. Marloes, aangezien jij me als promovendus al een aantal jaren geleden bent voorgegaan heb ik veel van je kunnen leren en begreep je me als geen ander in tijden dat het op onderzoeksgebied even wat minder ging. Je taak als paranymf Marloes is dan ook een speciale manier om jou te bedanken voor je steun en luisterend oor. Opa Koster, papa en Jort wil ik bedanken voor hun "handen" bijdrage. Handen zeggen veel en ik ben dan ook heel blij dat jullie mooie handen op de voor- en achterkant van mijn proefschrift staan. Ook wil ik mijn overige familie en vrienden, in het bijzonder Annemiek en Petra, bedanken voor hun stimulans, steun en interesse voor mijn onderzoek. Tot slot gaat mijn dank uit naar mijn lieve man Remco. Toen ik met de opleiding voor nurse practitioner begon, waren we nog niet getrouwd. Inmiddels zijn we een aantal jaren getrouwd (al ben ik tot jouw spijt binnen de wetenschap nog altijd bekend als Koster) en hebben we onze prachtige zoon Jort op de wereld gezet. Je hebt vanaf het begin achter me gestaan en vertrouwen gehad in een goede afloop. Ik ben je heel dankbaar dat je me de ruimte hebt gegeven om mezelf verder te ontwikkelen. Er zijn de afgelopen jaren veel vrije tijd uren naar mijn onderzoek gegaan en daardoor liepen werk en privé soms door elkaar, maar samen hebben we hier een goede balans in weten te vinden. Bedankt lieverd, voor je steun, inspiratie, vertrouwen, humor, liefde en vooral je aanwezigheid! En laten we vooral doorgaan met ons te blijven ontwikkelen. Want een mens is net een foto, als hij zich kan ontwikkelen wordt hij positief! 


\section{Curriculum Vitae}

Sandra Koster was born in Rotterdam on November 12, 1977. After graduating high school at the Hondsrugcollege in Emmen, she studied from 1995 until 1999 nursing at the HBO-V in Groningen. After this study she worked for several years as a nurse in the University Medical Center in Groningen in the Department of Internal Medicine. Next, she worked as a pediatric nurse at the municipal health service in Zwolle and Enschede. Since 2004 she works at Medisch Spectrum Twente in Enschede were she was employed as a nurse in the Department of Cardiothoracic Surgery. In 2007 she became a nurse practitioner in the Cardiothoracic Surgery. From 2007 until now she combined her work as a nurse practitioner with her $\mathrm{PhD}$ study. Also after her PhD study Sandra is intending to continue research and help other students in doing research, especially within her field of interest: older patients. 